\title{
Invertir cuando hacerlo cuenta: Generando la evidencia base para politicas y programas para adolescentes muy jóvenes-Guía y juego de herramientas
}

\author{
Erica Chong \\ Population Council \\ Kelly Hallman \\ Population Council \\ Martha Brady \\ Population Council
}

Follow this and additional works at: https://knowledgecommons.popcouncil.org/departments_sbsr-pgy

Part of the Family, Life Course, and Society Commons, Gender and Sexuality Commons, and the International Public Health Commons

How does access to this work benefit you? Let us know!

\section{Recommended Citation}

Chong, Erica, Kelly Hallman, and Martha Brady. 2006. "Invertir cuando hacerlo cuenta: Generando la evidencia base para politicas y programas para adolescentes muy jóvenes-Guía y juego de herramientas." New York: UNFPA and Population Council. 


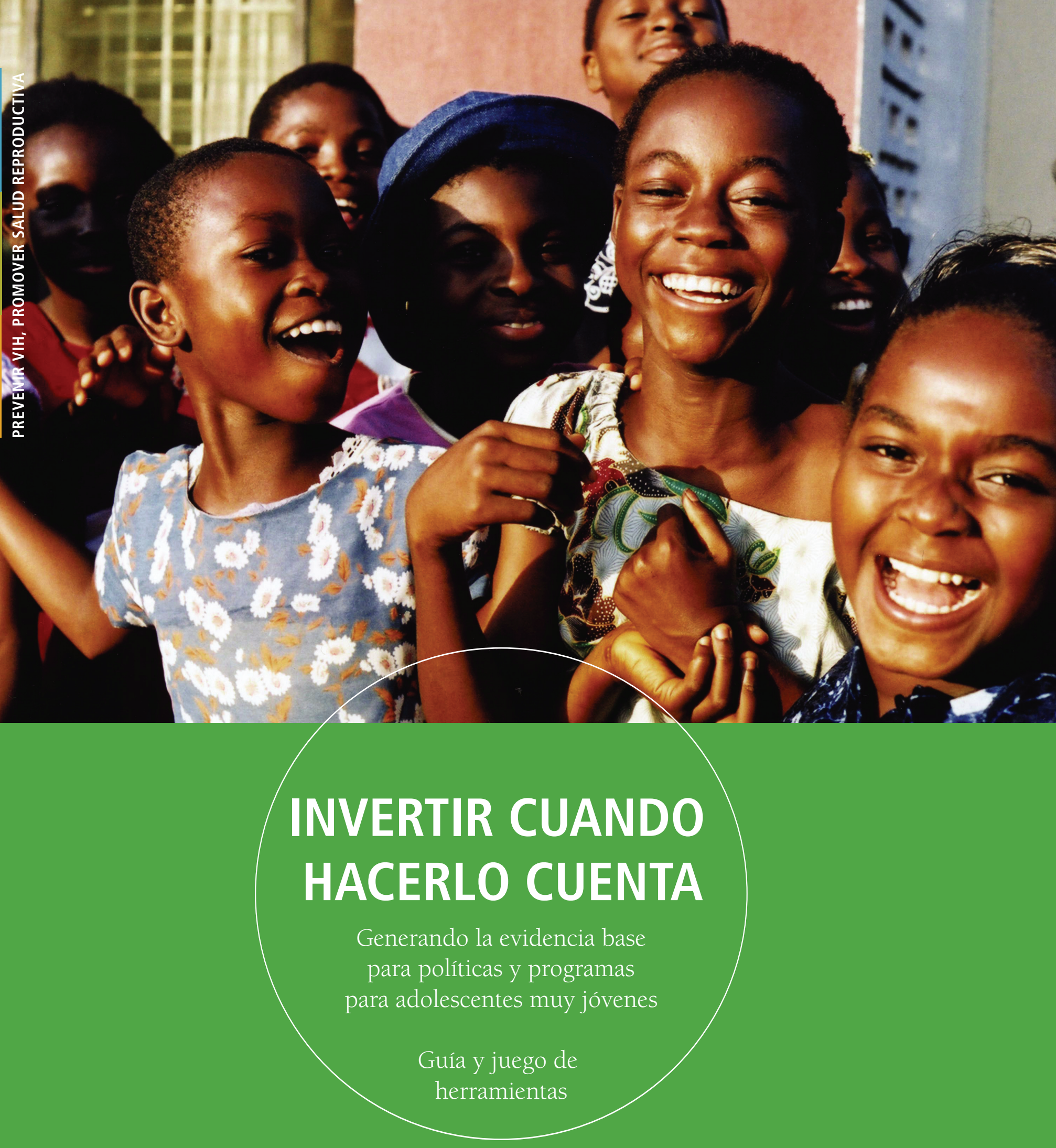

(2) Population Council : : 
Esta publicación fue escrita por Erica Chong, Kelly Hallman y Martha Brady, del Population Council. Laura Skolnik (UNFPA) y Rick Olson (UNICEF) ofrecieron comentarios sobre los borradores. Las autoras reconocen los esfuerzos críticos de Julitta Onabanjo y Judith Bruce para movilizar la agenda sobre adolescentes y propiciar la atención hacia los adolescentes muy jóvenes en particular.

(C) 2006 UNFPA y Population Council. Todos los derechos reservados.

UNFPA, el Fondo de Población de las Naciones Unidas, es una agencia de cooperación internacional para el desarrollo que promueve el derecho de cada mujer, hombre y niño a disfrutar de una vida sana, con igualdad de oportunidades para todos. El UNFPA apoya a los países en la utilización de datos para la formulación de políticas y programas de reducción de la pobreza, y para asegurar que todo embarazo sea deseado, todos los partos sean seguros, todos los jóvenes estén libres del VIH/SIDA, y todas las niñas y mujeres sean tratadas con dignidad y respeto.

UNFPA - porque cada persona es importante.

Fondo de Población de las Naciones Unidas

220 East 42nd Street

New York, N.Y. 10017, E.U.A.

www.unfpa.org

El Population Council es una organización internacional, no gubernamental y no lucrativa, que busca mejorar el bienestar y la salud reproductiva de las generaciones actuales y futuras en todo el mundo, y ayudar a lograr un equilibrio humano, igualitario y sustentable entre las personas y los recursos. El Council realiza investigación en biomedicina, ciencias sociales y salud pública, y ayuda a construir capacidades de investigación en los países en desarrollo. Establecido en 1952, el Council está gobernado por una junta directiva internacional. Su sede en Nueva York apoya una red global de oficinas regionales y de país.

Population Council

1 Dag Hammarskjold Plaza

New York, N.Y. 10017, E.U.A.

Tel. (212) 339-0500

Fax (212) 755-6052

Correo-e: pubinfo@popcouncil.org

www.popcouncil.org

Esta publicación fue posible gracias al apoyo financiero brindado por el UNFPA. Los puntos de vista y oportunidades que se expresan en esta publicación no reflejan, necesariamente, los del Fondo de Población de las Naciones Unidas (UNFPA).

ISBN: \#0-89714-769-3

Impreso en Estados Unidos de Norteamérica

Fotografía de la portada por Andrea Lynch, de la Internaional Women's Health Coalition.

Niñas en el Centro de la Iniciativa de Poder para las Niñas, Calabar, Nigeria. 
Los adolescentes muy jóvenes, cuyas edades oscilan entre los 10 y 14 años, sufren tremendos cambios físicos, emocionales, sociales e intelectuales. Durante esta etapa, muchos adolescentes muy jóvenes experimentan la pubertad, sus primeras vivencias sexuales y, en el caso de las niñas, matrimonios prematuros. Para una mayoría de niños, la adolescencia temprana está marcada por una buena salud y por circunstancias familiares estables, si buen puede tratarse también de un período de vulnerabilidad por las rápidas e intensas transiciones hacia nuevos roles y responsabilidades como guardianes, trabajadores, parejas y padres. En muchos países, el impacto que el VIH, la pobreza y los conflictos políticos y sociales han tenido sobre las familias y las comunidades ha erosionado las redes tradicionales de seguridad y ha incrementado la vulnerabilidad de los adolescentes jóvenes. De ahí que sea crítico para las políticas y los programas comprender las especiales oportunidades de los adolescentes muy jóvenes, tanto como sus vulnerabilidades. En la mayoría de los países, existen políticas para que al alcanzar tales edades, los niños estén ya en la escuela, y uno encuentra ahí a una proporción mayor de este grupo de edad en comparación con los adolescentes mayores. Capitalizar sobre lo anterior es crítico. Pero es igualmente importante advertir que muchos de estos adolescentes no van a la escuela y que por ello pueden estar en mayores riesgos de experimentar numerosas consecuencias negativas. Poniendo al sector educativo aparte, los adolescentes muy jóvenes han sido particularmente desatendidos por quienes formulan las políticas, pues están fuera del alcance de la mayoría de los programas convencionales de salud infantil, salud materna y empoderamiento de las mujeres.
Debemos aprender más acerca del momento, la naturaleza y consecuencias de las transiciones clave que los adolescentes jóvenes sufren y, particularmente, de la manera como ocurren en los grupos más vulnerables. Iniciar programas para los jóvenes de esta edad, o alrededor de ella, es reconocer su capacidad de desarrollo. Las intervenciones hechas en momentos estratégicos permiten resultados positivos antes de que se establezca la arquitectura de vida de estos jóvenes adolescentes. Si los Objetivos del Desarrollo del Milenio van a alcanzarse, se requieren inversiones sustanciales, meditadas y focalizadas en el capital social, de salud, financiero y personal de los jóvenes de las zonas más pobres del planeta. Tales inversiones son también esenciales si los gobiernos van a respetar las obligaciones adquiridas bajo acuerdos internacionales tales como la Convención sobre los Derechos del Niño, la cual reafirma los derechos de los niños a aprender, estar sanos, poder jugar y ser protegidos de la explotación y el abuso.

El Population Council, UNFPA, UNICEF y UNAIDS están comprometidos con la programación basada en la evidencia y con el desarrollo de políticas que se aboquen a los importantes problemas a los que los adolescentes jóvenes se enfrentan. Se requiere con urgencia de nueva investigación y de intervenciones dirigidas a los jóvenes de 10 a 14 años. Al atisbar el futuro nos imaginamos una estrategia de investigación y acción más fuerte, más audaz y dinámica para apoyar políticas y programas innovadores que brindarán a las niñas y niños adolescentes una transición segura, saludable y productiva a la edad adulta. El puente que une a la niñez con la vida adulta joven es demasiado precario para muchos niños del mundo en desarrollo. Fortalecer esta transición para asegurar que conduzca a un futuro más brillante merece mucha más de nuestra atención.

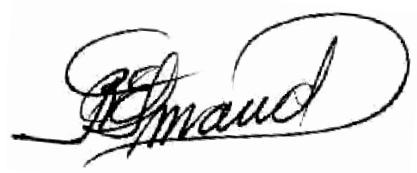
Rogelio Fernández Castilla
Director, División de Apoyo Técnico, UNFPA

Peter J. Donaldson

Presidente, Population Council 


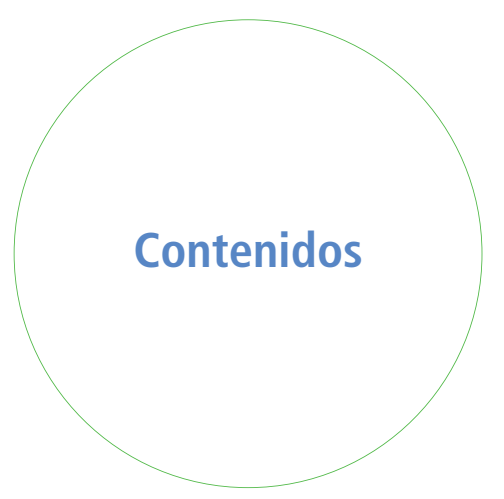

\section{Introducción}

Los adolescentes muy jóvenes - un grupo desatendido $\ldots \ldots \ldots \ldots \ldots \ldots \ldots \ldots \ldots \ldots$

Desarrollo de programas sobre el VIH/sida dirigidos a adolescentes muy jóvenes . . . . . . . . 5

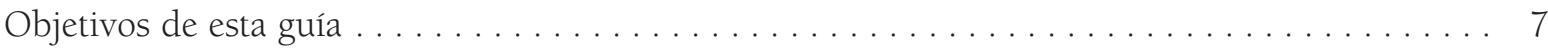

II. ¿Qué es lo que sabemos respecto de la vidas de los adolescentes muy jóvenes?

Hallazgos recientes . . . . . . . . . . . . . . . . . . . . . . . . . 10

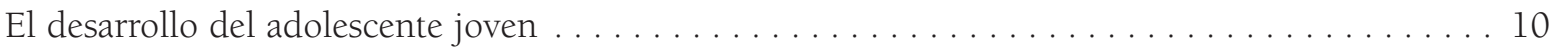

Obtención de información de encuestas nacionalmente representativas $\ldots \ldots \ldots \ldots \ldots \ldots 11$

III. Consideraciones éticas $\ldots \ldots \ldots \ldots \ldots \ldots \ldots \ldots \ldots \ldots \ldots \ldots \ldots \ldots \ldots \ldots \ldots \ldots$

IV. Enfoques y métodos de recolección de datos para suministrar información a programas para adolescentes muy jóvenes

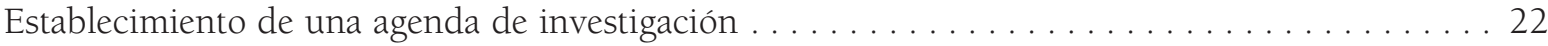

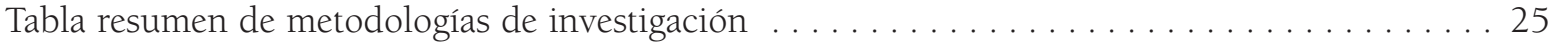

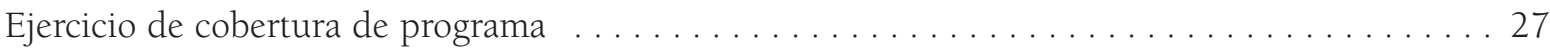

Métodos cualitativos

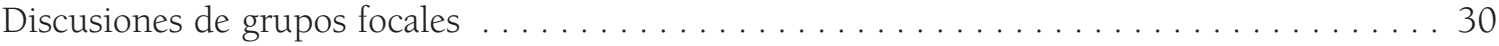

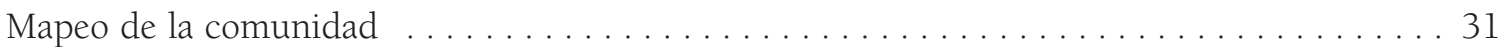

Entrevistas individuales a profundidad y semi-estructuradas con informantes claves . . . . . 34

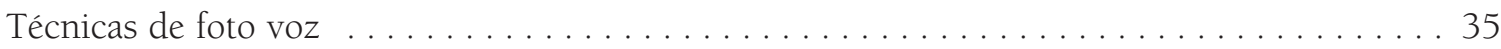

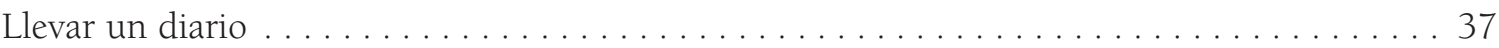

Métodos cuantitativos

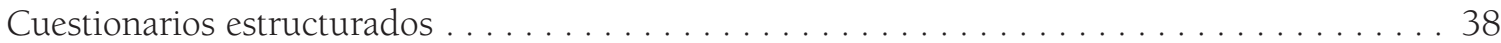

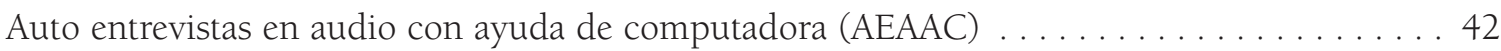

V. Conclusión / El camino hacia adelante $\ldots \ldots \ldots \ldots \ldots \ldots \ldots \ldots \ldots \ldots \ldots \ldots \ldots$

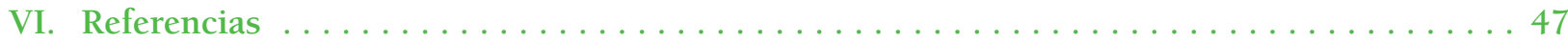

VII. Apéndices

A. Realización de un ejercicio de cobertura de programa

B. Recursos para grupos focales

C. Una guía para el facilitador del mapeo de escuelas y comunidades más seguras

D. Realización de entrevistas semi-estructuradas a profundidad con informantes clave

E. Técnicas de foto voz

F. Cuestionarios estructurados

G. AEAAC 


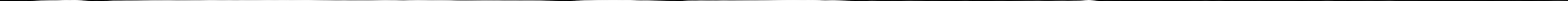




\section{Los adolescentes muy jóvenes* — un grupo desatendido}

En los países en desarrollo, la población adolescente ha alcanzado cifras sin precedentes - llegando a más de mil millones en el 2005. Quienes tienen entre 10 y 19 años representan una quinta parte de la población de esos países. El término "adolescente" engloba a un grupo diverso en extremo; las experiencias de los adolescentes difieren dramáticamente dependiendo de su edad, sexo, modos de vida, la zona en donde viven y también de su escolaridad, el estado civil y situación laboral y de crianza.

De entre los adolescentes, un sub-grupo que ha recibido atención mínima es el de los "adolescentes muy jóvenes" (AMJ) cuyas edades oscilan entre los 10 y 14 años. La inmunización y otras iniciativas de salud infantil y esfuerzos pueden alcanzar a niños más jóvenes para inscribirlos en las escuelas, mientras que los adolescentes mayores pueden constituir la población objetivo de la educación de pares o de las actividades de centros juveniles; pero los AMJ tienden a quedar desprotegidos por los vacíos existentes. La adolescencia temprana puede estar marcada por una salud relativamente buena y por circunstancias familiares estables; pero este periodo puede ser también de vulnerabilidad e intensa transición. Los adolescentes de 10 a 14 años transitan de ser claramente "niños" a los 10 años, a través del inicio de la pubertad, a ser percibidos en algunas sociedades como mujeres jóvenes suficientemente mayores para comenzar a tener relaciones sexuales, casarse y tener hijos, o como varones jóvenes de quienes se espera que contribuyan a mantener a sus familias y, posiblemente, a realizar su servicio militar.

Se ha hecho poca investigación en relación con los factores que contribuyen a la vulnerabilidad y a las precarias consecuencias de salud de los AMJ. Los jóvenes de 15 años son, típicamente, los adolescentes más jóvenes incluidos en las encuestas demográficas y de salud nacionales y en los estudios de seroprevalencia. Y aunque hace mucho que se recaba información sobre escolaridad y bienestar general de los adolescentes jóvenes, la mayoría de los investigadores se ha negado a cubrir temas sensibles, sea por las normas sociales relacionadas con los comportamientos propios de la edad, por consideraciones éticas acerca de efectos potencialmente dañinos de la investigación, o por dudas sobre la validez de sus respuestas como adolescentes jóvenes.

Algunos investigadores ponen en duda que los AMJ posean la habilidad cognitiva para responder a preguntas que requieren una evaluación meditada de las barreras a las que se enfrentan, o de las consecuencias potenciales de acciones futuras. Otros creen que el estigma que rodea la actividad sexual premarital de las jóvenes es demasiado alto para obtener información precisa, y que es más conveniente que los investigadores se apoyen en información retrospectiva de temas sensibles, aunque un cierto sesgo dado por el recuerdo pudiera estar presente. Por lo que hace a la logística, los tamaños de las muestras requeridas para la investigación sobre adolescentes muy jóvenes pueden ser de un tamaño prohibitivo, pues es probable que ciertos comportamientos de riesgo que son de interés sean relativamente raros en este grupo de edad. Todas estas inquietudes son válidas, pero no son insalvables. Es posible realizar investigación exitosa con AMJ, aunque con ciertas modificaciones en los métodos y enfoques actuales.

\section{Desarrollo de programas sobre el VIH/sida dirigidos a adolescentes muy jóvenes}

La necesidad de aprender más sobre los adolescentes muy jóvenes es crítica a la luz de la pandemia del VIH/sida, pues la mitad de todos los

\footnotetext{
* En este texto se entenderá, al nombrar a "los adolescentes", "los jóvenes" y "los niños", que se trata de las y los adolescentes, las y los jóvenes y
} las y los niños, y no exclusivamente de los varones, a menos que tal cosa se señale explícitamente. 
casos nuevos de infección por el VIH ocurren entre jóvenes de 15 a 24 años de edad. Las niñas son particularmente vulnerables. En África subsahariana, en donde habitan casi dos tercios de todos los jóvenes que viven con el VIH (6.2 millones), 75 por ciento de las infecciones se manifiestan en niñas y mujeres jóvenes (UNAIDS 2004a). Documentar una imagen fiel y precisa de las vidas de los AMJ es el primer paso para construir programas que puedan comenzar a mejorar estadísticas tan desalentadoras. Intervenir durante la adolescencia temprana puede contribuir a modelar comportamientos a medida que se forman, en vez de que ello ocurra durante la adolescencia tardía, cuando esos comportamientos ya se han establecido y es más difícil modificarlos. De igual modo, las intervenciones tempranas pueden contribuir a abordar los efectos de factores estructurales, como pueden ser las normas de roles de género y la pobreza que ponen en riesgo a los AMJ.

Figura 1 Porcentaje de niñas de 15 a 19 años que informaron haber tenido sexo o haberse casado antes de cumplir 15 años en 14 países de África Subsahariana

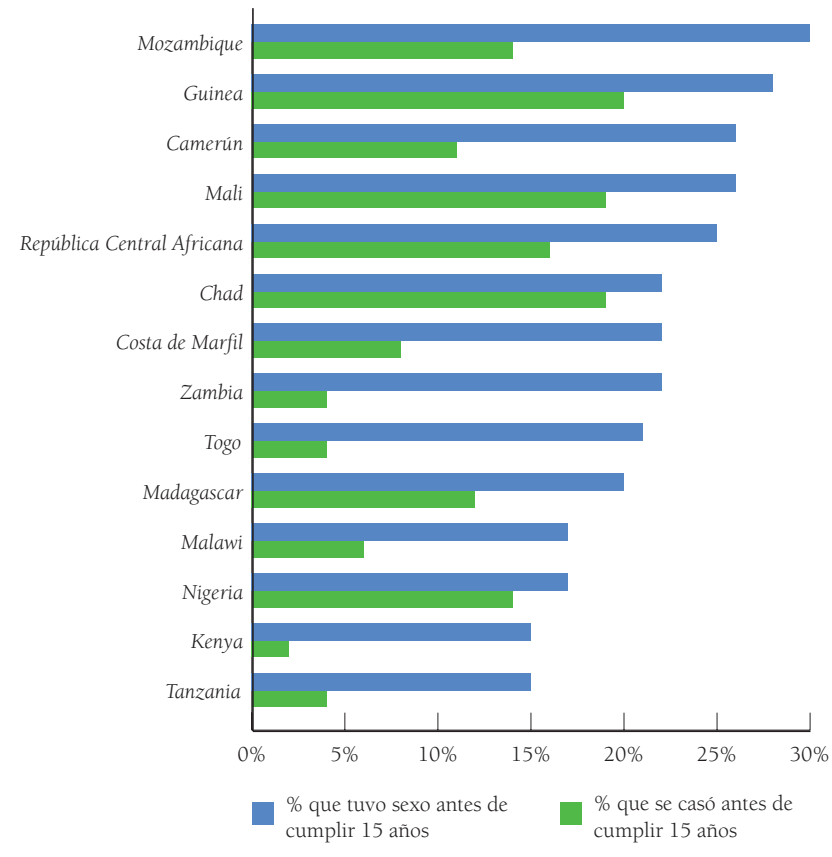

Fuente: Análisis del Population Council a datos de la Encuesta Demográfica y de Salud.
Los adolescentes muy jóvenes se han visto profundamente afectados por la epidemia del sida, que puede haberles causado la pérdida de sus padres o de otros miembros de la familia, que ellos mismos se infecten durante encuentros sexuales, o que ese contagio haya ocurrido cuando eran bebés. Se estima que en el año 2004, unos 640,000 niños menores de 15 años se infectaron por primera vez con el VIH, y que cerca de 510,000 murieron de SIDA (UNAIDS 2004b). La actividad sexual entre los adolescentes muy jóvenes es más común de lo que muchos diseñadores de políticas y miembros de la comunidad reconocen. En 14 países de África Subsahariana, 15 por ciento o más de las niñas informaron haber tenido relaciones sexuales antes de llegar a los 15 años (ver la figura 1).

Una proporción importante de los encuentros sexuales que involucran a AMJ son forzados o se experimentan mediante coacción (Jejeebhoy y Bott 2003). En algunos países, la prevalencia del matrimonio infantil es la causa predominante del debut sexual temprano (ver, por ejemplo, los casos de Chad y Nigeria en la figura 1). Con frecuencia, los jóvenes no poseen la información ni los conocimientos necesarios para protegerse del VIH/sida. Pero aun conscientes de ello, en su vida diaria enfrentan circunstancias sociales, económicas y culturales —a menudo vinculadas con cuestiones de género- que obstaculizan su habilidad para protegerse. Las niñas jóvenes encaran un riesgo de contagio del VIH especialmente alto a través del contacto sexual, pues sus parejas tienden a ser mucho mayores (y por ello con probabilidades igualmente mayores de estar infectados con el VIH u otra ITS al compararse con los más jóvenes), y también porque sus tractos genitales están aún inmaduros y son más vulnerables a la infección.

Otras poblaciones vulnerables que merecen atención especial son los refugiados (de los que hay casi dos millones con edades que van de los 10 a los 14 años), las niñas y los niños de la calle y 


\section{Los objetivos de esta guía incluyen:}

- la consideración de los cambios cognitivos y del desarrollo que se presentan durante la adolescencia temprana y el impacto que pueden tener sobre el diseño de un estudio de investigación;

- la revisión de las cuestiones éticas que deben considerarse antes de llevar a cabo investigación con AMJ;

- la exploración de la amplitud y limitaciones de la información que puede recogerse del conjunto de datos que existen, como las Encuestas Demográficas y de Salud;

- la introducción a ciertas metodologías de investigación que ya han sido probadas con adolescentes más jóvenes, o que puede esperarse que sean útiles en algunos escenarios, con comentarios acerca de sus ventajas y limitaciones;

- la descripción de resultados de investigación sobre AMJ que se han logrado a través del empleo de estas metodologías; y

- la provisión de herramientas prototipo ilustrativas y de instrucciones básicas para utilizarlas.

quienes se involucran en trabajo sexual (casi 10 millones de jóvenes entre 10 y 17 años son explotados por la industria del sexo) (UNAIDS y cols., de próxima aparición). Muchos de estos niños han perdido a uno de sus padres o a ambos, no asisten a la escuela, se inician en la actividad sexual a muy temprana edad con poca o nula protección, y pueden comenzar a abusar de substancias y a inyectarse droga. Es extremadamente difícil recolectar información de estas sub-poblaciones o que los programas y los servicios lleguen a ellos.

\section{Objetivos de esta guía}

Esta guía nace del impulso generado por una reunión internacional sobre adolescentes muy jóvenes que tuvo lugar en Ginebra en el año 2003. ${ }^{1}$ Expertos de una gama de disciplinas y regiones (incluyendo a socios activos como el Population Council y el Fondo de las Naciones Unidas para la Infancia [UNICEF]), se reunieron para revisar la experiencia programática y la evidencia de la investigación para el trabajo sobre adolescentes muy jóvenes. En la reunión fue evidente la escasez de datos generados respecto de esta población. Poco era lo que se sabía sobre los instrumentos y metodologías más adecuadas para recolectar información acerca de ellos, y el debate resultante fue si, y cómo, recolectar información acerca de este grupo.

En un esfuerzo por impulsar el tema hacia adelante, el Fondo de Población de las Naciones Unidas (UNFPA) y el Population Council convocaron a una reunión de consulta más pequeña que se abocó a temas y métodos de investigación y que congregó a expertos y colegas que trabajan en el campo de los adolescentes, quienes estaban llevando a cabo investigación sobre los adolescentes muy jóvenes, o bien que planeaban hacerlo. Numerosas organizaciones estuvieron representadas en esa reunión, incluyendo al Instituto Alan Guttmacher, Futures 
Group, YouthNet, OPS, Save the Children, UNICEF y YouthNet, entre otras. Esta guía es el resultado de ese encuentro y de las deliberaciones que en ella se suscitaron.

Las metodologías descritas en esta guía son útiles, principalmente, para descubrir a los AMJ más vulnerables, cuáles son sus necesidades y si los programas que existen están llegando a ellos. Los jóvenes son más capaces de tomar decisiones responsables acerca de su salud si se les ofrece información, técnicas, servicios y el apoyo que requieren para adoptar comportamientos seguros. Y aunque es importante incluir en las actividades programáticas y de investigación a los padres, los proveedores de servicios y otros "guardianes" (gatekeepers), tal esfuerzo queda fuera del ámbito de este documento, cuyo foco de atención es la fuente principal de información sobre las vidas de los AMJ: los adolescentes mismos. A lo largo de este documento se incorpora una visión de género, dado que durante esta etapa la vida de las niñas suele comenzar a ser dramáticamente diferente de las de los muchachos, en términos de escolaridad, movilidad, responsabilidades domésticas, acceso a los medios masivos de comunicación y estado civil.

Esta guía busca ser útil a cualquier persona que tenga planes, maneje, implemente, esté monitoreando o financie investigación o programas que involucren la recolección de información sobre adolescentes de 10 a 14 años. Aunque sobre metodologías de investigación y técnicas de recolección de datos no se ha alcanzado un consenso de "buenas prácticas", confiamos en que este texto ofrecerá información de uso práctico para construir la base de conocimientos y continuar el diálogo. Las metodologías de investigación requieren ajustarse a la particularidad de las comunidades y a sus sensibilidades culturales, y los investigadores deben trabajar estrechamente con los miembros de la comunidad en la planeación y ejecución de la investigación, la divulgación de resultados y el desarrollo de respuestas basadas en esos resultados. A pesar de que esta guía fue escrita teniendo en mente el desarrollo de programas sobre el VIH/sida dirigidos a adolescentes jóvenes, los enfoques descritos más adelante pueden emplearse en programas diseñados para abordar cualquier problema que amenace la salud y el bienestar de este grupo, incluyendo el embarazo temprano y no deseado, la violencia, el abuso en el consumo de substancias y la mutilación genital femenina.

Nota: esta guía no ofrece capacitación sobre las metodologías que describe; ofrece, más bien, una selección de posibilidades. Se requiere de entrenamiento para usar de manera adecuada las herramientas descritas. La guía no suministra tampoco directrices sobre el modo como la información recogida a partir de estos enfoques puede usarse para informar, mejorar o evaluar proyectos, lo cual requeriría ajustarse estrechamente al contexto y objetivos del proyecto. ${ }^{2}$

\footnotetext{
${ }^{2}$ Referimos a los lectores que buscan indicadores específicos para monitorear y evaluar programas a la publicación National AIDS Programmes: A Guide to Indicators for Monitoring and Evaluating National HIV/AIDS Prevention Programmes for Young People (Programas Nacionales sobre SIDA: Una Guía de los Indicadores para Monitorear y Evaluar Programas de Prevención del VIH/SIDA para Jóvenes), una publicación de la OMS y organizaciones socias (2004, de aquí en adelante citada como la "guía interagencial para monitorear y evaluar programas sobre el VIH/SIDA para jóvenes"). La publicación complementa indicadores ya incluidos en el documento de ONUSIDA: National AIDS Programmes: A Guide to Monitoring and Evaluation (Programas Nacionales sobre SIDA: Una Guía para el Monitoreo y la Evaluación) (2000) y propone nuevos indicadores que están en las fases tempranas de desarrollo y uso. Dado que estos indicadores están diseñados para encuestas nacionales grandes, tendrán que adaptarse para monitorear y evaluar programas de prevención del VIH de base comunitaria para jóvenes; pero pueden servir como un valioso punto de partida
} 


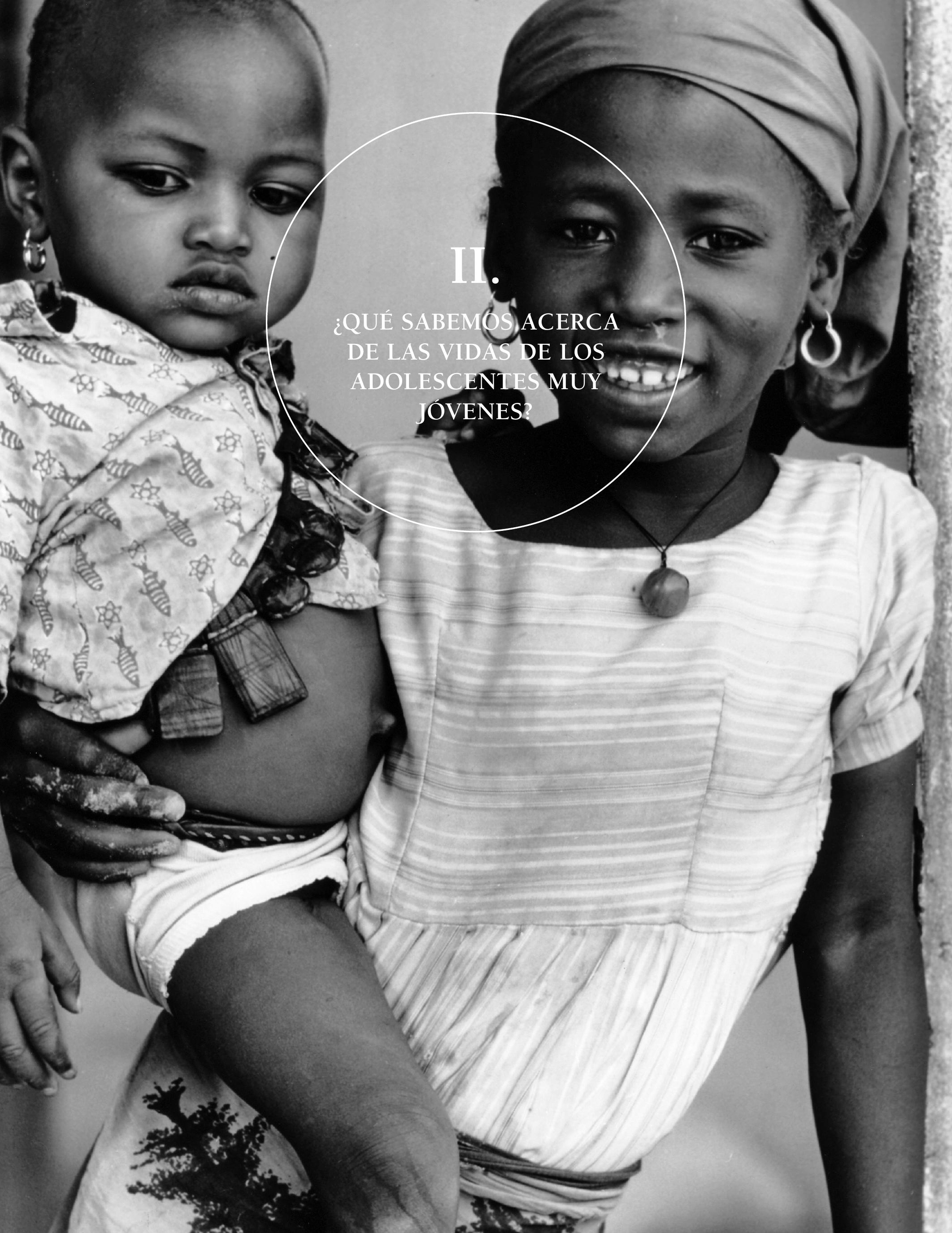




\section{Hallazgos recientes}

La naturaleza y calidad de la vida futura de los jóvenes depende de qué tan exitosamente gestionen las transiciones a sus roles como ciudadanos, parejas, padres y trabajadores. El National Research Council (Consejo Nacional de Investigación) y el Institute of Medicine (Instituto de Medicina) convocaron recientemente a un panel de expertos con el propósito de examinar la situación actual de los jóvenes en los países en desarrollo; identificar y explicar cambios recientes en la naturaleza, momento y secuencia de las varias transiciones a la vida adulta; y para establecer prioridades para la investigación a futuro. Los hallazgos de ese panel se presentan en Growing Up Global: The Changing Transitions to Adulthood in Developing Countries (Creciendo de manera global: las cambiantes transiciones a la vida adulta en los países en desarrollo) (2005). Los jóvenes están pasando más tiempo de su adolescencia en la escuela y la brecha de género, en donde existe todavía, se está cerrando rápidamente como resultado de mejoras en la educación de las niñas. Aunque la participación escolar y el logro de los niveles correspondientes han experimentado un crecimiento sin precedentes, persisten diferencias importantes en la asistencia a la escuela en función de los niveles de recursos y del lugar de residencia.

En términos generales, la salud de los jóvenes está mejorando, salvo en las zonas golpeadas más severamente por el VIH/sida (en la mayoría de las regiones las niñas se están viendo más afectadas que los varones). Aunque las niñas y las mujeres jóvenes continúan enfrentándose a riesgos de mortalidad y morbilidad materna significativos, los niños y los hombres jóvenes se ven afectados de manera desproporcionada por accidentes de tráfico, por la violencia, las guerras y el suicidio. Los problemas de salud mental son un tema emergente que abarca una proporción considerable, y posiblemente incrementada, de la enfermedad en este grupo de edad. En casi todos los lugares la edad al matrimonio se está incrementando; 38 por ciento de las mujeres jóvenes de 20 a 24 años se casó antes de cumplir 18 años, en comparación con 52 por ciento que lo hizo hace 20 años. (Estos porcentajes se basan en datos de encuestas que representan a 60 por ciento de la población del mundo en desarrollo). El hecho de inscribirse en la escuela tiene un efecto protector sobre la salud reproductiva: los estudiantes, al compararse con quienes no lo son, tienen menos probabilidades de haber tenido experiencias sexuales y, si son sexualmente activos, mayores probabilidades de practicar la anticoncepción.

\section{El desarrollo del adolescente joven}

La adolescencia es un periodo que puede extenderse por diez años o más, y a la luz del crecimiento y desarrollo significativos que ocurren en esos años, la mayoría de los científicos sociales y los profesionales consideran que la adolescencia está constituida por una serie de etapas distintas y no tanto por una etapa homogénea. Los administradores de programas deben, igualmente, comprender estas etapas para poder diseñar intervenciones acordes, articular mensajes apropiados, establecer metas idóneas y ofrecer el nivel de apoyo que los jóvenes requieren. Si bien los expertos en el campo describen las varias etapas de la adolescencia, hay poco acuerdo en relación con las edades que corresponden a cada etapa.

La Organización Panamericana de la Salud (OPS), publicó recientemente Youth: Choices and Change (Juventud: elecciones y cambio), en donde los autores resumen las clasificaciones del desarrollo que existen y los marcos teóricos dentro de los cuales dichas clasificaciones se produjeron. Por nombrar algunas, se refieren a teorías psicodinámicas sobre desarrollo emocional, al trabajo de Harry Stack Sullivan sobre desarrollo interpersonal, a los estudios de Jean Piaget sobre desarrollo cognitivo, y al de Carol Gillberg sobre 
Figura 2 Las etapas de la adolescencia (clasificación de la OPS)

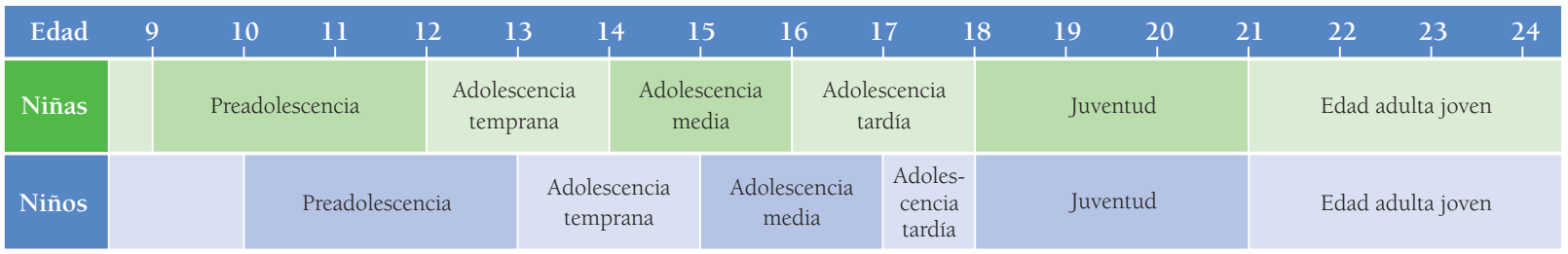

diferencias de género y desarrollo femenino (OPS 2005). En un esfuerzo por crear un modelo integral del desarrollo adolescente que funda estas teorías dispares e incorpore hallazgos de la investigación reciente sobre el impacto del ambiente, el funcionamiento neuropsicológico y el procesamiento de la información, la OPS propone una nueva clasificación de las etapas adolescentes, misma que se muestra en la figura 2.

Comenzando con la preadolescencia y finalizando con la edad adulta joven, los cambios se agrupan en cinco dominios del desarrollo: cuerpo, mente, sexual, emocional y social. Aunque los rangos de edad de la clasificación de la OPS son las edades promedio en las cuales los cambios ocurren en los cinco dominios, siempre habrá excepciones a esos límites, con los adolescentes precoces en un extremo y los que maduran tardíamente en el otro. La rapidez con la cual una persona joven avanza a través de esas etapas depende de numerosos factores endógenos y del ambiente, incluyendo diferencias biológicas, habilidades cognitivas, experiencias educativas, emocionales y vitales, y contextos culturales y sociales. Los adolescentes que crecen enfrentando la adversidad (pobreza extrema, hogares afectados por el SIDA, conflictos armados, violencia doméstica) son lanzados a desempeñar roles y a comportarse como adultos prematuramente; es poco lo que se conoce acerca de los efectos que las transiciones aceleradas de este tipo tienen sobre el desarrollo de los individuos en el largo plazo, o sobre su capacidad para desempeñar exitosamente sus roles como personas adultas.
Los principales cambios en cada uno de los cinco dominios se resumen en la Tabla 1. Considerando que esta guía focaliza en los adolescentes muy jóvenes, se incluyen únicamente aquellos cambios que pertenecen a la preadolescencia o la adolescencia temprana.

\section{Obtención de información de encuestas nacionalmente representativas}

Las Encuestas Demográficas y de Salud (EDS, o DHS por sus siglas en inglés), aunque focalizadas en temas de fecundidad, planificación familiar y más recientemente en el VIH, representan una importante fuente de información sobre los adolescentes muy jóvenes. Estas encuestas nacionalmente representativas se han realizado en más de 60 países en vías de desarrollo en todas las regiones del mundo. La mayor parte de la información sobre los adolescentes muy jóvenes se obtiene de las encuestas de hogares de las EDS, en las cuales el/la jefe del hogar responde a preguntas acerca de todas las personas que residen en la casa. Es posible también obtener información retrospectiva utilizando el cuestionario individual aplicado a las mujeres. Aunque los adolescentes jóvenes no responden directamente a las EDS, uno puede darse una idea bastante precisa de sus vidas a partir de la encuesta, incluyendo el lugar en donde viven, la escolaridad y la residencia de los padres, así como su experiencia de matrimonio temprano, sexo y crianza (ver el resumen de 49 países que se ofrece en la Tabla 2, más adelante en este texto). ${ }^{3}$ Tales análisis pueden sugerir áreas

\footnotetext{
${ }^{3}$ Population Council. 2003a. Para una lista completa de los informes disponibles, véase www.popcouncil.org/gfd/gfdcountries.html.
} 
Tabla 1 Etapas del desarrollo de los adolescentes muy jóvenes

\begin{tabular}{|c|c|c|}
\hline $\begin{array}{l}\text { Dominios del } \\
\text { desarrollo }\end{array}$ & $\begin{array}{l}\text { Preadolescencia } \\
\text { 9-12 años (niñas) } \\
\text { 10-13 años (niños) }\end{array}$ & $\begin{array}{l}\text { Adolescencia temprana } \\
12-14 \text { años (niñas) } \\
\text { 13-15 años (niños) }\end{array}$ \\
\hline Cuerpo & $\begin{array}{l}\text { El esfuerzo supremo de crecimiento comien-za y el } \\
\text { cuerpo adquiere de modo gradual características } \\
\text { sexuales secundarias. Hay un incremento en la grasa } \\
\text { y peso del cuerpo, y también una redistribución de } \\
\text { ellos para reflejar características sexuales secundarias. } \\
\text { Se manifiesta un incremento gradual en la búsqueda } \\
\text { de sensaciones. }\end{array}$ & $\begin{array}{l}\text { En las niñas se presenta la menstruación (edad } \\
\text { promedio = } 12.4 \text { años); en los niños ocurre la } \\
\text { eyaculación (edad promedio: } 13.4 \text { años). Se } \\
\text { manifiesta un esfuerzo supremo de crecimiento y un } \\
\text { marcado incremento en la búsqueda de sensaciones, } \\
\text { particularmente entre los niños. }\end{array}$ \\
\hline Mente & $\begin{array}{l}\text { Ocurre un cambio gradual del pensamiento } \\
\text { egocéntrico al sociocéntrico, con un pensa-miento } \\
\text { lógico más concreto. Están en pro-ceso de ser } \\
\text { adquiridas las tareas de conser-vación. Existe el } \\
\text { ansia incrementada de poseer nueva información, } \\
\text { pero el lenguaje es aún concreto. Hay todavía un } \\
\text { desarrollo limitado del lóbulo prefrontal y de las } \\
\text { funciones ejecutivas. }\end{array}$ & $\begin{array}{l}\text { Se utiliza un pensamiento más abstracto } \\
\text { (operaciones formales) y menos concreto. Casi } \\
\text { todos los adolescentes adquirirán todas las tareas de } \\
\text { conservación durante esta etapa. Hay todavía un } \\
\text { pequeño desarrollo del lóbulo prefrontal y de las } \\
\text { funciones ejecutivas, particularmente entre los } \\
\text { niños. }\end{array}$ \\
\hline Sexual & $\begin{array}{l}\text { Niños y niñas exploran roles masculinos y } \\
\text { femeninos más diferenciados en comparación con } \\
\text { los de años previos. Para las niñas, la androginia es } \\
\text { una alternativa viable a la feminidad exclusiva, en } \\
\text { tanto que para los niños la masculinidad exclusiva } \\
\text { es todavía la alternativa más esperada socialmente. }\end{array}$ & $\begin{array}{l}\text { El despertar sexual se incrementa, al igual que la } \\
\text { necesidad de masturbarse. Se manifiestan otros } \\
\text { comportamientos auto-eróticos, tales como las } \\
\text { fantasías sexuales y los sueños húmedos. Si bien la } \\
\text { identidad de género se desarrolla en los primeros años } \\
\text { de vida, su estabilidad se vuelve cada vez más un reto } \\
\text { con el desarrollo de la orientación sexual, la preferencia } \\
\text { y la exploración que involucran a otra persona } \\
\text { durante este periodo de edad, incluyendo a veces el } \\
\text { surgimiento de sentimientos homosexuales confusos. }\end{array}$ \\
\hline Emocional & $\begin{array}{l}\text { Ocurre un incremento gradual de la autocon-ciencia } \\
\text { con fluctuaciones en la auto imagen y sentimientos } \\
\text { incrementados de desconcierto. Surge la necesidad } \\
\text { por una mayor privacidad, individualidad y más } \\
\text { autonomía emocional respecto de los padres. Las } \\
\text { expresiones verbales y no verbales de emociones } \\
\text { intensas fluctúan (gestos faciales). Surge la habilidad } \\
\text { para explorar las múltiples razones de un } \\
\text { sentimiento, para comparar sentimientos y para } \\
\text { comprender interacciones triádicas entre estados } \\
\text { emocionales. Lo anterior se acompaña de la } \\
\text { capacidad para diferenciar sombras y gradaciones } \\
\text { entre estados emocionales. Hay un cambio gradual } \\
\text { de la moralidad preconvencional (premios y } \\
\text { castigos) a la moralidad convencional (reglas de la } \\
\text { sociedad). }\end{array}$ & $\begin{array}{l}\text { Se presenta un alto nivel de auto-conciencia y } \\
\text { fluctuaciones en la imagen propia. El nivel de tensión } \\
\text { se incrementa, especialmente entre las niñas. } \\
\text { Continua la necesidad de una mayor autonomía } \\
\text { emocional de los padres, alimentada por una de- } \\
\text { idealización más fuerte respecto de los propios } \\
\text { padres y una definición incrementada de las } \\
\text { opiniones propias del adolescente. Al mismo tiempo, } \\
\text { ocurre un incremento en la dependencia emocional } \\
\text { de los amigos propios. La intimidad, la lealtad, los } \\
\text { valores compartidos y las actitudes asumen un mayor } \\
\text { peso en la amistad. Hay un incremento en la empatía } \\
\text { e interés hacia los amigos cercanos y una habilidad } \\
\text { emergente para reflexionar sobre sentimientos en } \\
\text { relaciones con un sentido internalizado del yo. Se } \\
\text { asume una moralidad convencional. }\end{array}$ \\
\hline Social & $\begin{array}{l}\text { Surge la necesidad del mejor amigo del mismo sexo } \\
\text { (o similar) con quien divertirse y compartir secretos. } \\
\text { Las demandas y expertativas académicas y sociales } \\
\text { se incrementan. Todavía se pasa tiempo con los } \\
\text { padres y su supervisión está aún presente, aunque } \\
\text { comienza a disminuir de forma gradual acompanándose } \\
\text { de un incremento, también gradual, en los } \\
\text { conflictos entre los preadolescentes y sus padres. } \\
\text { Aumenta la susceptibilidad a la presión de los pares. }\end{array}$ & $\begin{array}{l}\text { Se pasa más tiempo con los subgrupos sociales } \\
\text { (camarillas) y/o solo. Surge un interés en amigos } \\
\text { del sexo opuesto ("diferentes"). Se pasa menos } \\
\text { tiempo con los padres, cuya supervisión disminuye; } \\
\text { se incrementan los conflictos relativos a la } \\
\text { independencia. Se esperan nuevos privilegios } \\
\text { sociales. La susceptibilidad a la presión de los pares } \\
\text { alcanza su pico. }\end{array}$ \\
\hline
\end{tabular}


fructíferas para investigación adicional. Por ejemplo, en algunos países de África subsahariana, una proporción sorprendentemente alta de niños de 10 a 14 años no van a la escuela ni viven con ninguno de los padres. Es posible que algunos de esos niños vivan con su familia extendida o tengan arreglos para ser acogidos en otros sitios; pero muchos son vulnerables a la explotación sexual, al trabajo inseguro y al abuso de substancias.

Mensch y sus colegas (2005) han analizado los resultados de las Encuestas Demográficas y de Salud realizadas en 27 países subsaharianos para investigar los vínculos entre tendencias en la edad al matrimonio y el comportamiento sexual premarital. Al comparar a los jóvenes de 20 a 24 años con las personas de 40 a 44 años, los autores encontraron que la prevalencia de matrimonio a los 18 años ha descendido de manera importante en 24 de los 27 países; que la prevalencia de haber tenido relaciones sexuales premaritales a los 18 años ha aumentado de modo significativo en 19 países, y que la de haber experimentado la iniciación sexual a los 18 años (ya sea antes del matrimonio o al casarse) ha disminuido de manera significativa en 12 países, se ha incrementado de manera importante en cuatro y no ha cambiado en 11. Los autores observan que "mientras la edad a la que se experimenta la primera actividad sexual ha permanecido inalterada o se ha incrementado, en muchos países ha ocurrido un cambio en el contexto del debut sexual, del matrimonio a la actividad sexual premarital" (página 12).

\section{Otros programas de encuestas importantes incluyen:}

\section{Comportamiento en salud de niños en edad escolar (CSNEE [o HBSC por sus siglas en} inglés]). ${ }^{4}$ El CSNEE recoge los datos de jóvenes de 11,13 y 15 años que van a la escuela, empleando un cuestionario auto-aplicado que se administra en el salón de clase. En la actualidad, la membresía está restringida a países de Europa; 36 países participaron en la ronda de recolección de datos de 2001-2002. El núcleo del conjunto de preguntas focaliza en factores del historial, tales como recursos individuales y sociales, comportamientos en salud y resultados sanitarios.

\section{Encuestas de vigilancia del comportamiento del VIH/sida/ETS (EVC [o BSS por sus siglas en} inglés]). ONUSIDA, la OMS, Family Health International y otras agencias han trabajado para desarrollar un marco de trabajo para vigilar el comportamiento del VIH que es apropiado a la etapa de la epidemia que cada país experimenta. La EVC es una metodología de monitoreo y evaluación diseñada para seguir la trayectoria de las tendencias en el conocimiento, actitudes y comportamientos de riesgo al VIH/sida en sub-poblaciones que tienen riesgos particulares de infección por el virus, como son las trabajadoras del sexo, los usuarios de drogas inyectables, los hombres migrantes y los jóvenes. La EVC se ha implementado en 15 países de Asia y África. Aunque las poblaciones de jóvenes encuestados no incluyen típicamente a los menores de 15 años, las preguntas retrospectivas de la EVC pueden arrojar datos importantes sobre comportamientos en la adolescencia temprana. ${ }^{5}$

Encuesta global de base escolar sobre salud de los estudiantes (EGBESE [GSHS por sus siglas en inglés]). ${ }^{6}$ La EGBESE es una colaboración de la OMS y los Centros para el Control de la

Enfermedades (CDC por sus siglas en inglés); se trata de un proyecto de vigilancia diseñado para ayudar a los países a medir y evaluar los factores de comportamientos de riesgo y factores de protección entre jóvenes de 13 a 15 años en diez áreas clave que son: ingesta de alcohol y uso de otras drogas, comportamiento alimenticio, higiene,

\footnotetext{
${ }^{4}$ Para mayor información, visite el sitio www.hbsc.org.

${ }^{5}$ Para mayor información, visite el sitio www.fhi.org or vea Amon, Brown y cols. (2000).

${ }^{6}$ Para mayor información y para acceder a las hojas de datos de países y cuestionarios, visite el sitio www.who.int/school_youth_health/assessment/ gshs/en/.
} 
Tabla 2 Resumen de datos seleccionados de la EDS sobre adolescentes muy jóvenes de 49 países en desarrollo

\begin{tabular}{|c|c|c|c|c|c|c|c|c|c|c|}
\hline \multirow[b]{2}{*}{ País } & \multirow[b]{2}{*}{$\begin{array}{c}\text { Año } \\
\text { de la } \\
\text { encuesta }\end{array}$} & \multirow[b]{2}{*}{$\begin{array}{l}\text { Porcentaje de } \\
\text { la población } \\
\text { de } 10-14 \\
\text { años }\end{array}$} & \multirow[b]{2}{*}{$\begin{array}{l}\text { Porcentaje } \\
\text { que vive } \\
\text { en áreas } \\
\text { rurales }\end{array}$} & \multirow[b]{2}{*}{$\begin{array}{c}\text { Porcentaje } \\
\text { de quienes } \\
\text { un o } \\
\text { ambos } \\
\text { padres } \\
\text { murieron }\end{array}$} & \multirow[b]{2}{*}{$\begin{array}{l}\text { Porcentaje } \\
\text { que no vive } \\
\text { con ninguno } \\
\text { de los padres } \\
\text { (niñas/os) }\end{array}$} & \multirow[b]{2}{*}{$\begin{array}{c}\text { Porcentaje } \\
\text { no inscrito } \\
\text { en la escuela } \\
\text { (niñas/os) }\end{array}$} & \multirow{2}{*}{$\begin{array}{c}\text { Porcentaje } \\
\text { que no vive } \\
\text { con ninguno } \\
\text { de los padres } \\
\text { ni está } \\
\text { inscrito en } \\
\text { la escuela } \\
\text { (niñas/os) }\end{array}$} & \multicolumn{3}{|c|}{$\begin{array}{l}\text { Porcentaje de niñas } \\
\text { de } 15-19 \text { años } \\
\text { que informaron }{ }^{2} \text { : }\end{array}$} \\
\hline & & & & & & & & $\begin{array}{l}\text { Haber } \\
\text { tenido } \\
\text { relaciones } \\
\text { sexuales } \\
\text { antes de } \\
\text { los } 15 \text { años }\end{array}$ & $\begin{array}{c}\text { Haber } \\
\text { casado } \\
\text { antes de } \\
\text { los } 15 \\
\text { años }\end{array}$ & $\begin{array}{c}\text { Haber } \\
\text { dado a } \\
\text { luz antes } \\
\text { de } \\
\text { cumplir } \\
15 \text { años }\end{array}$ \\
\hline Benin & 1996 & 14 & 60 & 12 & $32 / 18$ & $68 / 41$ & $26 / 8$ & 14 & 5 & 1 \\
\hline Burkina Faso & 1998-99 & 15 & 86 & $13^{\mathrm{b}}$ & $21 / 15^{b}$ & $79 / 70$ & $16 / 10^{\mathrm{b}}$ & 12 & 6 & 2 \\
\hline Camerún & 1998 & 14 & 67 & 16 & $24 / 21$ & $24 / 19$ & $6 / 4$ & 26 & 11 & 4 \\
\hline Chad & 1996-97 & 13 & 77 & 18 & $19 / 19$ & $71 / 50$ & $13 / 9$ & 22 & 19 & 4 \\
\hline Costa de Marfil & 1998-99 & 14 & 65 & 13 & $34 / 24^{b}$ & $53 / 35$ & $23 / 11^{b}$ & 22 & 8 & 6 \\
\hline Ghana & 1998 & 14 & 69 & $11^{\mathrm{b}}$ & $29 / 21$ & $20 / 18$ & $7 / 4$ & 7 & 4 & 0 \\
\hline Guinea & 1999 & 14 & 68 & 9 & $26 / 20$ & $75 / 62$ & $19 / 13$ & 28 & 20 & 7 \\
\hline Mali & 2001 & 14 & 73 & 13 & $19 / 14$ & $68 / 54$ & $14 / 7$ & 26 & 19 & 5 \\
\hline Níger & 1998 & 13 & 78 & 9 & $22 / 17$ & $78 / 68$ & $18 / 12$ & $\mathrm{nr}$ & 27 & 4 \\
\hline Nigeria & 1999 & 12 & 70 & 11 & $21 / 17$ & $30 / 26$ & $7 / 5$ & 17 & 14 & 7 \\
\hline República Central Africana & $1994-95$ & 13 & 55 & 10 & $28 / 25$ & $50 / 28$ & $17 / 8$ & 25 & 16 & 5 \\
\hline Rwanda & 2000 & 17 & 87 & 41 & $26 / 22$ & $59 / 59$ & $17 / 15$ & 3 & 0 & 0 \\
\hline Senegal & 1997 & 14 & 63 & $11^{\mathrm{b}}$ & $22 / 21^{b}$ & $69 / 58^{b}$ & $16 / 12^{b}$ & 10 & 8 & 2 \\
\hline Togo & 1998 & 15 & 70 & 16 & $29 / 23$ & $34 / 16$ & $12 / 4$ & 21 & 4 & 2 \\
\hline
\end{tabular}

salud mental, actividad física, factores de protección, antecedentes demográficos, comportamientos sexuales, adicción al tabaco, y violencia y daño no intencional. Veintidós países de todas las regiones han implementado la EGBESE o están en vías de hacerlo.

\section{Encuesta de grupo de indicadores múltiples}

(EGIM [MICS por sus siglas en inglés). ${ }^{7}$ La EGIM es un programa de encuestas de hogares desarrollado por UNICEF para ayudar a los países a llenar vacíos de información para monitorear la situación de niños y mujeres. La primera ronda de la EGIM fue realizada en 1995 en más de 60 países; la segunda se efectuó en el año 2000 en 65 países; la siguiente ronda de encuestas, que se realiza en la actualidad, será conducida en más de 50 países. La EGIM se compone de tres cuestionarios: uno de hogares, uno para mujeres de 15 a 49 años, y otro sobre la situación de los niños menores de cinco años (que contesta la persona que está a cargo del menor). Aunque la EGIM no pasa revista a los AMJ directamente, arroja datos retrospectivos ricos y es una importante fuente de información sobre los adolescentes que no asisten a la escuela.

\section{Encuestas internacionales de salud reproductiva de los Centros para el Control de las}

Enfermedades. ${ }^{8}$ Los CDC (por sus siglas en inglés) brindan asistencia técnica con encuestas de base poblacional para ayudar a la Agencia para el Desarrollo Internacional de Estados Unidos (USAID por sus siglas en inglés), a los Ministerios de Salud, las organizaciones donantes internacionales y las organizaciones no gubernamentales (ONG) a evaluar necesidades programáticas y monitorear el desempeño e impacto de los programas en el transcurso del tiempo. Las encuestas de salud reproductiva de los CDC han recogido información en 20 países respecto de temas diversos, incluyendo: comportamiento sexual de adultos jóvenes, educación sexual, opiniones y actitudes hacia la sexualidad y temas de género, atención a la salud reproductiva, VIH y ETS, y violencia del compañero íntimo. Estas encuestas abarcan a hombres y mujeres de 15 años y mayores.

\footnotetext{
Ver la EGIM o MICS en el sitio www.childinfo.org.

${ }^{8}$ Para mayor información, visite www.cdc.gov/reproductivehealth/Surveys/SurveyOverview.htm.
} 


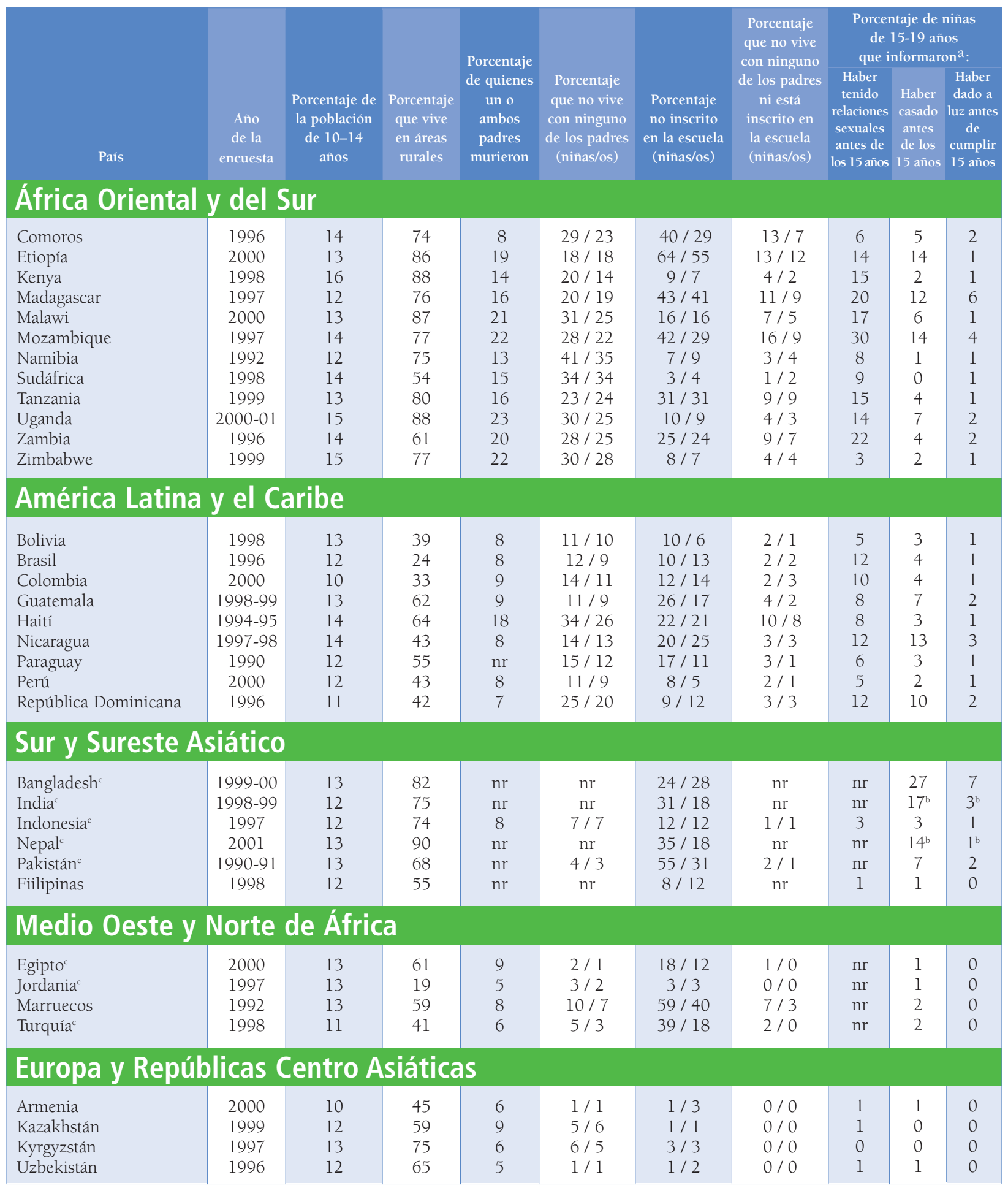

Note: Todos los análisis se basan en datos de las Encuestas Demográficas y de Salud. $\mathrm{nr}=$ Datos para el indicador no recolectados. ${ }^{2}$ Datos extraídos de la encuesta de hogares, excepto por la información retrospectiva de jóvenes de 15 a 19 años de la encuesta individual. ${ }^{b}$ Los datos para estos indicadores se tomaron de EDS previas (los años se indican como sigue) porque la información no fue capturada en la EDS enlistada en la tabla: Burkina Faso, 1992-93; Costa de Marfil, 1994; Senegal, 1992-93; India, 1992-93; Nepal, 1996.

‘En estos países se pasó revista a las mujeres alguna vez casadas. Los datos retrospectivos de los informes finales fueron ajustados matemáticamente para que sean representativos de todas las mujeres. Se presume que las mujeres que nunca se casaron no dieron a luz. Fuente: Population Council (2003a). 


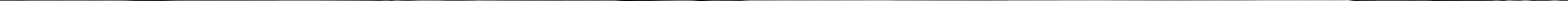


Mantener estándares éticos altos es crucial cuando se realizan actividades de recolección de información. Los niños y adolescentes requieren protecciones especiales porque son vulnerables a la explotación, el abuso y otras consecuencias dañinas, y también porque tienen menos poder que los adultos. Los investigadores deben ser sensibles a las presiones que los jóvenes adolescentes pudieran sentir de participar en una investigación — por no querer decir "no" a quienes están a cargo de ellos (padres, maestros, parejas o parientes políticos) o a los investigadores. De ahí que algunos investigadores recomienden obtener el consentimiento de los jóvenes adolescentes en varias ocasiones —antes de iniciar la investigación, en su transcurso y al principio de una entrevista. Los adolescentes deben sentirse libres para retirar su cooperación en cualquier momento, o declinar responder a una pregunta o elemento particular de la investigación (Miers y Murphy 2004).

En la reciente publicación Ethical Approaches to Gathering Information from Children and Adolescents in International Settings: Guidelines and Resources (Enfoques éticos para la recolección de información de niños y adolescentes en escenarios internacionales: pautas y recursos) (Schenk y Williamson 2005), se recomiendan dos importante principios para guiar todas las actividades: (1) siempre colocar primero los mejores intereses de los niños promoviendo y protegiendo sus derechos (como mínimo, los investigadores no deberían causarles ningún daño); y (2) fomentar y respetar la participación de los niños. Las mejores fuentes de información precisa acerca de sus vidas suelen ser los propios niños, quienes tienen el derecho a expresar sus opiniones sobre aquellas decisiones que los afectan, tanto como a sus familias o comunidades. Estos principios concuerdan con los artículos 3 y 12 de la Convención sobres los Derechos del Niño (CDN) (véase el recuadro). ${ }^{9}$ Implementar ambos principios puede requerir de

\section{Principios que guían la recolección de información de los niños}

En todas las medidas concernientes a los niños que tomen las instituciones de bienestar social -sean públicas o privadas-, los tribunales, las autoridades administrativas o los órganos legislativos, una consideración principal que se atenderá será el interés superior del niño. (Artículo 3).

Los Estados partes garantizarán al niño que esté en condiciones de formarse un juicio propio, el derecho a expresar su opinión libremente en todos los asuntos que lo afectan, teniéndose debidamente en cuenta las opiniones del niño, en función de su edad y madurez. (Artículo 12).

—Convención sobre los Derechos del Niño, 1989

un delicado acto de equilibrio que involucra llevar al máximo la participación de los niños mientras se reduce al mínimo su exposición al daño. Schenk y Williamson (2005) establecen una serie de seis tópicos acerca de los cuales cada investigador debería reflexionar cuidadosamente antes de iniciar la recolección de datos (ver el recuadro con el resumen en párrafos siguientes).

Con la comunidad deben realizarse consultas tempranas y frecuentes; mientras tanto, las actividades deben ser sensibles a las normas comunitarias que conciernen a los niños y la sexualidad. Algunos investigadores desarrollan cuestionarios para "niños" y cuestionarios para "adolescentes", de modo tal que a los niños más jóvenes no se les plantean preguntas sobre sexualidad. Un estudio hecho en Rwanda y Zambia, con niños huérfanos y vulnerables, utilizó una herramienta para niños de 6 a 12 años y otra distinta para los de 13 a 19 (Chatterjee y cols. 2005). La Encuesta 


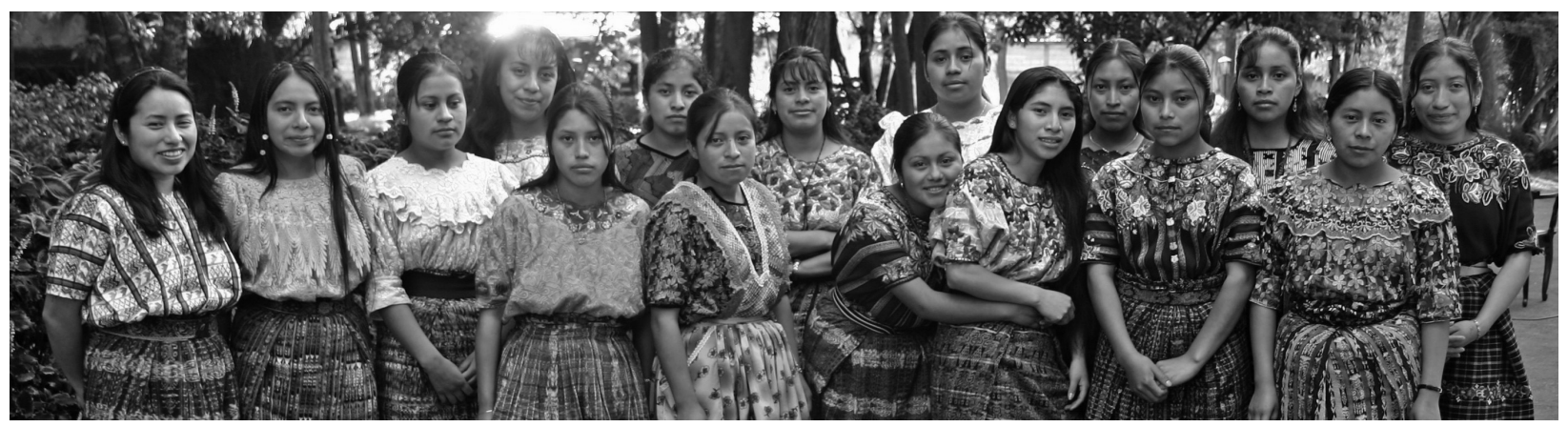

Guatemala - Foto: Jennifer Catino/Population Council

Nacional de Hogares sobre Prevalencia y Riesgo al VIH de Niños Sudafricanos empleó tres diferentes cuestionarios: uno para los padres/guardianes de los niños de 2 a 11 años, otro para los niños de 12 a 14 años que incluía un número limitado de preguntas sobre experiencias sexuales, y un tercero para los adolescentes de 15 a 24 años que cubría extensamente las experiencias y prácticas sexuales (Brookes y cols. 2004). Pattman y Chege (2003) subrayan, sin embargo, que los investigadores no deben suponer que los adolescentes más jóvenes (de 10 a 12 años) no han tenido experiencias sexuales. Un estudio hecho en Zambia encontró que niños de edades tan cortas como los seis años de edad estaban familiarizados con la actividad sexual, sin importar que hubieran experimentado o no sexo de penetración o que simplemente hubieran "jugado" con él, y que les divertía hablar de eso (Pattman, comunicación personal 2005).

La guía interagencial para monitorear y evaluar programas sobre el VIH/sida para jóvenes recomienda que en los lugares en donde no puedan plantearse a los adolescentes muy jóvenes preguntas relacionadas con la sexualidad, la investigación debe focalizar en el conocimiento relevante que posean para prevenir el VIH, en sus percepciones de la actividad sexual de sus pares y en el contexto dentro del cual los adolescentes jóvenes toman decisiones relacionadas con la sexualidad. Preguntas sustitutas relativas al comportamiento (por ejemplo, si creen que sus pares ya han mantenido relaciones sexuales) suponen que el informante contesta refiriéndose a un grupo similar al suyo. Con todo, la investigación ha mostrado que los adolescentes suelen creer que sus amigos se están involucrando en comportamientos de riesgo a tasas mucho más altas que las que en realidad ocurren (Robinson y cols. 1999).

\section{El Council for International Organizations of} Medical Sciences (Consejo de Organizaciones Internacionales de Ciencias Médicas, CIOMS por sus siglas en inglés), ha emitido y actualiza periódicamente, los International Ethical Guidelines for Biomedical Research Involving Human Subjects (Principios éticos internacionales para la investigación biomédica que involucra a sujetos humanos) (CIOMS 2002). Estos 21 principios incluyen directrices para quienes realizan investigación con niños, así como sugerencias relativas a temas de consentimiento y obtención de autorización por parte de los padres. El CIOMS recomienda obtener la cooperación voluntaria del menor, una vez que ha sido debidamente informado al grado que su madurez e inteligencia lo permitan. En algunos escenarios, los niños que no han alcanzado la edad legalmente establecida para dar su consentimiento pueden comprender las implicaciones de la investigación y dar su acuerdo informado para participar; no obstante, este "conocimiento informado" (o asentimiento) debe complementarse con el permiso de uno de los padres o del tutor legal. Aquellos niños que pudieran ser demasiado inmaduros para dar su consentimiento pueden registrar una "objeción deliberada”, que es una expresión de desaprobación o de rechazo a participar en los procedimientos de 
la investigación. Frente a tales situaciones, el CIOMS señala que "una objeción deliberada por parte de un niño a tomar parte en una investigación debiera respetarse siempre, aun si los padres han dado su autorización, a menos que el niño requiera de un tratamiento que no esté disponible fuera del contexto de la investigación, que la intervención de la investigación demuestre la promesa de un beneficio terapéutico y que no exista una terapia alternativa aceptable". (Norma 14).

Se debe proceder con las actividades para recolectar la información únicamente si los sistemas funcionales de apoyo para tratar consecuencias posibles están operando. Los entrevistadores deben estar capacitados para manejar aquellas situaciones en las que los niños estén perturbados por una sucesión de interrogatorios, y también para hacer las referencias que puedan ser necesarias. Si se descubren situaciones de abuso o negligencia, el personal debe estar familiarizado con los aspectos legales locales, los reglamentos y las normas que rodean el abuso físico y sexual, y estar preparado también para abordar la situación, al menos en un nivel que los miembros de la comunidad consideren apropiado y aceptable. En los sitios en donde la infraestructura local es débil, pudiera llegar a ser necesario reducir el alcance del trabajo.

\section{Pautas para implementar estándares éticos: Resumen}

A. Asegurar que la actividad de recolección de información es necesaria y se justifica.

- Antes de iniciar la actividad, definir claramente el propósito que se persigue y la audiencia, y asegurar que existe el personal y los recursos monetarios suficientes para llevarla a cabo éticamente.

- Con los niños, utilizar solamente métodos directos en caso de que la información que se requiere no esté disponible de otra manera.

- Si la actividad de recolección de información no va a beneficiar directamente a los niños y adolescentes involucrados o a su comunidad, no se debe proceder.

B. Diseñar la actividad para obtener información válida.

- Desarrollar un protocolo para aclarar los objetivos y procedimientos para recolectar, analizar y utilizar la información, respecto del cual todas las partes convienen.

- Aplicar definiciones de la comunidad para establecer criterios claros de inclusión. Utilizar los registros existentes, cuando sea posible, y reconocer las barreras sociales y culturales que puedan afectar la participación. Para las encuestas, utilizar un número mínimo de informantes a fin de lograr resultados demostrables.

- Todas las herramientas -tales como los cuestionarios- deben desarrollarse a partir de discusiones con expertos. A continuación, estas herramientas deben traducirse localmente y retomarse para luego ponerse a prueba en el campo.

- El uso de un grupo de comparación totalmente privado de servicios es inadecuado si se trata de niños vulnerables. Se deben explorar enfoques alternativos para fortalecer los hallazgos de la investigación. Se acudirá a grupos de comparación solamente bajo una cuidadosa supervisión ética.

C. Consultar con los grupos comunitarios.

- Realizar consultas locales para determinar quién debe dar la autorización para proceder con la actividad.

- Los entrevistadores deben ser sensibles al hecho de que pueden ser altamente visibles y una fuente de interés local. Aclarar los roles y expectativas a través de reuniones comunitarias y honrar los compromisos.

- Un grupo interesado (stakeholders) comunitario, local e independiente, debe monitorear las actividades.

D. Anticipar consecuencias adversas.

- De común acuerdo con la comunidad, anticipar todas las posibles consecuencias para los niños y adolescentes involucrados. No proceder a menos que se disponga de respuestas adecuadas a consecuencias potencialmente dañinas. 
- Evitar el estigma organizando reuniones de sensibilización comunitaria y emplear la terminología que la misma comunidad usa.

- Si la seguridad de los niños y adolescentes no puede garantizarse, se evitará proceder.

- Los entrevistadores deben poseer experiencia de trabajo con niños. Se les debe capacitar para responder a las necesidades infantiles y se les debe supervisar y apoyar sobre la marcha. Evitar proceder si no se dispone de entrevistadores con las habilidades adecuadas.

- De común acuerdo con la comunidad, determinar el tipo de seguimiento apropiado para responder a las necesidades infantiles reconociendo la edad, el género, el aspecto étnico y demás. Si no puede garantizarse un apoyo adecuado para satisfacer las necesidades de los niños, no se procederá.

- Preparar un plan de reacción para anticipar necesidades importantes. Si no es posible asegurar el apoyo para los niños, se evitará proceder.

- La confidencialidad debería ser quebrantada para suministrar protección inmediata al niño o al adolescente. El personal debe asegurar que los participantes están conscientes de ello antes de solicitar cualquier información.

E. Efectuar procedimientos de consentimiento y entrevista siendo sensibles a las necesidades específicas de los niños.

- Los niños deben dar su acuerdo para participar; pero se requiere del consentimiento de los adultos que correspondan.

- Los entrevistadores deben asegurar que los niños sepan que pueden detenerse o retirarse en cualquier momento.

- Los investigadores deben suministrar a los niños y adolescentes, lo mismo que a sus padres o guardianes, información sobre la actividad de una manera que sea apropiada a su cultura y educación. De forma conjunta con miembros de la comunidad se deben desarrollar formatos de consentimiento y herramientas de información, mismos que deberán ponerse a prueba en el campo.

- Acudir a un abogado independiente para que represente los puntos de vista de los niños en caso de que exista alguna duda sobre la protección que su guardián les ofrece.

- Evitar los esfuerzos por ejercer una influencia indebida sobre la participación mediante el uso de incentivos. Pero si se acude a ellos, en efecto, deberán ir acordes con los estándares de vida locales.

- Los procedimientos para las entrevistas deben reflejar la necesidad de proteger los mejores intereses de los niños y los adolescentes. Consultar con los miembros de la comunidad para determinar las prácticas que sean apropiadas.

F. Confirmar que todos los grupos de interés comprenden los límites de la actividad y los pasos siguientes.

- Utilizar procedimientos apropiados para salvaguardar la seguridad de los participantes.

- Compartir los hallazgos con los miembros de la comunidad en formatos accesibles y apropiados.

\section{Mensajes claves para llevar consigo}

1. Considerar los siguientes temas transversales mientras se preparan los planes y se implementa la actividad de recolección de información: principios éticos básicos; participación de los niños; requisitos legales y profesionales, incluyendo la supervisión ética; cultura y género; y especialmente los niños vulnerables.

2. Equilibrar la necesidad de llevar al máximo la participación de los niños escuchando sus propias opiniones sobre los problemas que afectan sus vidas, con la necesidad de reducir al mínimo su exposición al daño.

3. Una cuidadosa planeación anticipada es crucial. Los investigadores tienen la responsabilidad de anticipar todas las consecuencias posibles de la actividad de recolección de datos -tanto intencionales como no intencionales-, y asimismo de anticipar el efecto de la actividad sobre los jóvenes y sus familias. Si no pueden proporcionarse garantías apropiadas, la actividad no debe proseguir.

4. Conversar con los miembros locales de la comunidad, incluyendo a niños y adolescentes, siempre que tal cosa sea posible. Las reuniones comunitarias durante las diferentes etapas de recolección de los datos pueden servir a diversos propósitos, incluyendo la sensibilización, revisión e interpretación. Estas discusiones pueden, asimismo, servir al doble propósito de mejorar tanto la adherencia a estándares éticos como la calidad de la información reunida.

5. Si surgiera cualquier duda en cuanto a que la recolección de los datos pudiera perjudicar a los niños, iniciar la actividad únicamente si los servicios están en su lugar para abordar consecuencias posibles. Si la actividad de recolección de información no se vincula con un servicio, preparar información de referencias para que los niños accedan al apoyo requerido. No realizar la actividad a menos que los sistemas de apoyo funcional estén operando. 


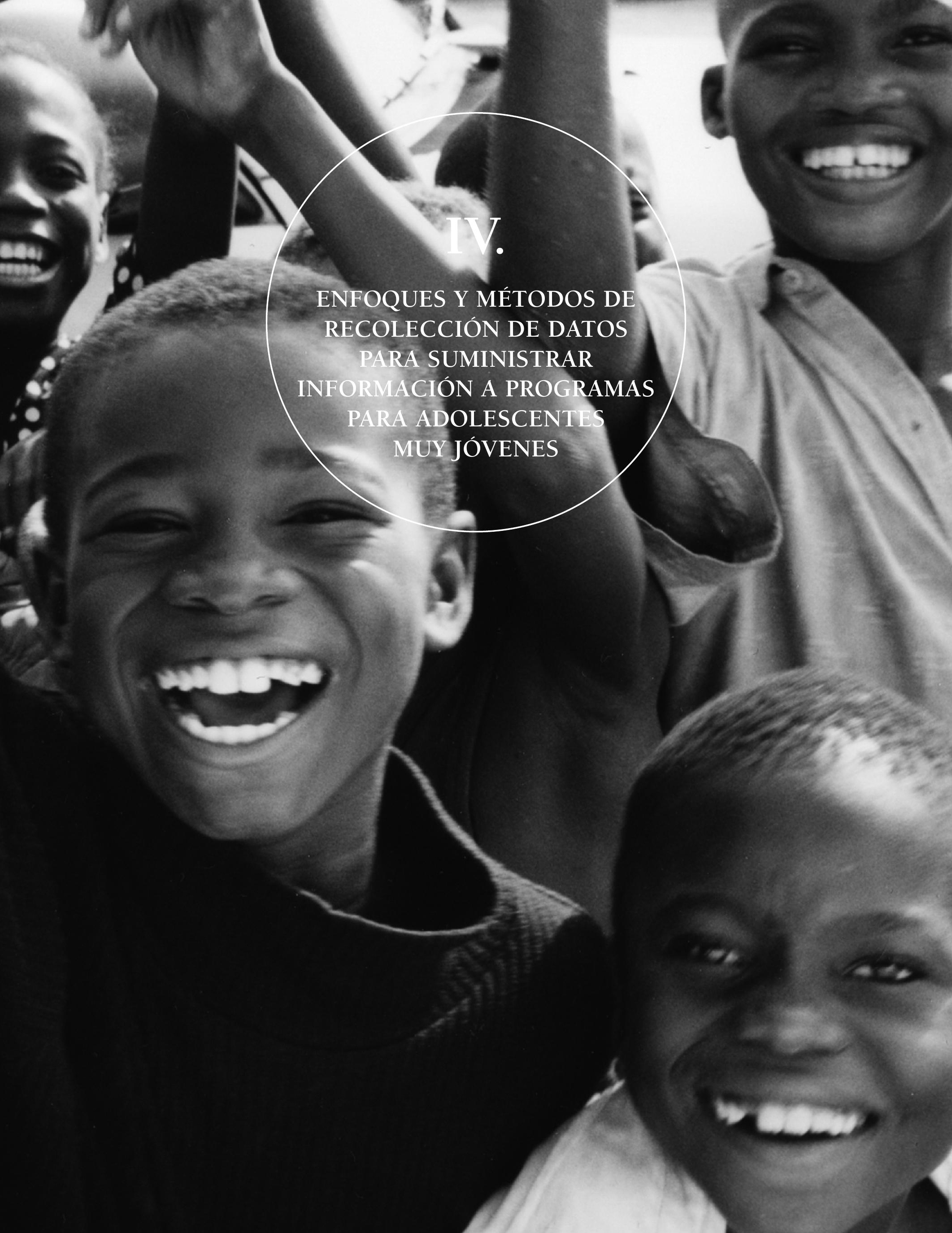




\section{Establecimiento de una agenda de investigación para iniciar 0 mejorar programas para adolescentes muy jóvenes}

Los equipos de país de las Naciones Unidas, en colaboración con socios claves (gobierno, investigadores, instituciones académicas y de políticas, y organizaciones no gubernamentales [ONG]) pueden jugar un papel crítico en la construcción de programas basados en la evidencia y dirigidos a los AMJ. Idealmente, las actividades de recolección de información aclararán la diversidad de las experiencias juveniles, destacarán cuáles subconjuntos de esta población son más vulnerables y cuáles no están siendo alcanzados por los esfuerzos programáticos actuales, y permitirán que las necesidades de estos jóvenes den forma al contenido y diseño de nuevos programas.

Para construir programas eficaces y fundamentados, Bruce (2003) sugiere los cinco pasos siguientes:

(1) Recolectar y analizar datos sobre adolescentes agrupados por edad, género, estado civil, escolaridad, lugar de residencia y otras variables relevantes, a través de análisis situacionales cuidadosos y de otras metodologías de investigación.

(2) Llevar a cabo una revisión/recolección de indicios/planeación de los grupos interesados, a partir de información que sea lo más integral y coherente posible.

(3) Estimar el número de adolescentes que están y no siendo alcanzados por las políticas y programas gubernamentales y no gubernamentales, y determinar sus características.

(4) Revisar la relevancia y alcance de los contenidos programáticos en relación con diversos subgrupos de adolescentes (diferenciados por edad, género, estado civil, escolaridad, lugar de residencia y otras categorías relevantes).
(5) Implementar un proceso de recolección de información que aporte indicios con respecto a las distintas necesidades y aspiraciones de diversos grupos de adolescentes (de nuevo, diferenciados por edad, género, estado civil, escolaridad, lugar de residencia y otras categorías relevantes).

El diseño de una agenda de investigación y de un marco para los resultados se logran mejor a través de la colaboración. Una práctica común es integrar grupos de trabajo que pueden ser útiles para definir vacíos críticos en el conocimiento y para identificar preguntas de investigación factibles y relevantes, intervenciones a ser puestas a prueba y la metodología asociada para la evaluación. Involucrar a grupos de interés (stakeholders) claves, como pueden ser los diseñadores de políticas, gerentes de programas, investigadores, proveedores de servicios, líderes juveniles y miembros influyentes de la comunidad, es útil para construir el apoyo político que incremente la atención hacia las necesidades de los adolescentes más jóvenes.

A nivel local, debe generarse una agenda de investigación específica del contexto, dependiendo de las necesidades percibidas y de los intereses del equipo del país. El tipo de datos a ser recolectados y las metodologías con las que se proseguirá

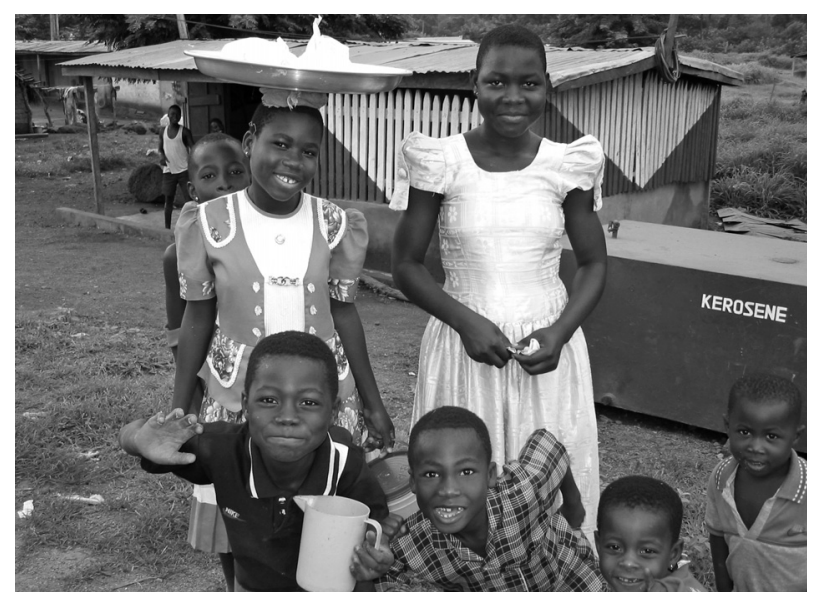

Ghana - Photo: Melissa May/Population Council 
dependerán de las cuestiones específicas que se abordarán. Como en cualquier proceso de investigación, la sensibilidad cultural y la relativa al género son esenciales, tanto en términos del tipo de preguntas de investigación que se planteen como de la manera como la investigación se realice.

La información que los investigadores, diseñadores de políticas y gerentes de programas requieren puede recolectarse de diversas maneras. Los métodos de investigación descritos en esta guía son los que los asistentes a la reunión de consulta discutieron o han usado en su investigación sobre adolescentes muy jóvenes. ${ }^{10}$ De este modo, la presente guía incluye aquellos métodos que se utilizan más comúnmente, aunque no ofrece un catálogo de todos los métodos posibles que pudieran emplearse con AMJ. Cada uno de esos métodos tiene sus propias ventajas, y el lector debería considerar el desarrollo de una estrategia que combine el uso de métodos múltiples, pues tal enfoque puede dar una imagen más precisa y completa que la que un solo método puede producir.

Las distintas metodologías pueden caracterizarse en dos dimensiones. La primera es la dimensión cualitativa/cuantitativa; la segunda es la dimensión vertical/participativa.

\section{La dimensión cuantitativa / cualitativa}

Los métodos cuantitativos como los de las encuestas, los estudios antropométricos y algunos tipos de análisis espaciales, generan información que puede capturarse de forma numérica. Estos métodos producen resúmenes estadísticos tales como las distribuciones de frecuencias, medias, medianas, rangos y otras medidas de variación que describen a una población en términos agregados. Por ello, son particularmente útiles para explicar el alcance de un problema, y dependiendo de la naturaleza de la muestra, la información recolectada puede utilizarse para detallar la

\footnotetext{
${ }^{10}$ Este capítulo es una adaptación de Freudenberger (1999).

${ }^{11}$ Ver Freudenberger (1999) para una guía integral de los métodos.
}

situación de poblaciones similares que, por ejemplo, no fueron informantes de la encuesta.

Los métodos cualitativos, por otro lado, no generan información que pueda generalizarse. Más bien exploran significados, procesos, razones y explicaciones - conceptos que no pueden capturarse fácilmente en una encuesta estructurada, o que son necesarios a fin de formular preguntas para encuestas estructuradas. A menudo los datos se capturan visualmente, en texto o diagramas. Ejemplos de métodos cualitativos serían las discusiones de grupos focales y las entrevistas individuales a profundidad. ${ }^{11}$

A veces, los profesionales de los métodos cualitativos y cuantitativos parecen estar en desacuerdo entre sí. Con todo, los debates de este tipo son contraproducentes, especialmente si uno considera que la carencia de buena información de todas las fuentes respecto de los adolescentes muy jóvenes es un hecho generalizado. De ahí que la clave esté en combinar el tipo de metodología con la clase de información que se requiere. Como se ha señalado anteriormente, en muchos casos el mejor enfoque involucra combinar varios métodos diferentes para obtener el panorama más completo posible de una situación dada. Por ejemplo, una encuesta que utilice técnicas de entrevista individuales suele ser la mejor elección para recolectar información clara de gran número de personas de una manera que permite comparaciones amplias a través de una muestra grande. Otro ejemplo es que en diversas regiones de un país podría realizarse una encuesta para determinar diferencias básicas en la proporción de jóvenes que alguna vez han tenido relaciones sexuales o que utilizaron condón en su última relación. Las encuestas son, en general, herramientas menos eficaces para obtener información sobre temas complejos o sensibles (aunque el desarrollo de métodos como la auto entrevista en audio con ayuda de computadora [AEAAC] puede facilitar la recolección de tales 
datos). Empleando métodos cualitativos, los entrevistadores pueden establecer comunicación con los jóvenes y animarlos a que respondan más francamente. Pueden plantearse preguntas de exploración para averiguar por qué las personas toman ciertas decisiones o se involucran en determinados comportamientos, y emplearse distintas herramientas para comprobar, una vez más, la información sensible. Un proyecto emplearía métodos cualitativos cuando deseara capturar la complejidad de una situación observando algunos casos a una profundidad considerablemente mayor de la que es posible alcanzar con la mayor parte de las encuestas. Más que competir entre sí, estos dos tipos de métodos se complementan.

\section{La dimensión vertical / participativa}

Las metodologías de investigación se pueden clasificar también evaluando el uso o no de un enfoque vertical o participativo. Los métodos verticales son aquéllos en donde los especialistas toman la mayoría de las decisiones esenciales sobre los temas que se abordarán y el modo como la información se empleará, en lugar de que lo hagan los miembros de la comunidad. En general, el papel de la gente local se limita a contestar las preguntas que los forasteros formulan. Los métodos se vuelven más participativos a medida que la gente desempeña papeles más importantes y activos en el proceso de recolección de la información. Contestar un cuestionario es una de las formas de participación más limitadas y pasivas. Una más activa participación puede incluir dibujar mapas o tomar parte en discusiones abiertas Estos dos tipos de interacción permiten a los miembros de la comunidad expresar sus inquietudes directamente, en vez de responder a preguntas de la encuesta. Se alcanza un nivel de participación aún mayor cuando los participantes locales delimitan la agenda para el estudio, determinan las preguntas, reúnen la información y se involucran de manera integral en el análisis y uso de los datos.
Tal y como Freudenberger lo plantea, el uso que un proyecto hace de un enfoque más participativo o de uno más vertical depende de lo que está tratando de lograr. Si el propósito de la investigación es simplemente reunir datos, puede no requerirse más participación local que la que una encuesta contempla. Desde luego, la ruta de la participación puede ser una elección pobre frente a tal situación, pues impone una carga considerable sobre los miembros de la comunidad que están involucrados, en términos de tiempo y esfuerzo. Pero si el objetivo de la investigación es una combinación de recolección de la información y propiciar que la gente local se involucre para promulgar el cambio sobre la base de los hallazgos, entonces el aspecto participativo se vuelve vitalmente importante. A mayor participación comunitaria en la investigación, mayor será su apuesta en el proceso. Y entre mayor sea esa apuesta, mayor la motivación para asumir responsabilidades en la toma de decisiones y el liderazgo.

Una familia de métodos y enfoques participativos que merece mención aparte es el Aprendizaje Participativo y Acción (APA). El APA permite a los miembros de una comunidad analizar, compartir y aumentar su conocimiento; planear y establecer prioridades; actuar y monitorear, y evaluar programas y políticas. Las tres características claves del APA, según las describe Chambers (1997) son: (1) el comportamiento y las actitudes de los forasteros, quienes facilitan en vez de dominar; (2) los métodos, que modifican el equilibrio normal de cerrado a abierto, de individual a grupal, de verbal a visual, y de medir a comparar; y (3) las alianzas y compartir información y experiencias entre miembros de la comunidad y forasteros, y entre organizaciones.

A este tipo de metodología se le conoce también con otros nombres, siendo el más común el de Valoración Participativa Rural (VPR). La metodología de la VPR se desarrolló a fines de la década de los ochenta, para ayudar a la gente local a jugar un papel más activo en el desarrollo de 
proyectos que se ponían en marcha en sus comunidades. El acrónimo APA (PLA en inglés), se emplea más a menudo en la literatura como resultado de su más amplia aplicación en contextos tanto rurales como urbanos, y porque el término indica su uso continuo durante la "acción" o las fases de implementación del ciclo del proyecto. En la VPR se emplea una amplia variedad de métodos verbales y visuales que incluyen el mapeo social, vías transversales, líneas de tiempo, jerarquización y asignación de puntajes, diagramas de Venn, discusiones de grupos focales, estudios de caso, historias y retratos (Shah y cols. 1999).

Las características cualitativas/cuantitativas, tanto como las verticales/participativas se representan mejor como continuos. Es difícil afirmar categóricamente que una metodología dada sea o no participativa o cuantitativa. Lo que hace más sentido pensar de un método es si se aplica de un modo más o menos participativo, o si recolecta una cantidad mayor o menor de información cuantitativa. Aunque los métodos cuantitativos se asocian con enfoques verticales y los métodos cualitativos se asumen como participativos, tal cosa no es, necesariamente, cierta. Podemos comparar, por ejemplo, el caso de un grupo focal en donde el equipo de investigación está integrado en su totalidad por forasteros y donde el informe se va a utilizar con propósitos académicos, con otro que tiene a miembros de la comunidad local en su equipo y contempla compartir información con esa comunidad.

La tabla 3, que resume las ventajas y desventajas de las metodologías a las que nos hemos referido en esta guía, incluye los fundamentos para su uso. Aunque el juego de herramientas es representativo de los métodos de investigación más comunes empleados en la actualidad con adolescentes muy jóvenes, no se pretende que sea una lista exhaustiva de todas las opciones.

Tabla 3 Metodologías de investigación para recolectar información sobre adolescentes muy jóvenes

(El color azul denota métodos que tienden a ser de naturaleza comparativamente cualitativa; el color amarillo denota métodos que tienden a ser más cuantitativos)

\section{\begin{tabular}{l|l|l|l} 
Método & Fundamento para su uso & Fortalezas/ventajas & Debilidades/desventajas
\end{tabular}}

Para obtener información sobre programas dirigidos a los AMJ

\begin{tabular}{l|l|l|l}
$\begin{array}{l}\text { Ejercicio de } \\
\text { cobertura del } \\
\text { programa }\end{array}$ & $\begin{array}{l}\text { Informa a los gerentes de } \\
\text { programa sobre aquéllos a } \\
\text { quienes el programa está } \\
\text { sirviendo }\end{array}$ & $\begin{array}{l}\text { Fácil de usar } \\
\text { Ofrece resultados rápidos } \\
\text { Construye capacidad de } \\
\text { investigación del personal del } \\
\text { programa }\end{array}$ & $\begin{array}{l}\text { No suministra datos sobre aquéllos } \\
\text { a quienes el programa no brinda } \\
\text { servicios }\end{array}$ \\
$\begin{array}{l}\text { Indica características de los } \\
\text { usuarios del programa }\end{array}$ &
\end{tabular}

Para obtener información de y sobre los AMJ

\begin{tabular}{l|l|l|l}
$\begin{array}{l}\text { Discusiones de } \\
\text { grupos focales }\end{array}$ & $\begin{array}{l}\text { Ofrecen información en la } \\
\text { etapa formativa del proyecto } \\
\text { Contribuye al diseño de guías } \\
\text { de preguntas para entrevistas } \\
\text { individuales a profundidad y } \\
\text { estructuradas }\end{array}$ & $\begin{array}{l}\text { Método participativo } \\
\text { implementar }\end{array}$ & $\begin{array}{l}\text { Requiere de facilitadores de grupo } \\
\text { bien capacitados } \\
\text { Se necesita entrenamiento para } \\
\text { analizar los datos; puede ser } \\
\text { necesario invertir tiempo para } \\
\text { realizar dicho análisis }\end{array}$ \\
& & $\begin{array}{l}\text { Falta de información a nivel } \\
\text { individual } \\
\text { Un pequeño número de } \\
\text { participantes puede producir } \\
\text { resultados no representativos }\end{array}$
\end{tabular}




\begin{tabular}{|c|c|c|c|}
\hline Método & Fundamento para su uso & Fortalezas/ventajas & Debilidades/desventajas \\
\hline $\begin{array}{l}\text { Mapeo } \\
\text { comunitario }\end{array}$ & $\begin{array}{l}\text { Útil para saber más, y más } \\
\text { rápidamente, acerca de una } \\
\text { comunidad }\end{array}$ & $\begin{array}{l}\text { Método participativo } \\
\text { No representa una amenaza } \\
\text { Es bueno para romper el hielo } \\
\text { con la comunidad } \\
\text { Los participantes pueden preparar } \\
\text { los mapas con facilidad } \\
\text { Potencial para capturar factores } \\
\text { importantes del contexto local }\end{array}$ & $\begin{array}{l}\text { Requiere de facilitadores de grupo } \\
\text { bien capacitados } \\
\text { Se necesita entrenamiento para analizar } \\
\text { los datos; puede ser necesario invertir } \\
\text { tiempo para realizar dicho análisis } \\
\text { Falta de información a nivel individual } \\
\text { Un pequeño número de participantes } \\
\text { puede producir resultados no } \\
\text { representativos }\end{array}$ \\
\hline $\begin{array}{l}\text { Entrevistas } \\
\text { individuales (semi- } \\
\text { estructuradas) a } \\
\text { profundidad con } \\
\text { informantes clave }\end{array}$ & $\begin{array}{l}\text { Tienen el potencial para llenar } \\
\text { vacíos en el conocimiento sobre } \\
\text { temas cruciales } \\
\text { Ayudan a diseñar guías de preguntas } \\
\text { para entrevistas individuales a } \\
\text { profundidad y estructuradas }\end{array}$ & $\begin{array}{l}\text { Método participativo } \\
\text { Suministra información a nivel } \\
\text { individual }\end{array}$ & $\begin{array}{l}\text { Se necesita entrenamiento para analizar } \\
\text { los datos; puede ser necesario invertir } \\
\text { tiempo para realizar dicho análisis } \\
\text { Un pequeño número de participantes } \\
\text { puede producir resultados no } \\
\text { representativos }\end{array}$ \\
\hline $\begin{array}{l}\text { Metodologías } \\
\text { visuales }\end{array}$ & $\begin{array}{l}\text { Compromete a los adolescentes } \\
\text { muy jóvenes como participantes } \\
\text { activos y agentes del cambio }\end{array}$ & $\begin{array}{l}\text { Método participativo } \\
\text { Creativo } \\
\text { Divertido } \\
\text { Abierto } \\
\text { No representa una amenaza }\end{array}$ & $\begin{array}{l}\text { Falta de orientación sobre mejores } \\
\text { prácticas con AMJ }\end{array}$ \\
\hline Llevar un diario & $\begin{array}{l}\text { Permite a los adolescentes } \\
\text { compartir pensamientos y } \\
\text { opiniones que pudieran no salir } \\
\text { a la superficie en las entrevistas } \\
\text { grupales o individuales }\end{array}$ & $\begin{array}{l}\text { Opera al ritmo de cada individuo } \\
\text { Permite la auto-expresión }\end{array}$ & Requiere población alfabetizada \\
\hline $\begin{array}{l}\text { Encuesta de } \\
\text { hogares: entrevistas } \\
\text { estructuradas } \\
\text { individuales } \\
\text { (método de } \\
\text { entrevista verbal e } \\
\text { individual) }\end{array}$ & $\begin{array}{l}\text { Suministra información sobre } \\
\text { tendencias entre la población } \\
\text { joven }\end{array}$ & $\begin{array}{l}\text { Información a nivel individual } \\
\text { Permite desagregar los datos } \\
\text { por edad, sexo, asistencia a la } \\
\text { escuela, estado civil y situación } \\
\text { socioeconómica }\end{array}$ & $\begin{array}{l}\text { La validez/confiabilidad de las } \\
\text { respuestas de los AMJ sobre temas } \\
\text { sensibles puede ser cuestionable } \\
\text { Falta de orientación sobre mejores } \\
\text { prácticas con AMJ } \\
\text { Costosa } \\
\text { Requiere de inversión de tiempo } \\
\text { Se necesita entrenamiento para } \\
\text { analizar los datos; puede ser } \\
\text { necesario invertir tiempo para } \\
\text { realizar dicho análisis }\end{array}$ \\
\hline $\begin{array}{l}\text { Encuesta de base } \\
\text { escolar: entrevistas } \\
\text { individuales } \\
\text { estructuradas } \\
\text { (método de } \\
\text { entrevista verbal e } \\
\text { individual) }\end{array}$ & $\begin{array}{l}\text { Brinda información sobre } \\
\text { tendencias entre la población } \\
\text { joven que va a la escuela }\end{array}$ & $\begin{array}{l}\text { Ofrece información a nivel } \\
\text { individual } \\
\text { Permite desagregar los datos por } \\
\text { edad, sexo, asistencia a la escuela, } \\
\text { estado civil y situación } \\
\text { socioeconómica } \\
\text { Se encuentra fácilmente a los } \\
\text { informantes } \\
\text { Requiere de una inversión de } \\
\text { tiempo menor y es menos costosa } \\
\text { que una encuesta de hogares }\end{array}$ & $\begin{array}{l}\text { Muestra no representativa (prescinde de } \\
\text { los jóvenes no inscritos en la escuela- } \\
\text { que pueden estar en mayor riesgo) } \\
\text { La validez/confiabilidad de las } \\
\text { respuestas de los AMJ sobre temas } \\
\text { sensibles puede ser cuestionable } \\
\text { Falta de orientación sobre mejores } \\
\text { prácticas con AMJ } \\
\text { Se necesita entrenamiento para analizar } \\
\text { los datos; puede ser necesario invertir } \\
\text { tiempo para realizar dicho análisis }\end{array}$ \\
\hline $\begin{array}{l}\text { Auto entrevistas en } \\
\text { audio con ayuda de } \\
\text { computadora } \\
\text { (AEAAC) }\end{array}$ & $\begin{array}{l}\text { Permite la recolección de } \\
\text { información precisa sobre } \\
\text { comportamientos sensibles }\end{array}$ & $\begin{array}{l}\text { Reduce los sesgos del } \\
\text { entrevistador } \\
\text { Puede reducir los sesgos de } \\
\text { conveniencia social }\end{array}$ & $\begin{array}{l}\text { El software estándar no está disponible } \\
\text { aún (requiere de programación) } \\
\text { Pocos datos disponibles sobre costo } \\
\text { del método } \\
\text { Falta de orientación sobre mejores } \\
\text { prácticas con AMJ }\end{array}$ \\
\hline
\end{tabular}




\section{Ejercicio de cobertura de programa}

Diferenciar según los propósitos a las audiencias actuales de las que se persiguen en los programas para la gente joven ha sido objeto de atención insuficiente, lo mismo que la recolección de datos confiables sobre la participación en, y el derecho a participar en programas patrocinados por el gobierno. Aun los datos de escolaridad que se reportan oficialmente no siempre son exactos, porque las cifras de inscripciones que se señalan con el propósito de recabar beneficios difieren de la asistencia real, a menudo de manera importante. Al informar acerca de, y evaluar los cuatro tipos de programas más populares para jóvenes (centros juveniles, programas de base escolar, servicios amigables para la juventud y educación de pares), rara vez se definen los subgrupos de jóvenes que están más comprometidos en estos programas y los que quedan rezagados. Tampoco se describe la relativa eficacia de cada tipo de programa para los diferentes subgrupos de jóvenes..$^{12}$ Un estudio multinacional sobre centros juveniles en África Subsahariana encontró que dichos programas pueden no ser tan eficaces como en general se cree (ver recuadro).

En los lugares en donde los programas para jóvenes se utilizan ampliamente, persisten las preguntas: ¿Quiénes los usan? ¿Aquéllos a quienes

\section{Populares, pero ¿eficaces? Una revisión de centros juveniles en cuatro países ${ }^{13}$}

Entre 1996 y 2000, el Population Council, en colaboración con asociaciones locales de planificación familiar, hizo una evaluación de 26 centros juveniles en cuatro países de África subsahariana. ${ }^{14}$ Se incluyeron dos de Kenya, tres de Zimbabwe, nueve de Ghana y 12 de Sudáfrica. Entre centro y centro había grandes diferencias. Algunos estaban bien consolidados y equipados; otros eran más modestos con recursos recreativos y de orientación vocacional limitados. Algunos centros habían trabajado durante muchos años, mientras que otros (especialmente en Sudáfrica) eran relativamente nuevos.

El equipo de evaluación reportó diez hallazgos principales:

1. La cobertura, esto es, el número de jóvenes que reciben servicios de un centro, suele ser bajo.

2. A menudo, los centros son estigmatizados por la comunidad y los jóvenes.

3. Los centros juveniles que integran actividades recreativas con servicios de salud reproductiva tienden a ser dominados por muchachos.

4. Las personas que hacen uso de los centros juveniles tienden a ser jóvenes mayores, o incluso adultos.

5. En los centros que integran actividades recreativas con servicios de salud reproductiva, una proporción baja de clientes buscan estos últimos.

6. Por sí solas, las clínicas de salud reproductiva para jóvenes alcanzan a un número relativamente grande de niñas.

7. La provisión de condones debe reforzarse.

8. El personal de los centros juveniles es muy conocedor, pero a menudo crítico.

9. La preservación de la confidencialidad y las actitudes críticas de los proveedores constituyen las principales preocupaciones de los jóvenes que reciben consejería.

10. Los jóvenes que visitan los centros no tienen, necesariamente, más conocimientos que otros acerca de la salud reproductiva, ni tampoco es probable que practiquen la abstinencia más de lo que lo hacen otros.

\footnotetext{
${ }^{12}$ La OPS y la OMS han definido a los adolescentes como aquellos individuos de entre 10 y 19 años de edad, a la juventud como quienes tienen de 15 a 24 años, y a la gente joven como las personas que tienen de 10 a 24 años. Las autoras señalan que en esta sección el término"juventud" se usa más libremente para incluir a quienes tienen de 10 a 24 años, considerando que términos populares como "centros juveniles" y "organizaciones que sirven a la juventud" no se adhieren a las definiciones de la OPS/OMS. Los adolescentes muy jóvenes no están excluidos de los centros juveniles y, desde luego, algunas de las organizaciones que sirven a la juventud los tienen entre su población objetivo.

3 Extraido de Population Council (2003b). Para informes de evaluación, ver Erulkar and Mensch (1997); Phiri y Erulkar (1997); Glover y cols. (1998); y Erulkar y cols. (2001)

${ }^{4}$ Los centros juveniles que formaron parte de este estudio fueron diseñados para servir a jóvenes de entre 10 y 24 años
} 
sirven son, de hecho, jóvenes? Si tal es el caso, ise trata de los jóvenes más necesitados? ¿A cuáles subgrupos de adolescentes no están sirviendo estos programas? Aun las preguntas superficiales pueden revelar que se está dando una excesiva atención programática a las necesidades de un grupo específico (los niños mayores, por ejemplo) mientras otros grupos importantes de adolescentes se descuidan (sería el caso de las niñas más jóvenes). Los programas pueden fracasar en alcanzar a ciertos grupos de adolescentes porque operan basados en supuestos incorrectos respecto de dónde encontrarlos y, a partir de ahí, a dónde deben dirigir sus esfuerzos para llegar a ellos. La creencia de que a los adolescentes se les encuentra en las escuelas y/o viviendo con uno o ambos padres está ampliamente difundida; pero este

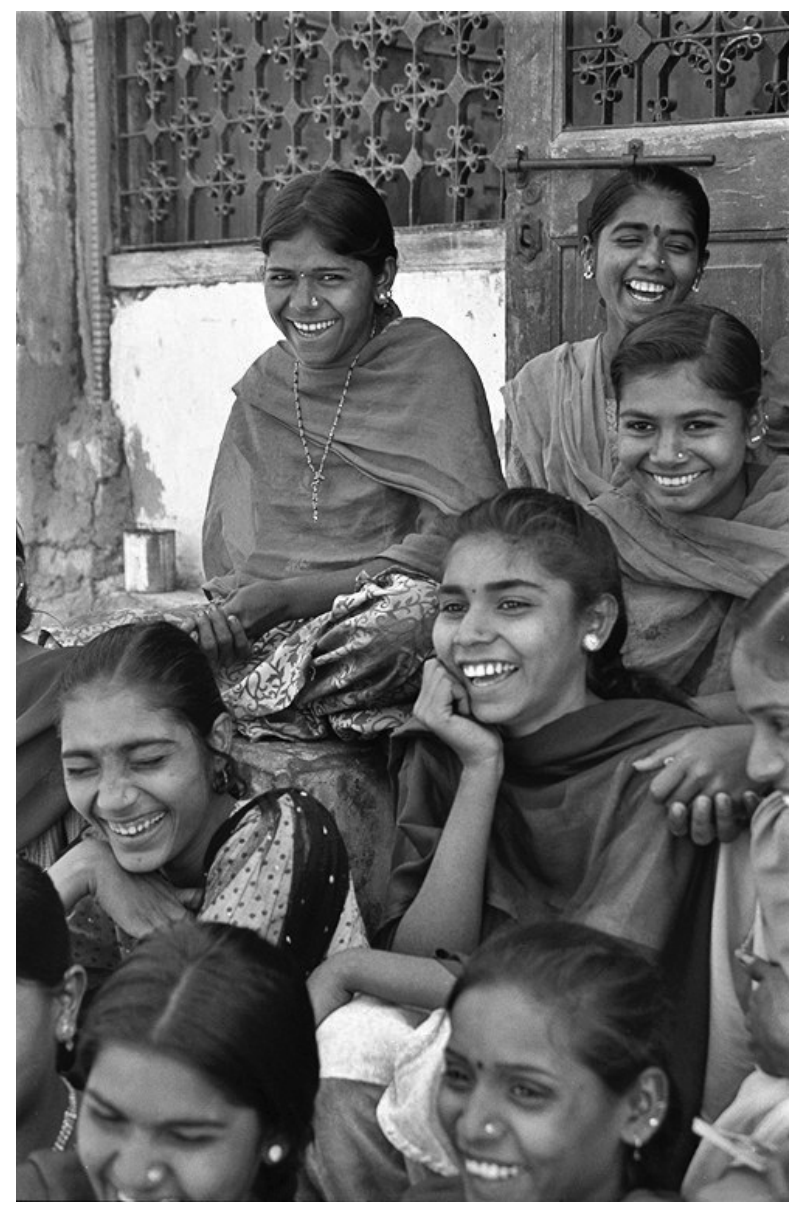

India - Foto: Population Council supuesto suele ser inexacto. Como resultado del matrimonio, de la migración en busca de trabajo o del colapso de las familias, muchos jóvenes no viven en los hogares en donde nacieron, o han abandonado la escuela antes del fin de sus años de adolescencia. Desarrollar estrategias para identificar y llegar a esta población de jóvenes internamente diversa debe ser una prioridad.

Los programas de base escolar son populares; con todo, suelen lanzarse sin que exista un análisis sobre quién va, de hecho, a la escuela -sin mencionar la eficacia de los programas en escuelas de calidad variable, en donde los maestros se enfrentan a menudo con sobrecargas de trabajo que intentan resolver para brindar contenidos que a veces resultan controversiales. Una mayoría de jóvenes de 10 a 14 años —niñas particularmentepueden no estar yendo a la escuela. Análisis de datos de la EDS hechos por el Population Council revelaron que sólo 21 por ciento de las niñas mayores de 10 a 14 años en Burkina Faso, 22 por ciento de las de Níger, 36 por ciento de las etíopes y 41 por ciento de las que viven en Rwanda estaban inscritas en la escuela. Surgirá más información útil de este tipo a medida que quienes planean programas y diseñan políticas evalúan a los adolescentes que están o no siendo alcanzados por los programas existentes.

El Apéndice A de esta guía describe los pasos que abarca la realización de un ejercicio de cobertura. La hoja de trabajo que aparece en ese apéndice es un ejemplo de una herramienta diseñada para capturar, en el transcurso de varias semanas, las características de los individuos a quienes un programa sirve. Idealmente, esta información la deberían recolectar observadores alertas o personal del programa registrando la información sobre cada persona que accede a los servicios o a la información programática. Puede ser revelador comparar estos resultados con los datos que se obtengan de directores de programas, relativos 


\section{Un ejemplo del campo: resultados de un ejercicio de cobertura de programa con organizaciones etíopes que ofrecen servicios a jóvenes}

Para ilustrar el alcance de los esfuerzos que se realizan en la actualidad, en Etiopía se realizó un ejercicio con 15 organizaciones que ofrecen servicios a jóvenes, muchas de las cuales estaban coordinadas por un grupo paraguas administrado por PACT Etiopía y la German Foundation for Population (Fundación Alemana para la Población) (Mekbib y cols. 2005). El grupo que las organizaciones participantes tenían en la mira eran jóvenes de 10 a 24 años, aunque algunas tenían como meta subgrupos específicos como y los trabajadores del sexo comercial y adolescentes seropositivos. Las organizaciones empleaban a educadores pares formando clubes del VIH y montando campañas de información sobre salud reproductiva. De manera conjunta se desarrolló una matriz de registro sencilla para que los educadores pares la usaran al realizar sus actividades cotidianas, lo que les permitía recolectar información sobre edad, escolaridad, trabajo y estado civil de sus contactos, lo mismo que sobre sus modos de vida y el contenido de la información suministrada durante la sesión.

Al estudiar los contactos de esas organizaciones durante un lapso de seis semanas se encontró que:

- Los programas llegaban más a varones que a mujeres; casi 60 por ciento de quienes se beneficiaban de los servicios eran niños u hombres.

- En los programas predominaban los niños mayores y los hombres; 45 por ciento de los contactos eran niños de 15 años de edad y mayores, y uno de cada cinco eran hombres de 20 años o más. Catorce por ciento de los contactos sobrepasaban el límite superior de edad de 24 años; tres organizaciones informaron que 30 por ciento de los contactos estaban fuera del rango de edad que buscaban.

- Un número desproporcionado de los adolescentes alcanzados asistían a la escuela (90 por ciento de los contactos de 10 a 19 años), cuando la realidad es que la vasta mayoría de los adolescentes etíopes no van a la escuela.

- Aunque 68 por ciento de los contactos recibió información sobre el VIH/sida, sólo 19 por ciento recibió información sobre condones.

- Únicamente 3 por ciento de los contactos femeninos había contraído matrimonio, a pesar de que la mayoría de las niñas etíopes se casa durante la adolescencia, y de que casi toda la actividad sexual de las niñas durante esa etapa (94 por ciento) ocurre en el contexto del matrimonio.

- Veintidós por ciento de los beneficiarios del programa tenían entre 10 y 14 años.

- Menos de la mitad del porcentaje de todos los contactos se había hecho con niñas de 10 a 14 años que vivían separadas de sus padres, aunque en Addis Ababa (en donde están concentrados casi todos los programas) 37 por ciento de las niñas en este rango de edad vive separada de ambos padres.

- Ochenta y cinco por ciento de las adolescentes etíopes vive en áreas rurales; todos los programas estaban operando en zonas urbanas exclusivamente.

tanto a los individuos que buscan servir y a quienes creen que, de hecho, están sirviendo. Sin querer, numerosos programas para jóvenes están dedicando recursos importantes para servir a varones mayores que pudieran llegar a predominar en dichos programas. Y aunque estos varones jóvenes tienen necesidades, indiscutiblemente, es probable que no sean tan vulnerables y no estén tan necesitados como otros adolescentes (señaladamente, las muchachas jóvenes). Pero, además, su presencia puede hacer que las niñas jóvenes se desanimen de participar en los programas.
Considerando que en la actualidad se sabe poco sobre los usuarios de los programas para jóvenes, estos enfoques, si bien rudimentarios, pueden suministrar valiosos indicios. La determinación más aproximada es probable que revele una falta de atención a grandes grupos vulnerables, como las jóvenes casadas, los adolescentes que no van a la escuela, quienes se emplean en el servicio doméstico y los que viven en ambientes inestables e inseguros, incluyendo a los refugiados jóvenes (ver recuadro a continuación). 


\section{Métodos cualitativos}

\section{Discusiones de grupos focales ${ }^{15}$}

Las discusiones de grupos focales son útiles para obtener información cuando un proyecto se inicia; a través de ellos es posible conocer creencias, ideas y opiniones comunitarias. Además, son una herramienta valiosa para diseñar guías de preguntas para entrevistas individuales a profundidad y preguntas para entrevistas estructuradas. Son también particularmente útiles para las organizaciones que tienen planes de generar ideas para programas, campañas o materiales; que quieren poner a prueba con antelación conceptos educacionales o promocionales, mensajes y materiales; que buscan mejorar un producto o servicio aclarando las actitudes y necesidades de los jóvenes; y para identificar tópicos para la investigación cuantitativa o para aclarar o elaborar a partir de hallazgos cuantitativos.

Un grupo focal es una discusión grupal organizada en la que se involucran entre seis y diez participantes, convocados para recabar información sobre un asunto en particular. Un moderador capacitado guía al grupo a través de una discusión sobre el tema específico. Una persona entrenada para ello toma nota y registra los detalles de la discusión. Las discusiones grupales suelen grabarse para luego transcribirse y analizarse. La discusión dura, generalmente, entre una y dos horas; a ella debe seguir inmediatamente después un recuento en el que todos los asistentes participan. Otro recuento completo debe tener lugar más tarde con el equipo. Esta sesión puede durar hasta dos horas. Entonces, una discusión de grupo focal requiera un mínimo de dos horas y un máximo de cuatro. Un estudio de grupo focal promedio incluirá de seis a ocho discusiones de grupos focales, de modo que para llevar a cabo todas las discusiones serán necesarios de dos a cuatro días. El análisis y la preparación de un informe del estudio de seis a ocho grupos focales requiere de una a dos semanas, dependiendo del entrenamiento y pericia del equipo de investigación.

Existen numerosos libros y manuales que dan cuenta de este método. Muchos de ellos tratan de cómo llevar a cabo discusiones de grupos focales para la investigación de mercados. En la década de los cincuenta, el método se volvió popular como medio para identificar las opiniones y sentimientos de las personas respecto de ciertos productos en el mercado. Hoy en día, en el contexto de los países en desarrollo, se utiliza ampliamente como medio para formarse una idea sobre temas de salud y desarrollo social y económico. El Apéndice B de la presente guía contiene una lista de recursos de información para conducir discusiones de grupos focales.

Para que el método funcione adecuadamente se debe dar atención cuidadosa a la composición del grupo y a la capacitación de los moderadores. Particularmente entre los adolescentes y con grupos de sexos mezclados, los roles de género suelen exagerarse; los muchachos pueden llegar a comportarse como fanfarrones y denigrar a las niñas silenciando sus voces. Los grupos de un solo sexo pueden mitigar este problema; pero pierden el beneficio del aprendizaje de los miembros del sexo opuesto cuando se escuchan sus puntos de vista. Un estudio realizado en Zambia bajo el patrocinio de UNICEF desarrolló un enfoque innovador en donde las entrevistas grupales se organizaron en dos etapas. En la primera, se hicieron entrevistas grupales con jóvenes del mismo sexo sobre problemas que ellos mismos y las personas del sexo opuesto experimentaron (ver Pattman y Chege 2003). La confianza y apoyo que las niñas adquirieron en la primera etapa les permitió mantener la ecuanimidad durante la segunda, en la cual niñas y niños se reunieron para presentar y discutir sus hallazgos. De hecho, las niñas retaron 
a los niños para volverse más reflexivos y críticos, incrementando la conciencia de los muchachos respecto de los problemas que genera percibirlos como duros y "fuertes" (se esperaba de ellos, por ejemplo, que pelearan, fumaran y bebieran y que ocultaran sus emociones).

Los moderadores diestros son críticos para negociar estas dinámicas de género, propiciar la participación de todos los miembros del grupo focal y crear un espacio seguro y no crítico para que los jóvenes compartan sus opiniones y experiencias. Para las niñas puede ser particularmente inquietante presentarse en grupos focales como "buenas", lo que quiere decir no tener novio, ni haber vivido experiencias sexuales o salir a los bares. Pattman (2005) aboga por un enfoque focalizado sobre la persona joven, en donde los entrevistadores traten a los participantes como sujetos activos escuchando de ellos cómo son las vidas de varones y niñas. Este enfoque implica invertir las habituales relaciones de poder entre adultos y niños, de modo tal que se fomente que los jóvenes establezcan la agenda y aborden temas que ellos mismos consideren significativos.

\section{Mapeo de la comunidad ${ }^{16}$}

En The History of Cartography (La historia de la cartografía) (1987:xvi) Harley y Woordward definen los mapas como "representaciones gráficas que facilitan una comprensión espacial de cosas, conceptos, condiciones, procesos o eventos en el mundo humano". La elaboración de mapas es una forma de comunicación que permite a las personas identificar aquellos aspectos de su sociedad y del ambiente que consideran importantes, y representar los elementos espaciales a otras personas.

Un mapeo de la comunidad es una representación visual del área local creada por participantes locales del programa y es, por lo tanto, intrínsecamente participativa. Esta clase de mapeo busca empoderar a los miembros de la comunidad involucrándolos en la recolección, manejo y aporte de datos para producir los mapas, y en la toma de decisiones respecto del uso y representación de los datos. Posteriormente, los mapas se emplean como vehículos para la discusión, el intercambio de información, el análisis y para apoyar la toma de decisiones y la abogacía.

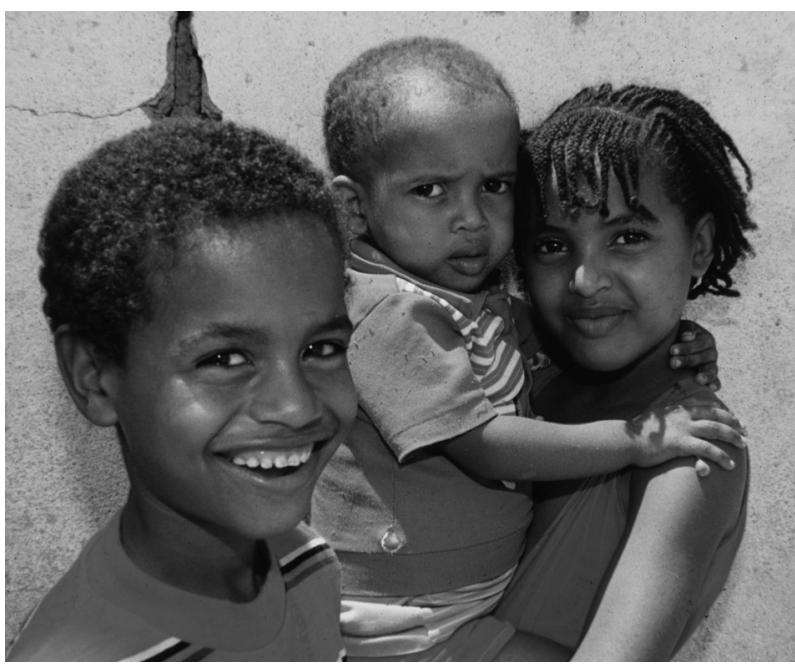

Eritrea / Foto: M.Grant

El mapeo de la comunidad es un mecanismo eficaz para reunir rápidamente información abundante, y es apto para emplearse con jóvenes. En virtud de que el método es participativo, para los jóvenes es divertido y atractivo, valora su conocimiento y genera entusiasmo. Puede funcionar muy bien para romper el hielo, por lo cual se le introduce a menudo en las primeras etapas de un proyecto. La naturaleza visual de los mapas se presta también para transmitir información a los jóvenes, especialmente a quienes pudieran ser analfabetas o semianalfabetas.

El mapeo de la comunidad puede suministrar distintos tipos de información que son importantes para comprender la naturaleza de una comunidad; puede mostrar lugares seguros e inseguros para distintos tipos de personas; las fronteras físicas y sociales de la comunidad; la infraestructura física 


\section{Un ejemplo del campo: diagramas de Venn de espacios públicos en Burkina Faso}

En dos poblaciones rurales en Burkina Faso, el Population Council realizó un ejercicio de mapeo con tres grupos de adolescentes de 10 a 19 años: niñas casadas, niñas solteras y niños solteros (Population Council 2003c). Los participantes identificaron sitios aceptables para reunirse. Hablaron sobre el tipo de actividades que en la actualidad están disponibles para ellos en cada lugar, propusieron servicios adicionales que podrían introducirse y consideraron en qué sitios ubicar actividades a futuro para que estuvieran accesibles para la mayoría de los adolescentes locales. Se crearon diagramas de Venn para representar sus hallazgos; los participantes diseñaron los símbolos y dibujos utilizados para representar los espacios en el mapa y simbolizaron los límites del poblado con un trazo oval (Figura 3).

\section{Hallazgos de los ejercicios de mapeo}

- Las organizaciones y colectivos que existen en las comunidades que fueron objeto de la encuesta sirven a los varones principalmente. Las pocas organizaciones de mujeres que existen sirven exclusivamente a mujeres adultas.

- En general, las niñas que colaboraron en el ejercicio de mapeo identificaron como sitios seguros los lugares de trabajo y las instituciones religiosas, mientras que los muchachos identificaron una variedad más amplia de lugares y eventos, reflejando su mayor movilidad y participación en la vida comunitaria.

- Las niñas adolescentes casadas disponen de mucho menos tiempo libre para acceder a los servicios o participar en capacitaciones en salud reproductiva. Es posible llegar a ellas en sus hogares o cuando visitan el centro de salud para consultas prenatales y de vacunación.

- Las unidades administrativas gubernamentales que existen en los poblados concentran su trabajo en actividades vinculadas con la agricultura y la ganadería, incluyendo capacitación. Los servicios sanitarios se limitan a los centros de salud y las farmacias, que frecuentan mujeres casadas principalmente, para cuidados prenatales y vacunas.

- En razón de que el foco de atención de la comunidad es la producción agrícola, es difícil que los adolescentes se ocupen en actividades de capacitación durante el otoño, a menos que se relacionen con la agricultura; eso incluye las actividades de salud reproductiva.

- Los espacios para la recreación se consideran esenciales para el desarrollo de los niños; les ayudan a volverse individuos desarrollados integralmente, equilibrados y felices; sin embargo, estos espacios se consideran peligrosos e inapropiados para las niñas adolescentes, solteras o casadas.

- Las niñas necesitan espacios privados y accesibles en donde su privacidad y anonimato se protejan y respeten. Según lo expresaron los adolescentes entrevistados, la información general puede difundirse en las celebraciones locales y los festivales. Todos los residentes de los poblados acuden en tales oportunidades; sin embargo, esos espacios son poco propicios para que las personas hablen ahí de sus problemas específicos. Por lo tanto, las niñas requieren también de más espacios privados en algún otro punto de reunión.

- A las niñas casadas se les puede ofrecer información sobre salud reproductiva en los centros de salud (podrían diseñarse promociones para propiciar que las niñas acudan) o en los centros religiosos. Para hacer uso de estos últimos centros se requeriría del permiso y apoyo de los líderes religiosos.

(como pueden ser los caminos, los puntos de abasto de agua, escuelas y clínicas); la infraestructura social (salones públicos, patios de juego, sitios para el culto y otros espacios públicos); la infraestructura económica (lugares de empleo formal e informal, establecimientos de venta al por menor, fuentes formales e informales de ahorro y crédito); y, si se prosigue en detalle, patrones de vivienda y el relativo bienestar de algunos barrios o aun de hogares específicos.

Normalmente, la metodología del mapeo supone llevar a cabo discusiones de grupos focales con grupos particulares de miembros locales de la comunidad, cuyo conocimiento y perspectivas sobre un tema se buscan. Las preguntas planteadas por un capacitador entrenado logran extraer información que se discute colectivamente y se exhibe gráficamente. Al interior de cada ejercicio grupal se puede emplear el mapa completo para explorar en mayor profundidad aspectos específicos de un tema dado. Los mapas mencionados son un buen punto de partida para conocer problemáticas locales que pueden abordarse específicamente a través de otras metodologías (ver el Apéndice C). 
Figura 3 Mapeo de la comunidad hecho por niñas casadas y solteras de 10 a 19 años, y niños solteros de 10 a 19 años, Natiaboani y Koaré, Burkina Faso

¿A dónde pueden ir los niños adolescentes solteros? Azul: A dónde van

Blanco: A dónde no van

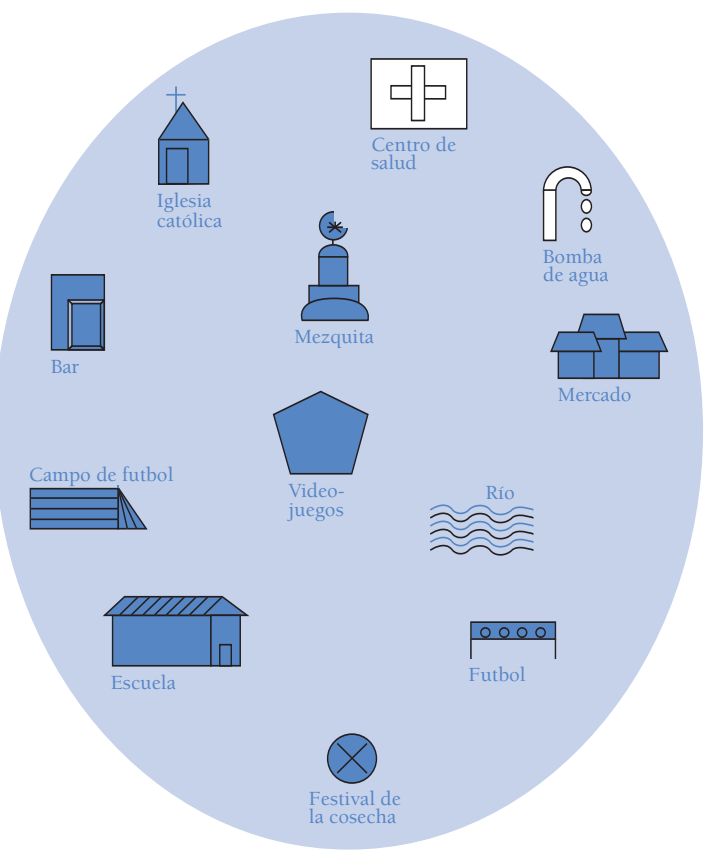

¿A dónde pueden ir las niñas adolescentes solteras? Verde: A dónde van Blanco: A dónde no van

¿A dónde pueden ir las niñas adolescentes casadas?

Azul: A dónde van

Blanco: A dónde no van

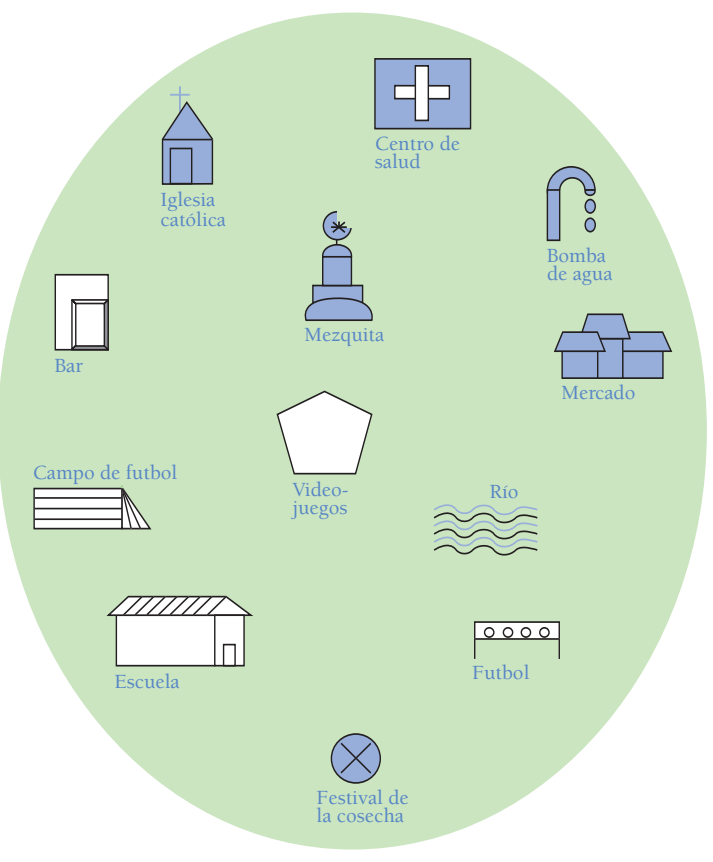




\section{Entrevistas individuales a profundidad y semi-} estructuradas con informantes clave $^{17}$

Las entrevistas individuales a profundidad y semiestructuradas se han definido como: "una conversación guiada en la cual sólo los temas se predeterminan y nuevas preguntas o indicios surgen como resultado de la discusión" (Shah y cols. 1999: 3.68). Este método se propone para complementar los hallazgos de métodos de base grupal, como las discusiones de grupos focales o el mapeo de la comunidad. Las entrevistas semiestructuradas son útiles para discutir temas sensibles, como pueden ser las actitudes y comportamientos sexuales. Es posible que los

\section{Componentes esenciales de las entrevistas semiestructuradas:}

1. Preparación: se debe preparar una guía para la entrevista y una lista de cotejo de temas a ser discutidos.

2. Contexto de la entrevista: el entrevistador debe estar consciente de la importancia del momento para la entrevista, la duración, el entorno y su lenguaje corporal y sesgos, que pueden influir para que el informante se sienta cómodo.

3. Entrevista sensible: el entrevistador debe escuchar cuidadosamente y mantener una actitud abierta.

4. Interrogatorio sensible: el entrevistador debe plantear preguntas abiertas y no dirigidas sondeando las respuestas cuidadosamente.

5. Evaluación, comprobación y verificación de respuestas.

6. Grabación de la entrevista: se deberán tomar notas y, si se considera apropiado, la entrevista debería grabarse en cinta

7. Revisión auto-crítica: el entrevistador debe llevar a cabo una revisión crítica para evaluar la eficacia de las preguntas y definir si su comportamiento influyó de alguna manera sobre la entrevista. adolescentes muy jóvenes se sientan más cómodos revelando información en una entrevista individual que haciéndolo en una de grupo. Un formato semi-estructurado permite que el entrevistador disponga de tiempo para construir un puente de comunicación con el adolescente. La selección de informantes clave dependerá de la naturaleza de la pregunta de investigación; por ejemplo, para conocer los niveles de conocimientos sobre salud reproductiva de niños que acuden a la escuela, un investigador puede entrevistar a una niña que es popular ahí y cuya opinión influye sobre las de sus compañeros. Para comprender mejor las presiones impuestas a niños huérfanos y otros pequeños vulnerables, un investigador puede elegir entrevistar a un niño que es jefe de familia y proveedor de sus hermanos.

Algunos de los temas que se han explorado con éxito utilizando entrevistas semi-estructuradas con adolescentes muy jóvenes abarcan:

- Comportamiento sexual: las preguntas pueden referirse a la edad a la que él/ella tuvo su primera relación sexual; con quién la tuvo; las razones para que ello ocurriera; la frecuencia de la actividad sexual y el número de compañeras/os; la razón por la que se cambió al compañero o compañera; si reciben o dan regalos o pagos a cambio de sexo; si utilizan anticonceptivos; quién de los miembros de la pareja decide el uso de anticonceptivos.

- Fuentes de información acerca del sexo: las preguntas pueden referirse a los sitios en donde se obtiene información sobre la reproducción y las infecciones de transmisión sexual (ITS), y dónde y de quién se busca ayuda relacionada con la salud reproductiva.

- Actitudes hacia el sexo: las preguntas pueden abarcar el punto de vista del adolescente sobre 
sus pares que tienen o no relaciones sexuales, las actitudes normativas en cuanto a la edad ideal para iniciar la experiencia sexual y para casarse, y la relativa seguridad percibida de las distintas prácticas sexuales.

El interrogatorio sensible es crucial para las entrevistas semiestructuradas (como lo es para toda la buena investigación participativa). Un entrevista carente de un interrogatorio sensible arrojará información pobre y comprensión limitada, sin importar qué otros métodos se usen o se apliquen. Es difícil desarrollar habilidades eficaces para las entrevistas porque ello depende de la conciencia auto-crítica, de una escucha perceptiva y de la observación cuidadosa. Y se requiere de tiempo y esfuerzo para adquirir estas cualidades. (El Apéndice D ofrece orientaciones para realizar entrevistas individuales a profundidad y semiestructuradas con informantes clave).

\section{Técnicas de foto voz $z^{18}$}

Las técnicas de foto voz pertenecen a un amplio conjunto de metodologías visuales, tales como el dibujo, el collage, el performance y los videos documentales, que se emplean para una mejor comprensión del modo como los miembros de una comunidad visualizan las presiones y retos que enfrentan en sus vidas. El concepto de foto voz fue desarrollado por Wang y Buris (ver Wang y Redwood-Jones 2001), y se basa en tres comprensiones teóricas principales: el enfoque de Paulo Freire sobre educación crítica, que sostiene que todo ser humano es capaz de pensar críticamente respecto de su propia realidad personal y social; la teoría feminista, que reconoce la dominación que los hombres ejercen sobre las mujeres y busca incorporar a la arena pública nuevas ideas y voces; y un enfoque de base comunitaria de la fotografía, que considera de qué manera la cámara puede emplearse como herramienta para el cambio social.

Las metas principales de los métodos de foto voz son: permitir que las personas registren y reflejen las fortalezas y problemas de su comunidad, promover el diálogo sobre temas importantes a través de la discusión grupal y las fotografías, e

Quienes participan en actividades de foto-voz suelen analizar las fotos que han tomado en un proceso de tres pasos:

1. Selección: eligen aquellas fotografías que reflejan con mayor precisión las inquietudes y valores de la comunidad.

2. Contextualización: narran historias acerca de lo que las fotografías significan.

3. Codificación: identifican los asuntos, temas o teorías que emergen.

Las cuestiones claves a considerar son:

- ¿Qué ves aquí?

- ¿Qué está sucediendo realmente?

- ¿Cómo se relaciona esto con nuestras vidas?

- ¿Por qué existe este problema o fortaleza?

- ¿Qué podemos hacer al respecto?

involucrar a los diseñadores de políticas. Al permitir que los miembros de la comunidad diseñen la agenda, el método de foto voz evita la posible desconexión entre lo que los funcionarios gubernamentales e investigadores creen que es importante y lo que la comunidad considera importante. Las técnicas de foto voz son sumamente adaptables y pueden ajustarse a metas de participación específicas (tales como la evaluación de necesidades, el mapeo de valores y

\footnotetext{
${ }^{18}$ Para mayor información sobre metodologías visuales, visite http://photovoice.com y también el sitio del proyecto "Metodologías visuales internacionales para el cambio social": http://www.ivmproject.ca.
} 


\section{Un ejemplo del campo: "Sentirse seguro y no tan seguro" en Swazilandia}

En un proyecto realizado en Mbabane, Swazilandia, se solicitó a 30 estudiantes del séptimo año tomar fotografías en sus escuelas expresando la idea de "sentirse seguro y no tan seguro". Divididos en grupos pequeños del mismo sexo, se les dieron 45 minutos para tomar fotos en los terrenos de la escuela. Para representar el sentirse seguro, un grupo tomó la fotografía de una niña sentada en un escritorio frente a una pizarra en donde se veía escrita la frase "ahora segura", indicando que la escuela se consideraba un refugio seguro. Las fotografías que aludían a sentirse vulnerables incluían imágenes de escenas que representaban una violación en los arbustos, áreas con agua contaminada y fotos numerosas de los baños. Las niñas consideraron que los cubículos de los sanitarios eran inseguros porque ahí podían ser violadas dado que no existe privacidad (los sanitarios carecen de puertas, son peligrosos y están sucios). Los maestros e investigadores se sorprendieron de que tantos estudiantes consideraran los cubículos de los sanitarios como espacios inseguros, y este hallazgo llevó a que la Unidad de Protección Infantil de UNICEF re-examinara las políticas alusivas a la seguridad en los entornos escolares.

la evaluación), a grupos y comunidades específicas, y a temas diversos de políticas y salud pública.

Las técnicas de foto voz se han empleado exitosamente con adolescentes más jóvenes y mayores. Componer activamente y tomar fotos (en vez de ser los sujetos de ellas, lo que por otra parte están acostumbrados a ser), favorece en los jóvenes el sentido de acción y desarrollo de sus voces durante una etapa en la cual sus opiniones rara vez son buscadas o consideradas. El aspecto creativo de la técnica de foto-voz es particularmente divertido y atractivo para los adolescentes jóvenes y los absorbe como no lograrían hacerlo las técnicas de investigación usadas con más frecuencia y las intervenciones sobre el VIH/sida. En Sudáfrica y Swazilandia, Mitchell y sus colegas (2005) realizaron proyectos de foto-voz en los que involucraron a adolescentes muy jóvenes, de 12 a 13 años, como parte de un proyecto mayor, "Juventud, género y sexualidad", cuyo foco de atención son las metodologías visuales y el cambio social (Mitchell y cols. 2005). Como parte de un estudio relacionado con abuso sexual en y alrededor de las escuelas, un proyecto realizado en Mbabane, Swazilandia, pidió a estudiantes del séptimo año fotografiar imágenes que iluminaran el concepto de "sentirse seguro" y "sentirse no tan seguro" (ver el recuadro siguiente para mayores detalles). En otro proyecto realizado en Durban, que estudiaba la participación de jóvenes y el VIH/sida, se pidió a estudiantes del séptimo grado tomar fotografías de "sentirse fuerte" y "sentirse no tan fuerte". El tercer proyecto, que se efectuó en KwaZulu-Natal, buscaba comprender y documentar las razones de la ausencia de numerosos estudiantes los días viernes. Los estudiantes del sexto año encontraron a sus compañeros ausentes en el mercado tratando de conseguir algún dinero para cubrir sus necesidades y tomaron fotografías de sus condiciones de trabajo.

Mitchell advierte que el proceso creativo y el contenido de entretenimiento que los métodos de

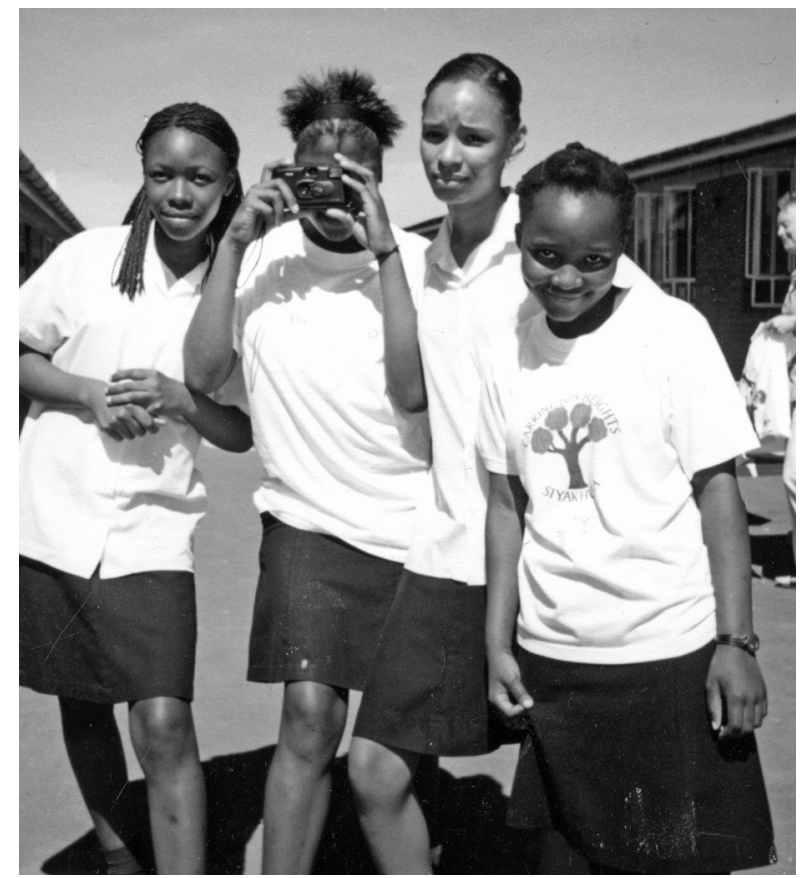

Sudáfrica - Foto: Claudia Mitchell 
foto-voz ofrecen pueden tener un impacto sobre la evidencia, evaluación y sostenibilidad de las intervenciones relativas al VIH/SIDA dirigidas a los jóvenes; pero que tales impactos son difíciles de medir e interpretar. Es importante conceptualizar la técnica de foto-voz no como una actividad o producto de "una única vez", sino más bien como un medio para desarrollar habilidades de reflexión crítica y un estímulo para la acción. Se requiere de más investigación a fin de evaluar el impacto de los proyectos de foto-voz en el transcurso del tiempo, para ver si los adolescentes muy jóvenes que se ocuparon en tales proyectos se involucraron en otro tipo de tomas de acción una vez que la actividad inicial de foto-voz ha concluido. En lugares de escasos recursos, el costo de los materiales y del revelado de las fotos puede ser prohibitivo para permitir que el enfoque de fotovoz se adopte en el más largo plazo.

El uso de las técnicas de foto voz requiere de un examen cuidadoso de los aspectos éticos a fin de reducir al mínimo los riesgos de los participantes y la pérdida de privacidad de los jóvenes fotógrafos y sus comunidades. Antes de distribuir las cámaras, el grupo debería hablar sobre ellas y las relaciones de poder, comentar sobre los riesgos potenciales para los fotógrafos y cómo reducirlos al mínimo, y discutir la práctica de dar a los miembros de la comunidad imágenes impresas para expresar su aprecio y respeto. Las preguntas específicas para plantear a los fotógrafos incluyen:

- ¿qué modo es aceptable para acercarse a alguien con el propósito de tomarle una fotografía?

- ise deben fotografiar a otras personas sin que tengan conocimiento de ello?

- ¿qué tipo de responsabilidades confiere traer consigo una cámara?

- ¿hay algo que no te gustaría que te fotografiaran haciendo?

- ¿a quién desearías darle fotografías y cuáles serían las implicaciones de un obsequio tal?
Antes de comenzar a tomar instantáneas se deben resolver otros asuntos, tales como la posesión de las fotografías, la confidencialidad y situaciones en las cuales la publicación o exhibición de fotografías es aceptable. (El Apéndice E ofrece orientaciones adicionales en relación con los proyectos de fotovoz que involucran a adolescentes muy jóvenes).

\section{Llevar un diario}

Llevar un diario es un método que puede permitir recolectar datos ricos de adolescentes alfabetizados. Se acostumbra pedir a los participantes que escriban en sus diarios al fin de cada día durante un cierto periodo y que respondan a preguntas específicas. Las preguntas son abiertas y se refieren a eventos significativos, emociones y relaciones. Se busca que quienes lleven diarios elaboren y suministren detalles ilustrativos. El mantenimiento de un diario puede generar material que no se obtiene mediante entrevistas grupales o individuales.

Un estudio hecho en Sudáfrica que acudió al uso de diarios y a discusiones de grupos focales encontró que las niñas que en entrevistas grupales tenían la tendencia a criticar a otras niñas que tenían novios, en sus diarios admitieron que ellas mismas tenían novio y disfrutaban ser atractivas para los niños (Pattman 2005). Mientras que en entrevistas grupales los niños se inclinaban por presentarse a sí mismos como física, emocional y sexualmente fuertes, los textos de sus diarios revelaron sus vulnerabilidades, temores y ansiedades en lo relativo al rechazo heterosexual y la violencia física. Muchos de los niños, lejos de alardear que dormían con una y otra chica, hicieron relatos románticos de sus novias y notas sinceras en las que señalaban que ellas los abandonarían. Dos ejemplos extraídos de Pattman (2005) ilustran tales apuntes:

Mpumelele: estaba decepcionado por las malas noticias que me dio. Ella me dijo que ya no me amaba. Pensé en darle una bofetada, pero no tenía caso lastimarla, así que la dejé y me 
volví a casa. Ella es la única chica a la que amo realmente. Tiene todas las cualidades que necesito en mi chica ideal (página 8).

Héctor: era tan feliz [pero] terminé estando triste. Estaba con otros cuates dando un paseo hasta que encontramos un billar, entonces jugamos ese juego. Se nos acercaron otros cuates diciéndonos que teníamos que comprarles cigarros. Nos negamos a hacerlo —nos golpearon- terminamos huyendo. Ya era tarde, uno de nuestros amigos resultó herido —-me sentí aburrido y triste (página 10).

Pattman observa que:

es importante no sólo para comprender a niños y niñas, sino también para trabajar con ellos, que no se supriman los relatos contradictorios entre sus diarios y las entrevistas grupales. Los diarios no permiten formarse una idea de cómo eran en realidad los niños y niñas, en contraste con lo que ocurre con las entrevistas en grupo; lo que sucede más bien con estas maneras radicalmente diferentes de presentarse ellos mismos, niños y niñas, en los diferentes formatos de investigación sugiere que las jóvenes feminidades y masculinidades contemporáneas en los países en donde llevamos a cabo nuestra investigación pueden vivirse y experimentarse de maneras bastante contradictorias (página 10).

\section{Métodos cuantitativos}

\section{Cuestionarios estructurados}

Las encuestas cuantitativas generan información que puede capturarse numéricamente. Una encuesta con una muestra de tamaño suficiente arroja estadísticas resumidas tales como distribuciones de frecuencias, medias, medianas, rangos y otras medidas de variabilidad que describen a una población o a subpoblaciones de manera agregada. Esta metodología es particularmente útil para describir el alcance de un conjunto de temas o problemas.

La elección de indicadores apropiados para recolectar dentro de una encuesta varía con las metas del programa. Como la diversidad de la epidemia del VIH ha aumentado, la Organización Mundial de la Salud propone dos conjuntos de indicadores esenciales, uno para la epidemia de bajo nivel y concentrada, y otro para la epidemia generalizada (ver OMS y cols. 2004). Debe darse atención a la prevención de la infección por el VIH y al cuidado de los jóvenes que se infectaron en ambos escenarios. Los indicadores capturan medidas de impacto a nivel de la población — tales como medidas epidemiológicas y, más señaladamente, tasas de prevalencia del VIH entre jóvenes y entre subgrupos específicos de gente joven. Se pueden complementar los indicadores esenciales con indicadores adicionales, si se considera apropiado en virtud de las metas de un programa en particular que esté en proceso de diseño o evaluación.

La investigación del Population Council revela que el análisis de indicadores por edad, sexo, asistencia a la escuela, estado civil y otras características de antecedentes de los jóvenes — como pudieran ser la orfandad, la pobreza y el grado de apoyo social-, es sumamente revelador (Population Council 2001-02). El desglose por edad es especialmente importante porque el comportamiento sexual varía ampliamente entre grupos etarios. En términos generales, es probable que los adolescentes de 10 a 14 años sean mucho menos activos sexualmente que quienes tienen de 15 a 19, que a su vez difieren de las personas de 20 a 24 años. El desglose de datos por grupos de edad permite a los investigadores, diseñadores de políticas y gerentes de programa buscar tendencias de cohortes que ocurren al transcurrir el tiempo. Por ejemplo, si los informantes de 15 a 19 años reportan menores proporciones de iniciación sexual antes de llegar a los 15 años, en comparación con informantes que tienen de 20 a 24, este hallazgo puede sugerir un descenso en el debut sexual temprano. 
Siempre que sea posible, los datos deben desagregarse cuando menos por los grupos de edades 10-14, 15-19 y 20-24. Algunos investigadores argumentan que aun la cohorte de 10 a 14 años de edad homogeniza demasiado la adolescencia temprana y sus rápidas transiciones. Dependiendo del contexto, los periodos claves para una intervención pueden detectarse mejor utilizando cohortes de seis meses, un año o tres años de edad. Además de la edad, la desagregación de datos por características de antecedentes (por ejemplo residencia urbana vs. rural, asistencia a la escuela y estado civil) permite a los diseñadores de políticas determinar cuáles poblaciones son las que pudieran enfrentar mayores riesgos. Lo anterior les permite también tomar decisiones programáticas mejor informadas, por ejemplo para incluir educación sobre el VIH/SIDA basada en habilidades para la vida para quienes cursan los primeros años de escuela. Los indicadores de interés pueden agruparse, a grandes rasgos, en dos categorías principales:

\section{Factores de riesgo y factores de protección. Ciertos} indicadores no están causalmente relacionados con la infección por el VIH entre los jóvenes, sino que contribuyen a comportamientos de riesgo y vulnerabilidad, o bien ofrecen protección contra la infección por este virus. Incluyen el conocimiento de los jóvenes, sus actitudes y percepciones; su acceso a la información en salud, y medidas de la calidad de la relación entre los jóvenes y las personas que principalmente están a cargo de ellos. Cubren también factores menos relevantes pero que son todavía potencialmente importantes para determinar el riesgo, tales como los modos de vida, la condición de orfandad, la asistencia a la escuela, el estado civil, la sociabilidad y la situación económica.

Comportamientos resultantes. Algunos indicadores miden las acciones individuales de los jóvenes que afectan directamente las consecuencias biológicas.

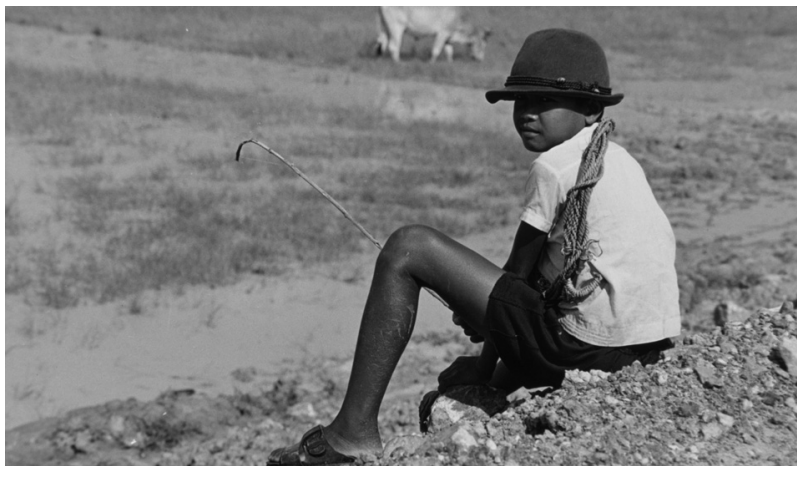

Camboya - Foto: P. Sudhakaran/UN

Se trata de medidas de uso del condón, inyectarse drogas, el sexo comercial, la proporción de jóvenes que han tenido experiencias sexuales a los 15 años, y las cifras de compañeros sexuales actuales y en el transcurso de la vida de los jóvenes. Además, se incluyen varios indicadores que no están causalmente relacionados con la infección del VIH, pero que contribuyen a la vulnerabilidad de los jóvenes; se trata de las relaciones sexuales forzadas y de las parejas sexuales transgeneracionales (especialmente entre mujeres jóvenes).

\section{Implicaciones de las etapas del desarrollo para el diseño de cuestionarios}

En su investigación con adolescentes jóvenes, Borgers y sus colegas (2000) consideran la descripción de Piaget sobre etapas del desarrollo y sus implicaciones. ${ }^{19}$ Durante el periodo llamado de desarrollo de operaciones concretas (entre los 8 y 11 años, aproximadamente), el lenguaje se desarrolla y se adquieren las habilidades para la lectura. Los niños de esta edad comienzan a distinguir diferentes puntos de vista (el propio en comparación con el de los demás), pero tienen problemas con las formas lógicas (tales como las negaciones) y las preguntas despersonalizadas o indirectas (por ejemplo, las preguntas que empiezan con "La mayoría de la gente..."). Del

\footnotetext{
${ }^{19}$ Según la teoría de Piaget del crecimiento cognitivo, el desarrollo intelectual de los niños evoluciona siguiendo una secuencia fija de etapas. Como ocurre con las distinciones de la OPS, Borgers y sus colegas (2000) señalan que las etapas tienden a traslaparse y que las habilidades varían según factores de la herencia, el aprendizaje, la experiencia y el ambiente social.
} 
mismo modo, el discurso ambiguo se les dificulta y casi no pueden distinguir entre lo que se dice y lo que se quiere decir. Contrario a lo que ocurre con las encuestas de adultos, en donde la práctica general es usar más o menos el mismo número de enunciados positivos y negativos para evitar agrupamiento de respuestas, Borgers y sus colegas señalan que con este grupo etario no deberían emplearse enunciados negativos. Del mismo modo, los investigadores deben estar conscientes de los problemas de "conseguir un buen resultado aunque no sea el mejor" (reduciendo el esfuerzo cognitivo que un informante invierte para contestar una pregunta) y de otros problemas que sugieren una falta de concentración o motivación, especialmente con cuestionarios extensos.

El funcionamiento cognitivo y las habilidades sociales están bien desplegadas en los adolescentes en la etapa de desarrollo del pensamiento formal (normalmente entre los 11 y 15 o 16 años). Sus comportamientos, empero, son sensibles al contexto; el mismo niño puede ser tímido y tranquilo en la escuela, pero alborotado y parlanchín en casa. Por lo tanto, el contexto ejerce una influencia importante sobre la calidad de los datos. Los investigadores deben ser sensibles a la presencia de padres, hermanos y compañeros de clase, y a las preocupaciones de los informantes en cuanto a la confidencialidad.

\section{Realización de encuestas con adolescentes muy jóvenes}

Se han hecho entrevistas estructuradas a adolescentes muy jóvenes en sus propios hogares y escuelas. Cada uno de esos sitios tiene sus beneficios y desventajas, y la decisión de elegir entre uno y otro debe tomar en consideración los recursos disponibles y la mano de obra, la población destinataria y su nivel de alfabetización, lo mismo que el efecto potencial de quienes posiblemente estén presentes (padres, maestros, pares) durante la entrevista. (El Apéndice F ofrece orientaciones relativas a la construcción de cuestionarios estructurados.

Encuestar a estudiantes en la escuela es una manera eficaz de llegar a una muestra amplia en

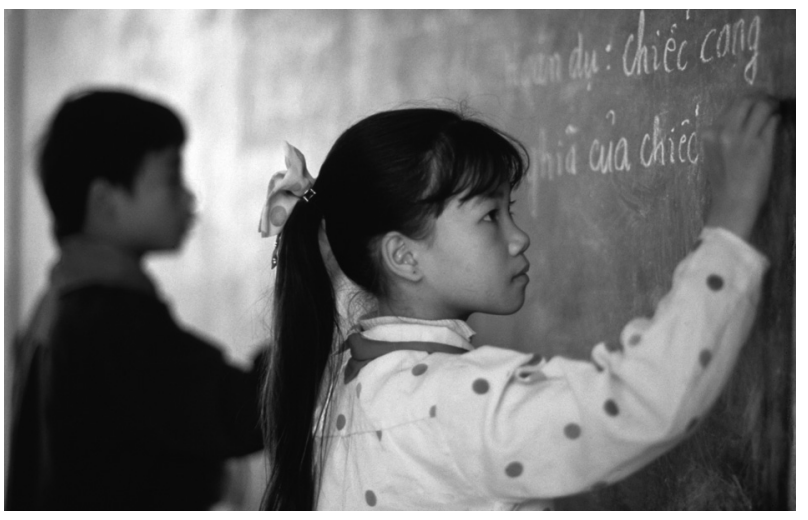

Vietnam - Foto: Chieko Ishikawa

un lapso breve. Un proyecto en Ghana recolectó información utilizando un cuestionario autoadministrado que un investigador leyó en voz alta para mantener en orden a la totalidad del grupo. ${ }^{20}$ Segregados por sexo, los grupos completaron el cuestionario en aproximadamente una hora. Para asegurar la privacidad a los estudiantes mientras contestaban preguntas sensibles se eliminaron los patrones de salto o pasar por alto (dado que los niños que iban a completar ciertas preguntas pondrían en evidencia su comportamiento frente a otros en el salón), y se incluyó una categoría de respuesta con el fin de que todos procedieran con la sección sin importar el comportamiento.

La implementación de las encuestas escolares tiende a ser mucho menos costosa que la de las encuestas de hogares. Este costo menor obedece, en gran medida, a una muestra más accesible (la ventaja de tener a un grupo de jóvenes en la escuela en lugar de tener que buscar a cada uno en su casa), y también a que la mayoría de las 
encuestas escolares utilizan cuestionarios autoadministrados. Una limitación obvia de las encuestas de base escolar auto-administradas es que los niños que no asisten a la escuela (que en algunos escenarios son la mayoría) quedan fuera de la encuesta. Este método puede no ser apropiado para poblaciones poco alfabetizadas. En un estudio hecho en Jamaica con 698 adolescentes de 11 a 14 años, se observó que los bajos niveles de alfabetización de la población del estudio limitó la cantidad y complejidad de la información que pudo ser recolectada. Una escala de 30 puntos para medir la autoestima tuvo que modificarse a una de seis con respuestas dicotómicas. De los resultados del estudio de Jamaica se desprenden, asimismo, ciertas preocupaciones sobre la exactitud de la información auto-reportada relativa a comportamientos sexuales: el estudio longitudinal incluía tres rondas de recolección de datos y encontró que, acerca de su experiencia sexual, 12 por ciento de las niñas y 65 por ciento de los niños respondieron de modo inconsistente entre rondas (Eggleston y cols. 2000). Un análisis multivariado de regresión logística señaló que los niños tenían 14 veces más probabilidades que las niñas de reportar su experiencia sexual de manera inconsistente.

A menudo, las encuestas a adolescentes jóvenes se realizan en los hogares lo mismo que en las escuelas. Las ventajas de las entrevistas individuales son que se concede tiempo para asegurar que el informante entiende cabalmente las preguntas y se dispone de mayor privacidad (lo cual creíblemente aumenta la precisión de las respuestas). Pero las entrevistas individuales son mucho más costosas y requieren de que se invierta más tiempo en comparación con las encuestas grupales. Organizaciones como el Instituto Alan Guttmacher (AGI) han incluido a adolescentes jóvenes en sus encuestas de hogares. Para el estudio del AGI denominado "Protegiendo a la próxima generación", se entrevistó a jóvenes de 12 a 19 años en Burkina Faso, Ghana, Malawi y Uganda. Aunque la importancia de las características de los entrevistadores no se ha estudiado bien, el AGI empleó explícitamente a entrevistadores del mismo sexo que tenían entre 18 y 25 años, a fin de facilitar la comunicación entre informante y entrevistador. Otros estudios han encontrado que las visitas repetidas son exitosas para ganarse la confianza: una niña que durante una primera entrevista no haya admitido haber tenido alguna experiencia sexual, pudiera llegar a sentirse suficientemente cómoda para responder con mayor franqueza durante una segunda o tercera visita (Erulkar y cols. 2004).

Es probable que los investigadores que realizan entrevistas en los hogares de adolescentes muy jóvenes necesiten afrontar las relaciones con padres y otros parientes -incluyendo a los parientes políticos-, con las parejas de los adolescentes casados y asimismo con los informantes. En escenarios socialmente conservadores puede ser necesario dar atención especial a esos otros para despejar sus temores y ofrecer al informante alguna privacidad. En el Alto Egipto, el proyecto Ishraq en el que estuvieron involucradas niñas de 13 a 15 años que no asistían a la escuela, encontró que los padres solían ser desconfiados y estaban renuentes a dejar a los entrevistadores solos con sus hijas. ${ }^{21} \mathrm{~A}$ pesar de los esfuerzos de los encuestadores (quienes, por ejemplo, leyeron las preguntas a los padres antes de la entrevista, o les permitieron estar presentes un rato antes de solicitar la privacidad), algunas entrevistas se hicieron en presencia de los padres, cuya tendencia era interferir y contestar las preguntas a nombre de sus hijas. No debe sorprender que en tales casos las niñas respondieran de conformidad con las expectativas de sus padres. Parte de esa resistencia puede ser aminorada en las etapas tempranas de planeación del estudio si se trabaja estrechamente con los líderes de la comunidad y los padres. 


\section{Auto-entrevistas en audio con ayuda de computadora (AEAAC)}

La administración computarizada de cuestionarios, desarrollada en parte para abordar las inquietudes relativas a la influencia de los entrevistadores sobre resultados de encuestas, trabaja bajo el supuesto de que a mayor privacidad y estandarización de la entrevista mejor será la calidad de los datos. La ventaja de la AEAAC sobre la entrevista individual es que ningún investigador ni persona alguna en el área en donde la entrevista se realiza escucha la pregunta o la respuesta, reduciendo así el sesgo probable que pudiera surgir si los informantes contestan lo que ellos mismos perciban como respuestas socialmente aceptables. Los informantes escuchan la pregunta y las opciones de respuesta a través de audífonos, y usan un teclado numérico externo para registrar sus respuestas. Pueden emplearse teclas de colores para repetir la pregunta y las respuestas o para pasar a la siguiente pregunta. A diferencia de lo que sucede con las

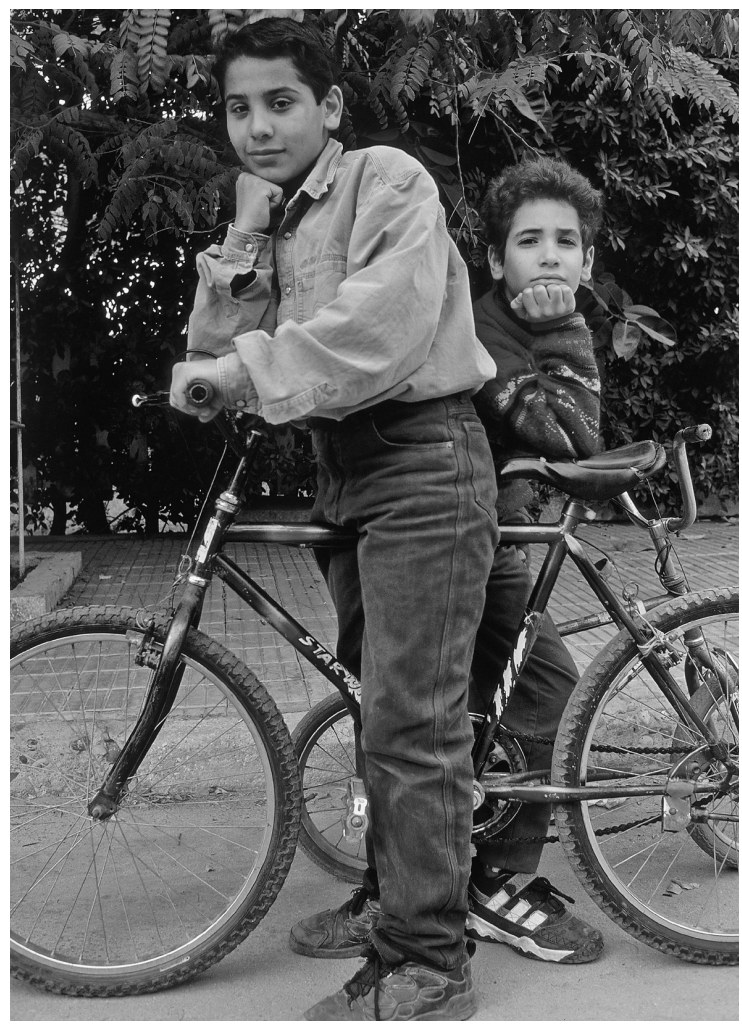

Egipto - Foto: @ 2000 Mohsen Allam, Courtesy of Photoshare entrevistas auto-administradas, que requieren que el informante sepa leer y escribir para completar un cuestionario, la AEAAC puede usarse sin que el informante haya leído las preguntas en una pantalla de computadora. Además, el investigador no tiene que preocuparse por las diferencias en las características del entrevistador o por sus estilos de plantear las preguntas (Tourangeau y cols. 2000).

En Estados Unidos, una amplia gama de tópicos sensibles se ha examinado en análisis que emplean la auto-administración computarizada, incluyendo el comportamiento sexual, la ingesta de alcohol, el uso de drogas y el aborto inducido (Aquilino 1994; Tourangeau y Smith 1996; Fu y cols. 1998; Turner y cols. 1998). A más de eso, hallazgos de otros estudios han revelado que la asignación aleatoria de informantes a la AEAAC o a entrevistas individuales resultó en un número mayor de informaciones sobre comportamientos de riesgo relacionados con el VIH cuando se empleó la computadora (Des Jarlais y cols. 1999); se observaron diferencias más grandes entre informantes seropositivos en comparación con seronegativos (Macalino y cols. 2002). La consistencia de estos hallazgos sugiere que en los países en desarrollo dicha técnica pueden arrojar datos más válidos y confiables que los que pueden obtenerse con otros métodos, aun entre poblaciones con bajos niveles de alfabetización o que no están familiarizadas con las computadoras. En efecto, un comentario aparecido en Science que resume los resultados de un experimento hecho en Estados Unidos comparando la AEAAC con los cuestionarios autoadministrados, advertía que la AEAAC podía ser especialmente idónea para recolectar datos en países en desarrollo, "en donde usualmente prevalecen condiciones de hacinamiento, la alfabetización es relativamente baja y algunos de los comportamientos en cuestión pueden ser particularmente pronunciados" (Bloom 1998:847).

Pocos estudios han evaluado el uso de la AEAAC en países en desarrollo (ver el estudio de Rumakom y colaboradores [1999] sobre comportamiento 
Un ejemplo del campo: AEAAC con adolescentes muy jóvenes en los Países Bajos

En un estudio realizado en los Países Bajos con 6,428 estudiantes de escuela primaria de 8 a 12 años de edad, se pusieron a prueba las auto-entrevistas en audio con ayuda de computadora (Van Hattum y de Leeuw 1999). El cuestionario lo componían 99 preguntas sobre actitudes relativas a intimidar, manejo de la intimidación por parte de padres y maestros, y la experiencia de intimidar como víctima o valentón. En comparación con los resultados del cuestionario impreso, la versión computarizada tenía, en promedio, una cantidad menor de datos faltantes ( 5.7 por ciento vs. 14.1 por ciento de valores ausentes; $p=0.00$ ) y menos variabilidad individual (3.4 vs. 25.0 desviación estándar). Cabe suponer que los niños que no se concentran o que son distraídos pueden fácilmente y por error brincarse una pregunta o hasta una página completa del cuestionario impreso (de Leeuw y cols. 2003). El programa de cómputo evita errores de salto y mantiene a los niños motivados pues los retroalimenta positivamente (les dice, por ejemplo: “ilo estás haciendo muy bien!”, o “¡bien, gracias!”). En términos de revelaciones más importantes, un número significativamente mayor de los niños que utilizaron la versión computarizada señalaron que estaban activamente involucrados en la intimidación, en comparación con el número de niños con los que se trabajó con la versión en papel; asimismo, se reportó mayor victimización de este tipo.

sexual entre estudiantes universitarios de Tailandia; el de factibilidad que van de Wijgert y colaboradores [2000] realizaron en Zimbabwe; y el de aborto inducido que Lara y colaboradores [2001] llevaron a cabo en México). En dos distritos de Kenya, Nyeri y Kisumu, tuvo lugar un experimento importante con formatos de entrevista; ahí, los investigadores buscaron determinar, con más de 6,000 adolescentes solteros, si la AEAAC es un medio para que se reporte información más válida sobre actividad sexual y comportamientos relacionados, en comparación con entrevistas individuales o auto-administradas. La AEAAC funcionó bien durante cerca de diez meses de entrevistas y a pesar de las arduas condiciones de trabajo que prevalecían en una localidad eminentemente rural de África Subsahariana. Se presentaron pocos problemas con el software o hardware de las computadoras y hubo, en efecto, algún mal funcionamiento del equipo, pero sólo en 3 por ciento de las más de 6,000 encuestas. Además, las probabilidades de que los informantes que usaron la AEAAC solicitaran asistencia durante la entrevista no fueron mayores en comparación con otros informantes (Hewett y cols. 2004). Los análisis arrojaron diferencias sustantivas y significativas en las tasas de actividad sexual reportadas entre los formatos de entrevista, aunque no siempre en la dirección esperada. Por un lado, el supuesto de que las niñas dan menos información acerca de su actividad sexual en entrevistas individuales en comparación con la AEAAC no fue confirmada por los datos de Nyeri. Por el otro, los resultados de Kisumu —en donde el instrumento de la encuesta se modificó a fin de plantear a los informantes el conjunto completo de preguntas sobre comportamiento sexual sin importar su respuesta sobre si alguna vez habían tenido sexofueron considerablemente más promisorios. La AEAAC generó niveles de información de comportamientos sensibles significativamente mayores entre las niñas, que incluyeron haber tenido sexo con un pariente, un extraño o un hombre diez o más años mayor que ellas, y haber experimentado el sexo bajo coerción. Por ejemplo, 21 por ciento de las niñas entrevistadas con la AEAAC informaron haber tenido sexo con un pariente, en comparación con 1 por ciento de las niñas entrevistadas individualmente (Mensch y cols. 2003; Hewett y cols. 2004).

A la fecha, la AEAAC ha sido usada sólo con adolescentes de 15 años y mayores en localidades de países en desarrollo. Especulando si su uso es apropiado con jóvenes de 10 a 14 años, Mensch (comunicación personal, 2005), consideró que los jóvenes podrían llegar a dominar los aspectos técnicos y encontrar el proceso novedoso y divertido. El uso de esta técnica con este grupo de edad es un campo que merece mayor atención. (El Apéndice $G$ ofrece una descripción más detallada de cómo se empleó la AEAAC en el estudio de Kenya). 


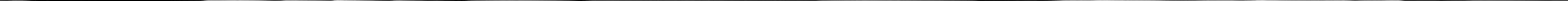


La escasez de investigación sobre adolescentes muy jóvenes es notable y ha resultado en graves vacíos en el conocimiento respecto de los factores que modelan los contornos de las vidas jóvenes. Para mejorar nuestra comprensión de los retos que los jóvenes enfrentan necesitamos ampliar la visión a través de la cual observamos a los adolescentes jóvenes y profundizar en nuestro análisis de sus factores de riesgos y protectores. Debemos definir las transiciones claves en su paso hacia la edad adulta. Nuestra recomendación es obtener más información sobre los adolescentes muy jóvenes mediante el uso de las diversas metodologías que hemos comentado en este documento, en los siguientes campos, como mínimo:

- inicio de la pubertad y consecuencias en términos de movilidad, escolaridad y matrimonio

- modos de vida

- experiencia escolar

- uso del tiempo, movilidad y redes sociales

- condición de salud, conocimiento en salud y acceso a servicios de salud

- transición al matrimonio, incluyendo hasta qué punto tuvieron que ver personalmente con el momento del matrimonio y la elección de pareja

- actividad sexual y contexto en el que ocurre

- situación económica y oportunidades de modos de vida sustentables

- participación y membresía en grupos sociales y cívicos

Es evidente que la prioridad relativa de estos temas variará en distintos escenarios. Sin embargo, nuestro argumento es que toda la investigación necesita distinguir las dimensiones específicas del género y la edad en la experiencia adolescente. Además, las circunstancias sociales y económicas de los adolescentes muy jóvenes deben comprenderse mejor a fin de que puedan diseñarse e implementarse intervenciones programáticas adecuadas y significativas.

A la luz de la rápida transición de la adolescencia temprana, recomendamos que los investigadores resistan la tentación de sacar conclusiones basadas en análisis de datos que usen cohortes de cinco años, puesto que tales análisis llevan a homogeneizar experiencias extremadamente diversas. Los investigadores deben reconocer que las transiciones claves en las vidas de los adolescentes muy probablemente no se presentarán en intervalos de cinco años, sino en periodos mucho más breves: intervalos de uno, dos o tres años. Conforme la investigación avance, surgirá un panorama más detallado del umbral de los periodos de cambio.

\section{El camino hacia adelante}

El propósito de esta guía es el de ofrecer un muestreo de las metodologías y herramientas de investigación a las que los gerentes de programa y los investigadores pueden acudir para recolectar información acerca de los adolescentes muy jóvenes. Ninguna metodología o enfoque funcionará en todos los escenarios o con la totalidad de los subgrupos de adolescentes muy jóvenes. De ahí la necesidad de la experimentación. Al reunir información sobre las capacidades, riesgos y oportunidades de los adolescentes muy jóvenes, se pueden idear programas que, teniendo a este grupo como meta, sean eficaces y les suministren información vital, habilidades y servicios. 
Las recomendaciones de pasos a seguir a fin de avanzar en la comprensión de las vidas de los adolescentes muy jóvenes incluyen:

- que los grupos de interés (stakeholders) lleven a cabo investigación y recaben información sobre los adolescentes muy jóvenes, focalizando en la determinación de los factores de riesgo y protección en las áreas del VIH/SIDA y la salud reproductiva;

- que se desarrollen guías y herramientas para los gerentes de programa que buscan diseñar y poner en marcha programas y servicios que alcancen a los adolescentes muy jóvenes, los cuales deberían ser relevantes y apropiados a sus necesidades.
Creemos que es momento oportuno para que surja una nueva generación de investigación e intervenciones programáticas dedicadas a los adolescentes muy jóvenes. Confiamos en que los investigadores promoverán una nueva oleada de interrogantes de tipo cuantitativo y cualitativo respecto de las vidas jóvenes. La participación de los adolescentes muy jóvenes y de sus comunidades en el diseño, puesta en marcha y uso de todas las actividades de investigación debe promoverse vigorosamente. Además, confiamos en que sus socios - los diseñadores de políticas, proveedores de servicios y gerentes de programasse inspirarán en la información que se recopiló en esta investigación, para crear nuevos programas diseñados a proteger y apoyar a los adolescentes muy jóvenes, ayudándoles a lograr una transición segura y exitosa a la vida adulta. 
Adamchak, Susan, Katherine Bond, Laurel MacLaren, Robert Magnani, Kristin Nelson y Judith Seltzer. 2000. A Guide to Monitoring and Evaluating Adolescent Reproductive Health Programs, Tool Series 5. Washington, DC: FOCUS on Young Adults.

Amon, J. y cols. 2000. Behavioral Surveillance Surveys: Guidelines for repeated behavioral surveys in populations at risk of HIV. Research Triangle Park, NC: Family Health International.

Aquilino, W.S. 1994. "Interviewer mode effects in surveys of drug and alcohol use: A field experiment." Public Opinion Quarterly 58: 210-240.

Bernard, H. 1995. Research Methods in Anthropology: Qualitative and Quantitative Approaches. Second edition. Thousand Oaks, CA: Sage Publications.

Bloom, D.E. 1998. "Technology, experimentation, and the quality of survey data." Science 280:

847-848.

Borgers, Natacha, Edith de Leeuw y Joop Hox. 2000. "Children as respondents in survey research: Cognitive development and response quality." Bulletin de Mèthodologie Sociologique 66: 60-75.

Brookes, Heather, Olive Shisana y Linda Richter. 2004. The National Household HIV Prevalence and Risk Survey of South African Children. Capetown, Sudáfrica: Human Sciences Research Council.

Bruce, Judith. 2003. "Steps in building evidencebased programs for adolescents." In Adolescent and Youth Sexual and Reproductive Health: Charting Directions for a Second Generation of Programming. Nueva York: Population Council.
Chambers, Robert. 1997.

Whose Reality Counts? Putting the First Last. Londres: Intermediate Technology Publications.

Chatterjee, Minki, Leanne Dougherty y cols. 2005. "The Well-being of Children Affected by HIV/AIDS in Gitarama Province, Rwanda, and Lusaka, Zambia: Findings from a Study." Community REACH Working Paper No.2. Washington, DC: Community REACH Program, Pact.

The Council for International Organizations of Medical Sciences (CIOMS). 2002. International Ethical Guidelines for Biomedical Research Involving Human Subjects. Ginebra: CIOMS.

de Leeuw, E., J. Hox, y S. Kef. 2003. "Computerassisted self-interviewing tailored for special populations and topics." Field Methods 15(3): 223-251.

Des Jarlais, D.C.D.P. y cols. 1999. "Audiocomputer interviewing to measure risk behavior for HIV among injecting drug users: A quasirandomized trial." The Lancet 353: 1,657-1,661.

Eggleston, Elizabeth, Joan Leitch y Jean Jackson. 2000. "Consistency of self-reports of sexual activity among young adolescents in Jamaica." International Family Planning Perspectives 26(2): 79-83.

Erulkar, Annabel y Barbara S. Mensch. 1997. Youth Centers in Kenya: Evaluation of the Family Planning Association of Kenya Program. Nairobi: Population Council.

Erulkar, Annabel, Mags Beksinska y Queen Cebokhulu. 2001. An Assessment of Youth Centers in South Africa. Nairobi: Population Council Frontiers Program. 
Erulkar, Annabel, Tekle Ab Mekbib, Negussie Simie y Tsehai Gulema. 2004. The Experience of Adolescence in Rural Amhara Region, Ethiopia. Accra: Population Council.

Freudenberger, Karen Schoonmaker. 1999. RRA and PRA: A Manual for CRS Field Workers and Partners. Baltimore: Catholic Relief Services. http://catholicrelief.org/publications/pdf/ Gen1199_e.pdf.

Fu, H. y cols. 1998. "Measuring the extent of abortion under-reporting in the 1995 National Survey of Family Growth." Family Planning Perspectives 30: 128-133, 138.

Glover, Evam Kofi, Annabel Erulkar y Joana Nerquaye-Tetteh. 1998. Youth Centers in Ghana: Assessment of the Planned Parenthood Association of Ghana Program. Nairobi: Population Council.

Green, L.W. y M.W. Kreuter. 1999. Health Promotion Planning: An Educational and Ecological Approach. Third edition. Mountain View, CA: Mayfield Publishing.

Hallman, Kelly. 2005. "Gendered socioeconomic conditions and HIV risk behaviours among young people in South Africa." African Journal of AIDS Research 4(1): 37-50.

Harley, J. Brian y David Woodward. 1987. The History of Cartography. Volume 1. Chicago: University of Chicago Press.

Hewett, Paul, Barbara S. Mensch y Annabel S. Erulkar. 2004. "Consistency in the reporting of sexual behaviour by adolescent girls in Kenya: A comparison of interviewing methods." Sexually Transmitted Infections 80(supplement 2): ii43-ii48.
Jejeebhoy, Shireen y Sarah Bott. 2003. "Nonconsensual Sexual Experiences of Young People: A Review of the Evidence from Developing Countries." Regional Working Paper No.16. Nueva Delhi: Population Council.

Lara, D., C. Ellertson, C. Diaz y J. Strickler. 2001. "Measuring the prevalence of induced abortion in Mexico City: Comparison of four methodologies." Ponencia presentada en la 24a. Conferencia sobre la Población de la Unión Internacional para el Estudio Científico de la Población, Salvador de Bahia, Brasil, 18-24 de agosto.

Linking Complex Emergency Response and Transition Initiative. 2000. Rapid Assessment Procedures (RAP): Addressing the Perceived Needs of Refugees E Internally Displaced Persons Through Participatory Learning and Action. Juego de herramientas para las crisis de la transición. Center for Refugee and Disaster Studies, The Johns Hopkins University School of Public Health. Este documento está disponible en: http://www.certi.org/ publications/manuals/rap-16_section2.pdf.

Macalino, G.E. y cols. 2002. "Risk behaviors by audio computer-assisted self-interviews among HIV-seropositive and HIV-seronegative injection drug users." AIDS Education Prevention 14(5): 367-378.

Mekbib, T., A. Erulkar y F. Belete. 2005. "Who are the targets of youth programs: Results of a capacity building exercise in Ethiopia." Ethiopian Journal of Health Development 19(1): 60-62.

Mensch, Barbara S., Paul C. Hewett y Annabel Erulkar. 2003. "The reporting of sensitive behavior by adolescents: A methodological experiment in Kenya." Demography 40(2): 247-268. 
Mensch, Barbara S., Monica J. Grant y Ann K. Blanc. 2005. "The Changing Context of Sexual Initiation in Sub-Saharan Africa." Policy Research Division Working Paper No. 206. Nueva York: Population Council.

Miers, Anne y Julieanne Murphy. 2004. "Giving kids a voice: Methodological and practical considerations in conducting research with children and young people." Survey Methods Newsletter 22 (Spring): 6-18.

Mitchell, C., L. Moletsane, J. Stuart, T. Buthelezi y N. Delange. 2005. "Taking pictures, taking action! Using photo-voice techniques with children." ChildrenFIRST 9:(60): 27-31.

National Research Council e Institute of Medicine. 2005. Growing Up Global: The Changing Transitions to Adulthood in Developing Countries. Ed. Cynthia B. Lloyd, Committee on Population and Board on Children, Youth and Families. Washington, DC: National Academies Press.

Pan American Health Organization (PAHO). 2005. Youth: Choices and Change. Washington, DC: PAHO.

Pattman, Rob. 2005. "Young-person-centered methods and researching and working with teenage boys and girls in Africa in the context of HIV/AIDS." Ponencia presentada en el taller sobre Adolescentes muy Jóvenes, organizado por el Population Council y UNFPA, 15 de marzo.

Pattman, Rob y Fatuma Chege. 2003. Finding Our Voices: Gendered and Sexual Identities and HIV/AIDS in Education. Nairobi: UNICEF.

Phiri, Alford y Annabel Erulkar. 1997. A Situation Analysis of the Zimbabwe National Family Planning Council's Youth Centers. Nairobi: Population Council.
Population Council. 2001-02. "Facts about adolescents from the Demographic and Health Survey: Statistical tables for program planning." Nueva York: Population Council.

Population Council. 2003a. "Selected DHS data on 10-14-year-olds: Annex to 'Facts about adolescents from the Demographic and Health Survey: Statistical tables for program planning.' " Nueva York: Population Council.

2003b. Adolescent and Youth Sexual and Reproductive Health: Charting Directions for a Second Generation of Programming. Documento de antecedents para el taller de UNFPA, Nueva York, 1-3 de mayo de 2002.

Population Council. 2003c. "Venn diagrams of public spaces for adolescents." No publicado.

Population Council and Crime Reduction in Schools Project. 2005. "Guidance for mapping safer schools and communities." Informe a la agencia donante UNICEF, Sudáfrica, Nueva York: Population Council.

Pretty, Jules, Irene Guijt, John Thompson y Ian Scoones. 1995. Participatory Learning and Action: A Trainer's Guide. Londres: International Institute for Environment and Development.

Robinson, K.Lynne, Susan Telljohann y James Price. 1999. "Predictors of sixth-graders engaging in sexual intercourse." Journal of School Health 69: 369-375.

Rumakom, P., P. Guest, W. Chinvarasopak, W. Utmarat y J. Sontanakanit. 1999. "Obtaining accurate responses to sensitive questions: A comparison of two data collection techniques." Bangkok: Population Council. No publicado. 
Schenk, Katie y Jan Williamson. 2005. Ethical Approaches to Gathering Information from Children and Adolescents in International Settings: Guidelines and Resources. Washington, DC: Population Council.

Shah, Meera Kaul, Sarah Degnan Kambou y Barbara Monahan. 1999. Embracing Participation in Development: Worldwide Experience from CARE's Reproductive Health Programs with a Step-by-step Field Guide to Participatory Tools and Techniques. Atlanta: CARE.

Tourangeau, R. y T.W. Smith. 1996. "Asking sensitive questions: The impact of data collection mode, question format and question content." Public Opinion Quarterly 60: 275-304.

Tourangeau, R., L.J. Rips, y K. Rasinski. 2000. The Psychology of Survey Response. Cambridge, Inglaterra: Cambridge University Press.

Turner, C.F. y cols. 1998. "Adolescent sexual behavior, drug use, and violence: Increased reporting with computer survey technology." Science 280: 867-873.

UNAIDS (Programa Conjunto de Naciones Unidas sobre el VIH/SIDA). 2000. National AIDS

Programmes: A Guide to Monitoring and Evaluation. Ginebra: UNAIDS.

2004a. 2004 Report on the Global AIDS Epidemic. Ginebra: UNAIDS. 2004b. AIDS Epidemic Update: December 2004. Ginebra: UNAIDS.
UNAIDS, WHO (Organización Mundial de la Salud), and UNFPA (Fondo de Población de las Naciones Unidas). Forthcoming. Seen But Not Heard . . Very Young Adolescents Aged 10-14. Ginebra: UNAIDS.

Van de Wijgert, J., N. Padian, S. Shiboski y C. Turner. 2000. "Is audio computer-assisted selfinterviewing a feasible method of surveying in Zimbabwe?" International Journal of Epidemiology 29: 885-890.

Van Hattum, M.J.C. y E.D. de Leeuw. 1999. "A disk-by-mail survey of pupils in primary schools: Data quality and logistics." Journal of Official Statistics 15: 413-429.

Wang, Caroline C. y Yanique A. Redwood-Jones. 2001. "Photovoice ethics: Perspectives from Flint Photovoice." Health Education and Behavior 28(5): 560-572.

Winch, Peter J., Jennifer A. Wagman, Rebecca A. Malouin y Garrett L. Mehl. 2000. Qualitative Research for Improved Health Programs: A Guide to Manuals for Qualitative and Participatory Research on Child Health, Nutrition, and Reproductive Health. http://sara.aed.org/publications/cross_cutting/qualitative/ qualitative.pdf.

World Health Organization (Organización Mundial de la Salud), Family Health International, MEASURE DHS, UNAIDS, UNESCO, UNFPA, UNICEF, USAID y el World Bank. 2004. National AIDS Programmes: A Guide to Indicators for Monitoring and Evaluating National HIV/AIDS Prevention Programmes for Young People. Ginebra: WHO. 


\section{Apéndice A: Realización de un ejercicio de cobertura de programa ${ }^{22}$}

Los cuatro pasos principales para realizar un ejercicio de cobertura de programa son:

1. planeación, que incluye seleccionar a las organizaciones que participarán y capacitar al personal que será responsable de implementar el ejercicio;

2. llevar el ejercicio al campo;

3. analizar los datos recolectados, y

4. diseminar la información obtenida a gerentes de programas, organizaciones contrapartes, donantes interesados y ministerios de gobierno.

\section{Planeación y capacitación del personal}

Determine cuáles son las organizaciones de servicio a jóvenes que se incluirán en el ejercicio de cobertura. Cualquier organización cuya población objetivo sean los niños o niñas adolescentes se beneficiaría al participar en el ejercicio de cobertura, pudiéndose tratar de programas de educación de pares y servicios de salud amigables para jóvenes. Idealmente, las organizaciones participantes habrán solicitado participar y, por lo tanto, comprenderán el valor programático de los datos que se recaben.

Reproduzca las herramientas para recolectar los datos (registro de la actividad [página ..... de esta guía] y la hoja suplementaria para recabar información de grupos grandes [página .....]), para que cada persona que participe en el taller pueda revisarlas y asentar sus propias marcas.

Organice una capacitación con duración de un día para los proveedores directos de servicios a jóvenes. En el caso de los programas educativos de pares, se tratará de los educadores de pares o líderes de clubes juveniles. En la capacitación, revise los objetivos del ejercicio y el registro de la actividad con los proveedores y recabe sus aportaciones a fin de que el formato refleje sus actividades.

\section{Resumen del taller de capacitación}

(1) Auto presentaciones.

(2) Introducción al ejercicio —cómo opera, por qué es importante y cómo ayudará a mejorar los servicios.

(3) Introducción al registro de la actividad. Revise el formato columna por columna y mencione cómo debe llenarse.

- Escriba los códigos en los espacios provistos para el efecto (utilice los códigos que aparecen al pie del formato).

- Desarrolle códigos por cada tema cubierto.

- Explique la recolección de datos de grupos extensos utilizando una hoja suplementaria.

- Discuta el bombardeo de problemas, como pudieran ser que una persona joven cuestionara lo que se está haciendo con la información recolectada, o el manejo de situaciones en donde se señalara un tema que no está contemplado en la lista, o cómo responder a alguien que no desea que sus datos se registren.

(4) Discusión sobre la recolección de datos. ¿Quién queda anotado en el registro?

- Quedarán incluidos todos aquellos que reciben información o servicios de usted personalmente, ya sea en grupo o en forma individual, sin importar la edad, y los jóvenes que son referidoa, lo mismo que los que acudan a representaciones dramáticas o a discusiones grupales. No se registran, por ejemplo, los contactos casuales o de amigos en donde no están involucrados mensajes programáticos, o los contactos hechos para arreglar actividades del programa (como el caso de profesores de quien usted solicitaría autorización para llevar a cabo una charla).

Pautas para las anotaciones en el registro

- En todo momento lleve consigo el registro.

- Anote la información recibida de un cliente en el momento que haga contacto con él/ella.

- No suponga que conoce la información que está buscando; haga todas las preguntas al cliente. 
- Recuerde que el registro de nombres es opcional. Si un cliente no quiere que su nombre aparezca, esto es aceptable; pero trate de recordar otros detalles acerca de esa persona.

- Registre una sola respuesta por columna, con excepción de las columnas 14 y 15 en donde es posible asentar más de una respuesta.

- Si una respuesta se codifica como "otro, especifique", anote la respuesta en el registro.

- Escriba claramente poniendo un círculo al código de respuesta únicamente. Si comete un error y tiene que cambiar la respuesta, ponga una $\mathrm{X}$ en el código incorrecto y un círculo alrededor del código correcto.

- Algunos participantes pueden negarse a ser registrados. Explíqueles con amabilidad la razón por la que se está recolectando la información. Recuerde a cada cliente que toda la información que se reúna es confidencial y que es voluntario proporcionar o no su nombre. Si el cliente sigue negándose a suministrar la información, registre solamente el sexo del cliente y deje el resto en blanco.

(5) Dramatice el formato en el grupo grande estando en parejas. Vuelva con el grupo grande para discutir las dificultades que hayan surgido, los cambios que deberían incorporarse al formato y las observaciones sobre las técnicas de entrevista.

Después de la capacitación, revise el formato para asegurar que el llenado sea fácil para los educadores pares, empleando términos idiomáticos o locales que se hayan acordado durante la capacitación. Reproduzca el formato suelto y colóquelo en carpetas con una hoja en la que se anote "Pautas para la recolección de datos", que deberá ir dentro de la cubierta de la carpeta.

\section{Llevar el ejercicio al campo}

A los educadores pares y a los proveedores de servicios se les entrega una carpeta para que comiencen a recolectar los datos. La información se recaba durante un período de tiempo acordado. Los supervisores deben asegurarse de que los formatos se completan de manera precisa y consistente durante el periodo de recolección de la información. En la medida de lo posible, los supervisores deben visitar también los lugares de recolección para estar ciertos de que los datos se están recabando y para contestar cualquier pregunta que pudiera surgir. Todos los registros de la actividad se recogen cuando las entrevistas han concluido.

\section{Análisis de los datos}

Borrador de la pantalla para ingresar los datos e ingreso de los datos. Debe tenerse especial cuidado con el desarrollo de la pantalla para ingresar los datos, para que sea clara, fácil de usar y que capture la información relevante. Los supervisores deben capacitar exhaustivamente al personal que ingresará los datos y verificar periódicamente que ese paso se está haciendo de forma correcta. Considerando el tiempo que debe invertirse y los requisitos técnicos del análisis, algunas organizaciones pueden verse en la necesidad de solicitar asistencia técnica de sus organizaciones socias.

Análisis de los datos desagregando los contactos por sexo, edad, modos de vida y estado civil. El Population Council puede proporcionar maquetas. Determine si algunos grupos están subrepresentados y si los beneficiarios deseados del programa son los beneficiarios reales.

Discuta los hallazgos con los educadores pares y sus supervisores y recabe sus ideas para análisis adicionales

\section{Diseminación}

Programe un taller de diseminación en un sitio que convenga a todas las partes interesadas. De un aviso anticipado sobre la celebración de este taller a aquellos medios masivos que sean relevantes. Desarrolle un resumen de hallazgos significativos y reprodúzcalo para distribución. 

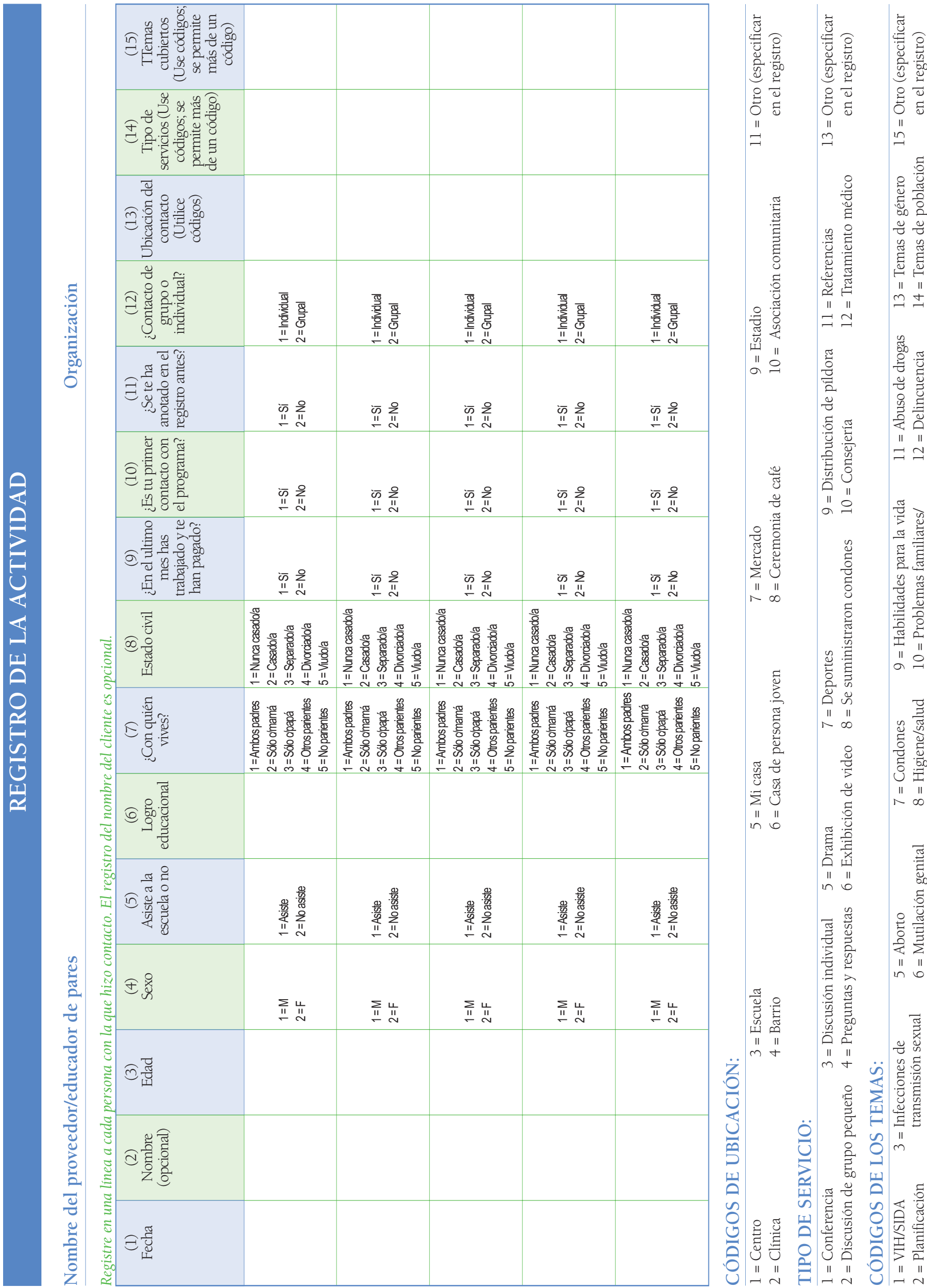

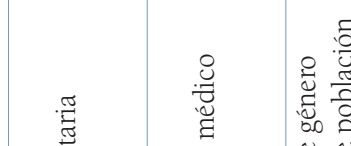

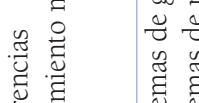

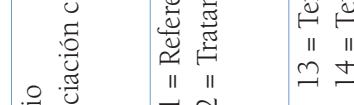

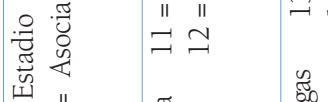

II

$\pi$
$\frac{\pi}{0}$
$\frac{\pi}{2}$
$\frac{\pi}{2}$

号

ช

宅

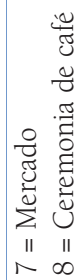

:월

그

$\infty$ 


\section{Hoja de registro para grupos}

\begin{tabular}{|c|c|c|c|c|c|c|}
\hline $\begin{array}{c}\text { (1) } \\
\text { Nombre } \\
\text { (opcional) }\end{array}$ & $\begin{array}{l}\text { (2) } \\
\text { ¿Qué edad } \\
\text { tienes? }\end{array}$ & $\begin{array}{l}\text { (3) } \\
\text { ¿Niño o } \\
\text { niña? }\end{array}$ & $\begin{array}{c}\text { (4) } \\
\text { ¿Estás en la } \\
\text { escuela o no? }\end{array}$ & $\begin{array}{l}\text { (5) } \\
\text { ¿Cuál es el } \\
\text { nivel de } \\
\text { educación } \\
\text { más alto que } \\
\text { terminaste? }\end{array}$ & $\begin{array}{c}\text { (6) } \\
\text { ¿Vives con tu } \\
\text { mamá y papá, } \\
\text { con tu mamá } \\
\text { solamente, tu } \\
\text { papá } \\
\text { solamente, } \\
\text { otros } \\
\text { parientes o no } \\
\text { parientes? }\end{array}$ & $\begin{array}{c}\text { (7) } \\
\text { ¿Estás } \\
\text { casado/a, } \\
\text { nunca te has } \\
\text { casado, estás } \\
\text { divorciado/a, } \\
\text { eres viudo/a? }\end{array}$ \\
\hline
\end{tabular}

\begin{tabular}{c|c}
$\quad(8)$ & $(9)$ \\
$\begin{array}{c}\text { ¿En el ultimo } \\
\text { mes has } \\
\text { trabajado y } \\
\text { recibido un } \\
\text { pago? }\end{array}$ & $\begin{array}{c}\text { ¿Es ésta tu } \\
\text { primera } \\
\text { reunión con } \\
\text { alguien de este } \\
\text { programa? }\end{array}$ \\
& No
\end{tabular}

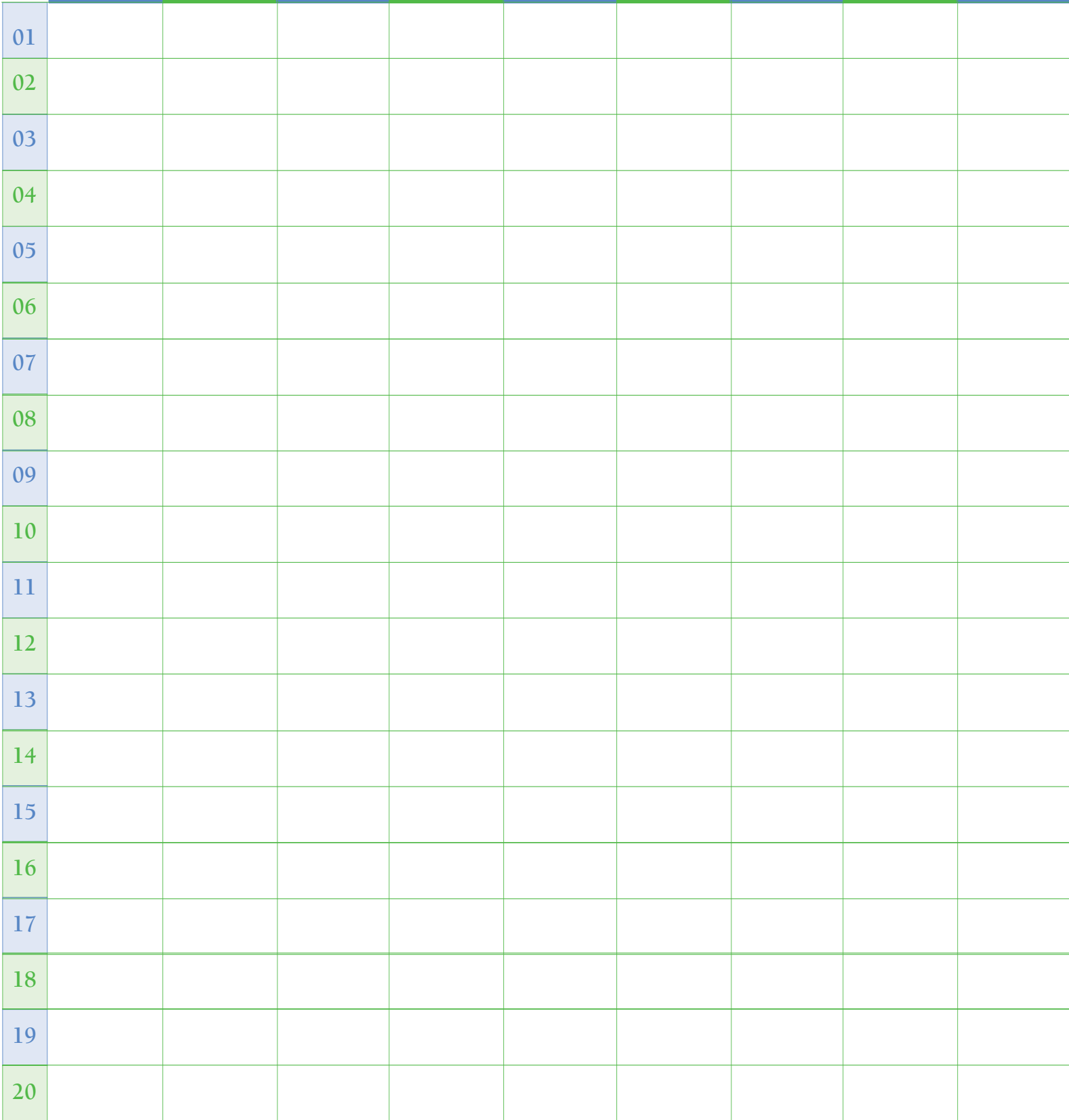




\section{Apéndice B: Recursos para grupos focales $^{23}$}

\author{
(1) A Manual for the Use of Focus Groups (Un \\ Manual para Uso de Grupos Focales), por \\ Susan Dawson, Lenore Manderson y \\ Verónica L. Tallo. 1993, 96 páginas.
}

¿A quién beneficiaría el uso de este manual?

El uso de este manual sería benéfico para investigadores, miembros de programas de control de enfermedades y funcionarios de departamentos de salud que estén trabajando en proyectos de investigación cualitativa. Si bien las directrices que este manual ofrece se aplican a grupos focales en una diversidad de locaciones, sus ejemplos y técnicas se basan en la experiencia que las autoras poseen en la conducción de discusiones de grupos focales sobre malaria en África e infecciones respiratorias agudas en Filipinas. Aunque estas áreas de investigación se mencionan en la publicación, no se ofrece una guía completa de preguntas en relación con ninguna enfermedad en particular. Por ello, los investigadores deben saber qué problemas son los más relevantes para su estudio y desarrollar una lista de temas. Las personas que ya están familiarizadas con la investigación con grupos focales, lo mismo que las que carezcan de experiencia previa podrán hacer uso de este texto.

\section{Organización del manual}

Esta publicación ofrece información breve y completa acerca de los grupos focales -qué son, cuándo emplearlos y a quién involucran, con instrucciones sencillas y detalladas sobre cómo realizar discusiones de ese tipo. El manual se divide en dos partes: la parte I -Entrenamiento para el líder de equipo del grupo focal- inicia con una definición de los grupos focales y menciona los tipos de proyectos de investigación a los que esa metodología puede beneficiar. Se describen la estructura y conducción de las discusiones, incluyendo orientaciones para seleccionar y capacitar al personal y a los participantes del estudio y para desarrollar la secuencia de preguntas. Esta parte concluye con una sección sobre manejo de la información recabada durante los grupos focales y un análisis de los resultados. La parte II -Entrenamiento del personal para las discusiones de grupos focales-, incluye una serie de sesiones de capacitación para el personal involucrado en la investigación. Se identifican los puntos principales a ser cubiertos en la capacitación del personal de campo, incluyendo (pero sin limitarse a) las habilidades requeridas, las diferencias de lenguaje, el estímulo de la discusión y el manejo de problemas imprevistos.

\section{Disponibilidad del manual}

Una versión completa del manual está disponible en inglés y francés en el sitio: http://www.unu.edu/ unupress/food/foodnutrition.html

\section{(2) Qualitative Research for Improved Health Program Design (Investigación Cualitativa para un Mejor Diseño de Programas de Salud), por Judi Aubel. 1993, 58 páginas, disponible en inglés, francés y español.}

¿A quién beneficiaría el uso de este manual?

Este texto fue escrito explícitamente para trabajadores de las áreas de salud y desarrollo de países en desarrollo que están involucrados en la implementación de programas de salud y nutrición, así como para investigadores que brindan apoyo a tales programas. Las directrices están diseñadas para usarse cuando ya existe un programa de salud o nutrición, o cuando se han formulado planes para poner uno en marcha. 
El manual describe de qué manera un grupo de interés programático puede involucrarse en todos los pasos de la planeación, implementación y culminación de un estudio cualitativo usando entrevistas de grupo. Este enfoque, que se basa en los principios del aprendizaje organizacional y de adultos, se propone tanto para incrementar la relevancia de la investigación para quienes implementan programas, como su sentido de propiedad de los resultados de la investigación.

\section{Organización del manual}

El capítulo inicial describe una entrevista de grupo y se refiere a situaciones en las que ese tipo de investigación puede emplearse; ofrece información breve sobre las diferencias entre métodos de investigación cualitativos y cuantitativos, criterios a considerar al decidir el enfoque apropiado, y las ventajas de involucrar a personal del programa en la investigación con entrevistas de grupo.

La parte más importante del manual presenta 17 pasos de la metodología de grupos focales y explica el propósito y enfoque a seguir para cada uno. Los 17 pasos son:

(1) Definir el tema.

(2) Revisar la literatura que existe.

(3) Constituir el equipo del estudio.

(4) Identificar las necesidades de información de los gerentes de programa.

(5) Desarrollar un mapa del tema.

(6) Conducir análisis de influencia social.

(7) Elegir a los informantes que serán entrevistados.

(8) Definir los objetivos específicos de la recolección de datos.

(9) Desarrollar guías para las entrevistas en grupo.

(10) Seleccionar y capacitar a los facilitadores.

(11) Realizar las entrevistas de grupo.

(12) Analizar los datos.

(13) Resumir los hallazgos.
(14) Realizar sesiones de trabajo con grupos de interés para formular recomendaciones.

(15) Elaborar un plan para difundir los resultados.

(16) Terminar los informes.

(17) Evaluar la implementación. (Para este último paso, los miembros del equipo de investigación ofrecen retroalimentación sobre el análisis y los procesos de la metodología de investigación y la implementación. Se les pide comentar acerca de lecciones aprendidas relativas al proceso de implementación que puedan ser útiles para quienes efectúen estudios similares en el futuro).

El manual ofrece también un calendario de la actividad y una lista de los materiales y recursos requeridos para realizar un estudio de este tipo. Trabajar con investigadores cualitativos experimentados representa un beneficio innegable para efectuar estudios de grupos focales; el enfoque de este manual, sin embargo, es útil para quienes no poseen experiencia previa con este tipo de grupos o con otra investigación de naturaleza cualitativa.

\section{Información para solicitar el manual}

El manual está disponible gratuitamente y puede solicitarse a:

Christine Sutton

Departamento de Desarrollo de Políticas

Organización Internacional del Trabajo (OIT)

Ginebra, Suiza

Fax: (41) 227996111

Correo-e: sutton@ilo.org

ISBN 92-2 1085201.

\section{(3) Getting It In Focus: A Learner's Kit for Focus Group Research}

Getting It In Focus: A Learner's Kit for Focus Group Research (Poniéndolo en la Mira: Una Herramienta para el Aprendiz de la Investigación con Grupos 
Focales) es una colección integral de manuales, hojas de trabajo, ejemplos y ayudas visuales. Se ofrecen amplias instrucciones de capacitación para que las personas desempeñen todos los roles necesarios para la investigación con grupos focales. Se incluyen también directrices para realizar un taller con duración de cuatro días. Aunque este juego de herramientas puede ser útil para quienes se interesan en conocer más sobre los grupos focales, los materiales son una herramienta excelente para los interesados en conocer directrices sobre cómo emplearlos en proyectos de investigación nuevos o que ya existen.

El juego de herramientas es un paquete de tres componentes diseñado para ayudar a los investigadores a emplear eficazmente la técnica de grupos focales. Incluye:

- The Handbook for Excellence in Focus Group Research (Manual de Excelencia para la Investigación con Grupos Focales) (1988), por Mary Debus;

- A Skill-building Guide for Making Focus Groups Work (Una Guía para la Construcción de Habilidades para Hacer que los Grupos Focales Funcionen) (1995), por Anne Roberts, Mary Debus, Elizabeth Younger, Valerie Uccellani y Sylvia López Gaona; y

- A Training Video for Moderating Focus Groups (Un Video de Capacitación para Moderar Grupos Focales) (1995), por Lynda Bardfield van Over.

El Handbook for Excellence fue escrito para la Academia de Desarrollo Educacional en 1998. La guía y el video se desarrollaron como materiales de capacitación para complementar y elaborar a partir de las ideas introducidas por el Handbook for Excellence. Los dos manuales y el video ofrecen un panorama de la investigación cualitativa, descripciones de los métodos de entrevista a profundidad y de los grupos focales, y orientaciones para seleccionar e integrar cada técnica al estudio propio de cada investigador. El propósito principal de Getting It In Focus: A Learner's Kit for Focus Group Research es brindar orientaciones detalladas para que usted pueda conducir su propio estudio de grupo focal. Se incluyen instrucciones sobre cómo diseñar un taller para capacitar a otros en la preparación de su propia investigación con grupos focales. El video fue diseñado para emplearse como parte del taller de capacitación, pero puede usarse también de forma independiente.

\section{Información para solicitar el juego de herramientas}

El juego está disponible en dos sitios:

BASICS Information Centre

1600 Wilson Boulevard, Suite 300

Arlington, VA 22209

Teléfono (703)312-6800

Fax: (703)312-6900

Correo-e: wwwinfo@basics.org

Sitio en internet: http://www.basics.org

ó en

Support for Analysis and Research in Africa (SARA) (Precio: \$10 dólares, incluye manejo y envío), Academy for Educational Development 1825 Connecticut Avenue, NW

Washington, DC 20009

Teléfono (202)884-8700

Fax (202)884-87891

Correo-e: saramail@aed.org

Sitio en internet: http://www.info.usaid.gov/regions/ afr/hhraa/child.htm\#subtopics 


\section{Apéndice C: Una guía para el facilitador de mapeo de escuelas y comunidades más seguras ${ }^{24}$}

Este ejercicio se realizó con adolescentes muy jóvenes y medianos en KwaZulu-Natal, Sudáfrica, como parte de una iniciativa de investigación orientada a la acción diseñada para mejorar la seguridad de jóvenes que asisten a la escuela. Para el mapeo se convocaron a grupos de dos tipos de comunidades: un poblado rural y un barrio urbano pobre. En cada sitio, el ejercicio abarcó discusiones de grupos focales con niñas y niños de quinto año, niños de quinto año, niñas de octavo y noveno años y niños de octavo y noveno años. Se encontraron diferencias por sexo y edad en relación con los que se consideraron espacios seguros e inseguros. Las probabilidades de que los niños consideraran las clínicas y la escuela y sus alrededores como lugares seguros fueron mayores en comparación con la apreciación de las niñas. Aunque los niños de ambos sexos señalaron que los puentes eran sitios inseguros en donde las pandillas demandaban cuotas para cruzarlos, esas cuotas tomaban la forma de dinero o bienes en el caso de los niños, pero para para las niñas contemplaban favores sexuales. Otro hallazgo importante fue que los niños y niñas describieron la misma comunidad de diferente manera. Los mapas dibujados por las niñas presentaban áreas limitadas espacialmente, como los sub-barrios, que fueron caracterizados de manera prominente por las instituciones sociales; los niños, entre tanto, dibujaron áreas geográficas más amplias con caminos y carreteras dominando el espacio. La información sobre lugares seguros e inseguros a partir del ejercicio de mapeo se ha compartido con autoridades escolares locales, comités de desarrollo económico y la policía, en un esfuerzo por reducir el peligro que rodea a esas áreas y para aprender más sobre los espacios que las niñas y niños consideran seguros. Abajo aparece la guía para el facilitador que fue usada en el estudio en KwaZulu-Natal.

\section{Agenda para el taller}

\section{Palabras de bienvenida}

\section{Marco y objetivos}

De manera clara y amable, describa al grupo los objetivos del estudio, que son: identificar espacios seguros e inseguros en la comunidad; comprender qué es lo que hace que esos espacios sean seguros o inseguros; explorar de qué modo las personas enfrentan las situaciones peligrosas en tales espacios, y aprender cómo es qué la comunidad identifica sus propias soluciones.

La información recabada durante el estudio se compartirá con grupos de interés claves (el Departamento de Educación, la policía metropolitana y la Community Presidencial Project Office [Oficina de Proyecto Comunitario Presidencial]), con la intención de que estas entidades empleen sus recursos y trabajen con las comunidades para mejorar la seguridad. Se informa a los participantes que la confidencialidad de sus identidades será protegida.

\section{Antecedentes para el ejercicio de "Mapeo para escuelas y comunidades seguras"}

El Department of Education (Departamento de Educación), el South African Council of Educators (Consejo Sudafricano de Educadores) y UNICEF están trabajando asociados con el Crime Reduction in Schools Project (Proyecto de Reducción del Crimen en las Escuelas, PRCE, o CRISP por sus siglas en inglés) y el Population Council para responder a los problemas de violencia y falta de lugares seguros en escuelas y comunidades de KwaZulu-Natal. El PRCE es una organización sudafricana de investigación, facilitación y capacitación, cuyo foco de atención son los jóvenes. El Population Council es una organización internacional de investigación y construcción de 
capacidades, que tiene el propósito de mejorar la salud y el desarrollo. Los facilitadores para este ejercicio incluyen a miembros de la comunidad que han recibido capacitación para realizar mapeo comunitario. El proceso de mapeo permitirá que la comunidad comprenda mejor los problemas relacionados con la seguridad de los jóvenes y dará oportunidad a los facilitadores e investigadores de campo para que adquieran también una comprensión mejor y más profunda de esos hechos. La información que se obtenga contribuirá a sentar bases esenciales para la planeación futura con la comunidad.

\section{Presentaciones personales}

\section{Formas de consentimiento}

Para un grupo de adultos, distribuya y revise los formatos de consentimiento. Recoja las versiones firmadas y deje una copia con cada participante. Si se trata de un grupo de jóvenes, recoja los formatos de consentimiento previamente firmados por sus padres (en caso de que no se hayan recolectado antes).

\section{Instrucciones para el mapeo}

En un espacio apropiado para el ejercicio, solicite al grupo preparar una representación visual de su comunidad que nos ayudará a entenderla. Anime a los participantes recordándoles que los expertos son ellos. Distribuya gratuitamente entre el grupo materiales que les permitan elaborar el mapa. Pida al grupo pensar en un lugar distintivo y prominente de su comunidad en la que les gustaría "anclar" el mapa; se dibujarán otras instalaciones y recursos comunitarios en relación con ese lugar. (Para los jóvenes que asistan a la misma escuela, ésta podría ser el lugar prominente adecuado. En un grupo donde los participantes vayan a escuelas distintas, o en el caso de adolescentes que no acuden a la escuela, algún otro sitio en la comunidad pudiera ser más apropiado). Pida a los participantes dibujar las otras características de su comunidad en relación con ese lugar prominente para que los forasteros puedan entender mejor cómo es que el medio lo contempla. Deje que el grupo prepare por sí mismo el mapa y observe el proceso. El facilitador, quien se encargue de llevar cuenta del contenido y el observador del proceso tomarán nota detallada de lo que se va dibujando y el orden en que ello ocurre. La totalidad del ejercicio puede grabarse en video si existe una cámara disponible y es aceptable hacerlo. Pueden usarse etiquetas o símbolos para identificar las instalaciones de la comunidad, características o infraestructura. Permita que los participantes seleccionen los símbolos. Asegúrese de anotar lo que cada símbolo significa.

\section{Preguntas para los participantes al completar el mapa}

Para cada lugar en el mapa, solicite a los participantes señalar si se sienten seguros yendo y estando ahí. Pida que marquen los espacios inseguros con estrellas rojas y los seguros con estrellas azules, variando el número de estrellas para indicar hasta qué grado consideran el espacio seguro o peligroso. Pregunte qué es lo que hace seguro o inseguro ir a, o estar, en esos lugares. Si en el mapa no aparece una escuela, pregunte a los participantes si hay alguna en la comunidad. Si de hecho existe una, indague por qué razón no fue incluida en el mapa. Averigüe si los participantes se sienten seguros o inseguros en ella y cuál es la razón. Si no aparece una clínica o centro de salud en el mapa, pregunte a los participantes por ella. Y si el mapa no la muestra, pregunte por qué razón no fue dibujada, si los participantes se sienten seguros ahí o no, y porqué. 


\section{Apéndice D: Realización de entrevistas semi-estructuradas a profundidad con informantes clave ${ }^{25}$}

\section{Propósito}

Eliminar los vacíos en nuestro conocimiento sobre problemas de alta prioridad.

\section{Preparaciones}

\section{Desarrollo de una guía etnográfica de campo}

El equipo decide qué vacíos en la información sobre problemas de alta prioridad son los más relevantes y de cuáles grupos demográficos deberá recolectarse la información. El equipo desarrolla entonces una guía etnográfica de campo que se usará como ayuda para realizar la entrevista. La guía suministra ideas para las preguntas iniciales y temas que el entrevistador planea abordar. Los temas comunes incluyen las causas y efectos de los problemas que los adolescentes muy jóvenes enfrentan, especialmente los grupos vulnerables, estrategias para enfrentarlos y soluciones propuestas.

\section{Materiales requeridos}

- Papel y plumas para tomar notas

- Grabadora, en caso de estar disponible y si es aceptable para los informantes

- Guía etnográfica de campo

\section{Selección de los informantes}

A veces, las entrevistas a informantes claves se realizan cuando otras actividades de recolección de datos han concluido, lo que da al equipo más tiempo para identificar a los grupos más afectados por un problema y, al interior de esos grupos, precisar quién puede hablar con autoridad sobre la manera como el problema se vive. Un informante clave debe estar al tanto del problema a ser discutido, o ser una parte interesada en él. Los grupos de interés potenciales incluyen a personas que se han visto más cercanamente afectadas por el problema o que están en mayor riesgo de padecerlo, a aquéllos a quienes los individuos afectados consideran responsables de abordarlo (quizás conforme a la tradición), y quienes ya están, en alguna calidad, trabajando en el problema.

\section{Pasos para recolectar los datos}

La entrevista se inicia con una bienvenida, presentaciones informales y una explicación del proyecto y de los procedimientos de consentimiento correspondientes. (Los datos demográficos sobre los informantes se recaban mejor al terminar la entrevista).

Bernard (1995), describe pasos importantes para las entrevistas iniciales, entre ellos, asegurar el anonimato de todos los informantes. Explique que lo que usted desea es escuchar lo que ellos piensan y cuáles son sus observaciones, y no lo que otras personas creen. Mencione a los informantes la razón por la que fueron elegidos y enfatice que necesita conocer sus opiniones porque usted es un forastero y, por eso mismo, ignora sus situaciones.

La entrevista debe comenzar con una pregunta general para estimularlos a hablar sobre el tema de interés. Una manera de iniciar la conversación es decir: "Quisiera que me hablaras sobre las situaciones a las que se enfrentan los jóvenes de tu edad en esta comunidad. Dime por favor cómo es un día típico de tu vida."

\footnotetext{
${ }^{25}$ Adaptado de la iniciativa Linking Complex Emergency Response and Transition Initiative. 2000. Una guía para el entrevistador para acompañar este manual está disponible también en: Linking Complex Emergency Response and Transition Initiative. 2000. Interviewers Guide Rapid Assessment Procedures (RAP): Addressing the Perceived Needs of Refugees \& Internally Displaced Persons Through Participatory Learning and Action. Crisis is Transitions Toolkit. Center for Refugee and Disaster Studies, The Johns Hopkins University School of Public Health: http://www.certi.org/ publications/manuals/rap-interview-17.pdf
} 


\section{La entrevista}

Permita al informante conducir la conversación lo más que sea posible. Tenga presente que es usted quien está tratando de saber la historia de él/ella. Conceda tiempo suficiente al informante para considerar sus preguntas y responder completamente. Indíquele que puede interrumpirlo durante la entrevista si tiene algo importante que decir. Haga preguntas de exploración sobre problemas específicos que surjan -del tipo que se sugieren en la guía de la muestra. Dichas preguntas contribuyen a que el informante continúe con una sucesión de pensamiento. Focalice las preguntas de seguimiento sobre los temas que ayuden a describir más profundamente problemas de alta prioridad en la situación del informante. Tales preguntas debieran provocar una descripción del problema; el momento en que ocurre (durante el día, en días especiales, durante estaciones específicas); quiénes son los grupos más vulnerables que están experimentando el problema; en dónde ocurre con más frecuencia; a qué estrategias recurren en la actualidad, en especial los grupos vulnerables; cuales son las causas percibidas y los efectos del problema, y cuáles las soluciones sugeridas.

El entrevistador debe ser cuidadoso de no cambiar de un punto a otro del problema demasiado rápido. Por ser amplio el rango de problemáticas a ser cubiertas, una sola entrevista será insuficiente para recabar la información deseada; haga los arreglos para volver con el mismo informante a fin de realizar una entrevista de seguimiento para aclarar hechos surgidos durante la primera ocasión y proseguir con otros temas de interés. Durante la segunda entrevista, el informante suele estar más relajado porque ya conoce al entrevistador y entiende el propósito y tipo de las preguntas.

Evite explorar temas sensibles, pues recordar eventos violentos o traumáticos puede ocasionar desasosiego en el informante. (Si el entrevistador es un profesional psicosocial que tiene posibilidades de disponer de ayuda profesional, o si todos los informantes están vinculados con un servicio de consejería competente y que esté operando para auxiliar a quienes han sido testigos o han experimentado violencia o trauma, los hechos o eventos sensibles podrán abordarse durante la entrevista). Los entrevistadores deben tomar en consideración la comprensión de las preguntas por parte de los adolescentes muy jóvenes y el lapso que dura su atención.

\section{Comprensión y uso de la información}

Las entrevistas a informantes clave ofrecen una mayor comprensión de las dimensiones de los problemas que son prioritarios. Es posible que la información que se reúne de esta manera contribuya a que los miembros de la comunidad puedan idear una estrategia apropiada para abocarse a tales problemas. Por ejemplo, si los entrevistados informados son capaces de articular sus percepciones sobre las causas de un problema, hay más probabilidades de que una estrategia aborde sus causas de raíz y no tanto sus síntomas superficiales. Es más probable que una estrategia tenga el mayor beneficio posible cuando su meta sean aquéllos que se ven más afectados por el problema. 


\section{Apéndice E: Técnicas de foto-voz ${ }^{26}$}

Las técnicas de foto-voz emplean cámaras en calidad de "voces" para saber de hechos particulares y de temas que pueden explorarse de manera más eficaz visual y verbalmente y no sólo con palabras.

\section{¿Qué tipos de cámaras pueden usarse?}

Muchos de los investigadores que acuden a las técnicas de foto-voz trabajan con cámaras desechables que sencillamente permiten enfocar y disparar; la calidad de este tipo de fotos es adecuada para la técnica que nos ocupa. Las cámaras digitales permiten a los participantes ver las fotografías luego después de que se toman; los costos del revelado se ahorran, pero se requiere de una computadora y una impresora para hacer copias de las imágenes.

\section{Consejos para usar la técnica de foto-voz}

Haga indicaciones precisas y focalizadas (por ejemplo, puede dar instrucciones a los participantes para tomar fotos de "sentirse fuerte" y "no sentirse tan fuerte", de "sentirse seguro" y "sentirse inseguro", o acerca de "los retos y soluciones para tratar el VIH/SIDA". Trabaje en un escenario grupal para que los miembros compartan una misma cámara y juntos interpreten las fotos. Realice una actividad de "ver y observar" al comenzar el proyecto; estudie algunos ejemplos de fotos que incluyan objetos (y no solamente personas) y ángulos diferentes (por ejemplo, parados sobre una silla mirando para abajo, acostados mirando hacia arriba). Cuando el grupo comience a tomar las fotos, anime a los participantes

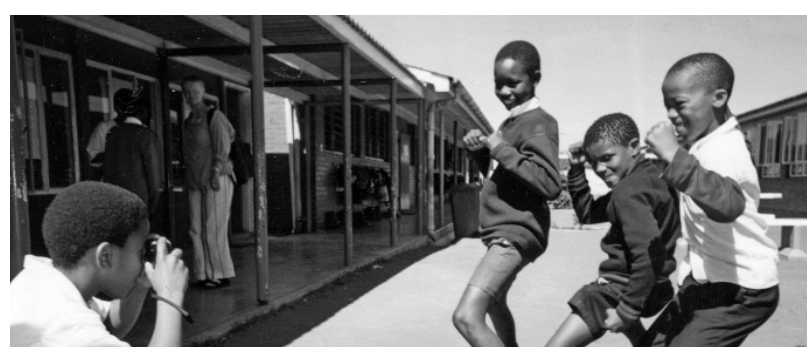

Sudáfrica - Foto: Kathleen Pithouse a tomar notas sobre cada una: ¿quién la tomó?, ¿por qué? Haga copias de las fotos y conserve un juego de respaldo. Guarde los negativos en un lugar seguro. Ponga número a las fotos en uno de los juegos y anote qué persona o grupo tomó cada una.

\section{Trabajo con las fotos}

Los participantes deben involucrarse activamente para seleccionar las fotos, comentarlas y decidir de qué modo sus percepciones pueden estar mejor representadas visualmente.

Una caminata a propósito. Una buena manera de romper el hielo es, simplemente, amplificar algunas de las fotos, colocarlas en una pared y dar tiempo a los participantes para que caminen alrededor de ese sitio para que las observen. Cerca de ahí se coloca papel y marcador para que los participantes anoten sus comentarios sobre ellas.

Una mirada cercana 1 - Selección. Aparte tiempo durante la sesión para que los grupos o individuos puedan ver su colección completa. Pídales elegir tres o cuatro fotos que les gusten especialmente y explicar por qué les gustan las que escogieron.

\section{Una mirada cercana 2 - Clasificación. Si los} fotógrafos han estado trabajando en grupos en la fase inicial de toma de las fotos, pídales crear relatos acerca de ellas utilizando un tablero para carteles. En esos relatos pueden contar "historias que sus fotos dicen", y se puede alentar a los fotógrafos a "elegir las fotos que crean que son las que mejor explican los retos para abordar el VIH/SIDA". Si les suministra marcadores, pregunte a los participantes si desean asignarles nombres o leyendas.

Exhibición. De a conocer las fotografías en una exposición pública que puede ser especialmente importante para llegar a una comprensión más profunda de lo que significan para los fotógrafos. Cuando las fotos se exhiben se convierten en una invitación a una mayor participación comunitaria.

\footnotetext{
${ }^{26}$ Este apéndice está basado en Mitchell y Walsh. Se puede acceder a él en el sitio: www.ivmproject.ca/tools/photovoice.pdf 3/15/05
} 


\section{Apéndice F: Cuestionarios estructurados}

Más que señalar los numerosos y complejos pasos que implica la realización de una encuesta estructurada (que comprende esquemas de muestreo, desarrollo de cuestionarios y pre-pruebas, reclutamiento y capacitación de entrevistadores, ingreso y limpieza de los datos y demás), aquí nos concentraremos en los importantes campos a incluir en los cuestionarios estructurados. Referimos a los lectores que busquen información sobre cómo realizar encuestas estructuradas a las siguientes fuentes:

Bulmer, Martin y Donald Warwick. 1983. Social Research in Developing Countries: Surveys and Censuses in the Third World (Investigación Social en Países en Desarrollo: Encuestas y Censos en el Tercer Mundo). Nueva York: John Wiley.

Grosh, Margaret y Paul Glewwe (eds.). 2000. Designing Household Survey Questionnaires for Developing Countries: Lessons from Ten Years of LSMS Experience (Diseño de Cuestionarios de Hogares para Países en Desarrollo: Lecciones de diez años de LSMS). Ginebra: World Bank.

Una buena referencia general es: Evaluating the Impact of Development Projects on Poverty: A Handbook for Practitioners (Evaluación del Impacto de Proyectos de Desarrollo sobre la Pobreza: Un Manual para Practicantes), a la cual se puede acceder en el sitio: http://siteresources. worldbank.org/INTISPMA/Resources/handbook.pdf.

La Organización Internacional del Trabajo ha publicado materiales para profesionales con un enfoque sobre trabajo infantil, a los cuales puede accederse en: http://www.ilo.org/public/english/standards/ipec/the mes/timebound/downloads/pp3_3en.pdf y en: http://www.ilo.org/public/english/standards/ipec/the mes/timebound/downloads/pp3_4en.pdf
Una guía sobre muestreo puede encontrarse en: http://www.fantaproject.org/downloads/pdfs/ sampling.pdf

\section{Marcos de trabajo útiles}

La salud es una función de los individuos y de los ambiente en los que están inmersos, incluyendo a la familia, redes sociales, organizaciones, comunidades y las sociedades como un todo. Los marcos conceptuales que ilustran estas relaciones pueden ser útiles para reflexionar sobre las preguntas críticas a incorporar en una encuesta, que evidentemente variarán dependiendo de la subpoblación específica y del problema de salud que un investigador busque abordar. Mencionamos aquí tres marcos de trabajo para ilustrar algunas de las diferentes formas para una vida saludable; ningún marco de trabajo es el "correcto", y alentamos a los lectores a adaptar estos $u$ otros marcos para adecuarlos a las características de sus pesquisas.

En la publicación Youth: Choices and Change, de la OPS, el modelo de Green y Kreuter PRECEDENCIA-CONTINUACIÓN (PRECEDEPRECEED) para planear y evaluar la promoción en salud se presenta en la figura 1 (a continuación). Green y Kreuter (1999) subrayan la identificación de determinantes de salud pertinentes en el diseño de intervenciones de promoción de la salud; tales determinantes son fuerzas que predisponen, habilitan y refuerzan estilos de vida individuales o que moldean los modos de vida del ambiente en maneras que afectan la salud de las poblaciones.

El modelo PRECEDENCIA-CONTINUACIÓN es útil para identificar determinantes de la salud en diferentes niveles de influencia, aunque sin un enfoque particular en los jóvenes y en cómo estos factores pueden impactarlos de modo diferenciado. Adamchack y cols. (2000) construyeron un marco de trabajo de factores que influyen sobre la salud 
Figura 1 Los factores del modelo PRECEDENCIA—CONTINUACIÓN que predisponen, habilitan y refuerzan (Fase 4: evaluación educacional y ecológica

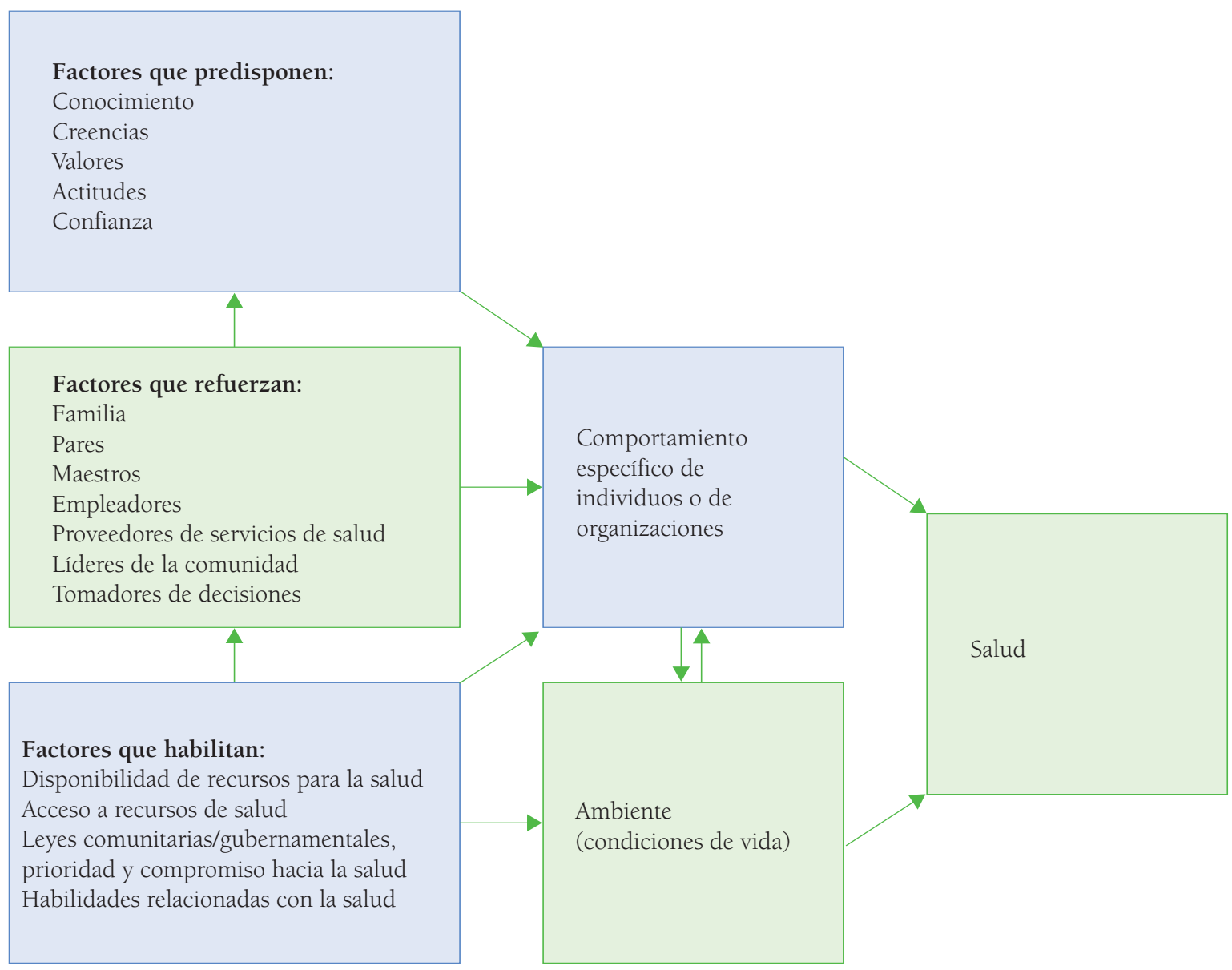

Fuente: Adaptación de Green y Kreuler (1999), como en OPS (2005).

reproductiva de los jóvenes, después de sintetizar hallazgos de investigación de más de 350 estudios, de los cuales alrededor de 250 se realizaron en Estados Unidos y cerca de 100 se efectuaron en África, América Latina y el Caribe y Asia (ver la figura 2 a continuación). Los autores eligieron agrupar los factores sociales que influyen sobre la salud reproductiva de los jóvenes en cinco esferas de influencia:
- características individuales, incluyendo conocimiento, actitudes, creencias, valores, motivaciones y experiencias

- compañeros sexuales y pares

- familias y adultos en la comunidad

- instituciones que apoyan a los jóvenes y les brindan oportunidades, tales como las escuelas, lugares de trabajo y organizaciones religiosas

- comunidades, a través de las cuales se 
Figura 2 Factores que influyen sobre la salud reproductiva de los jóvenes

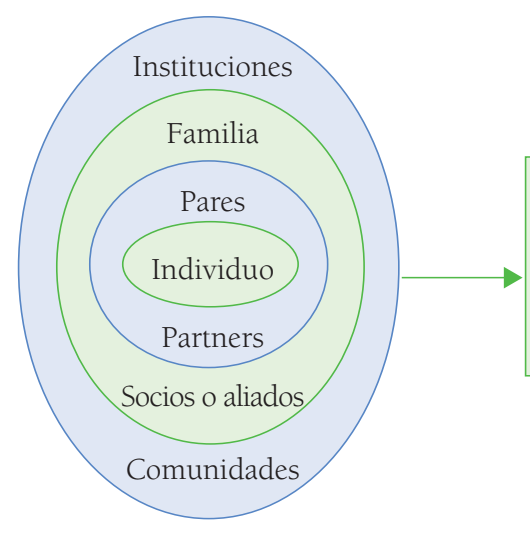

Toma de decisiones y comportamientos en salud reproductiva de la gente joven

\section{Individual}

- Edad y género

- Lugar de residencia

- Conocimiento, actitudes y creencias

- Religiosidad

- Auto-eficacia

- Habilidades

- Motivación para un buen desempeño escolar

- Compromiso activo con el aprendizaje

- Adicción al alcohol o las drogas

- Otros comportamientos de riesgo relacionados

- Depresión, tensión

- Huida del hogar

- Abuso sexual
Pares y socios

- Percepción del comportamiento de los pares

- Percepción de que los pares son sexualmente activos

- Percepción de que los pares están consumiendo droga o alcohol

- Relación con los socios o aliados - Diferencias de edad $y$ en ingresos

- Intercambio de dinero o bienes por sexo

- Presión sexual

- Sentido de compromiso con los socios o aliados

\section{Familia y hogar}

- Bajos niveles educativos y económicos

- Actitudes familiares perjudiciales

- Educación devaluatoria

- Experiencia de matrimonio y crianza tempranos

- Desalentar el acceso de los jóvenes a información y servicios

- Relaciones armónicas con la familia - Interacción de alta calidad con la familia - Valores familiares transmitidos a los jóvenes

- Supervisión de los miembros de la familia por parte de un adulto

\begin{tabular}{|l|}
\hline Consecuencias para la salud \\
reproductiva: \\
- Fecundidad \\
- Aborto \\
- Morbilidad \\
- Infecciones de transmisión \\
sexual/VIH \\
- Infecciones del tracto \\
reproductivo \\
- Anemia \\
- Mortalidad \\
- Situación nutricional
\end{tabular}

Instituciones

- Vínculo con organizaciones religiosas

- Vínculo con escuelas

- Disponibilidad de educación

- Ambiente escolar seguro

- Desempeño académico y aspiraciones

- Disponibilidad de programas juveniles

- Actividades recreativas

- Consejería

- Servicios para tratar el abuso sexual

- Relaciones con otros adultos a través de instituciones comunitarias

\section{Comunidades}

- Desorganización (niveles altos de desempleo, pobreza, bajos niveles de educación, inestabilidad política, guerras, crimen, altas tasas de migración)

- Normas sociales

- Falta de oportunidades

- Política (legalidad de los anticonceptivos, edad para el matrimonio legal, servicios de salud y educación para los jóvenes)

- Política (ilegalidad del aborto, débil aplicación de las leyes sobre violación)

- Medios masivos (transmiten modelos de roles y ejemplos de comportamientos responsables)

- Medios masivos (transmiten pornografía e imágenes sexualmente permisivas y violentas)

Fuente: Adaptación de Adamchak y cols. (2000). FOCUS on Young Adults. 
Figura 3 Marco conceptual de las influencias de riesgo de los jóvenes para adquirir el VIH

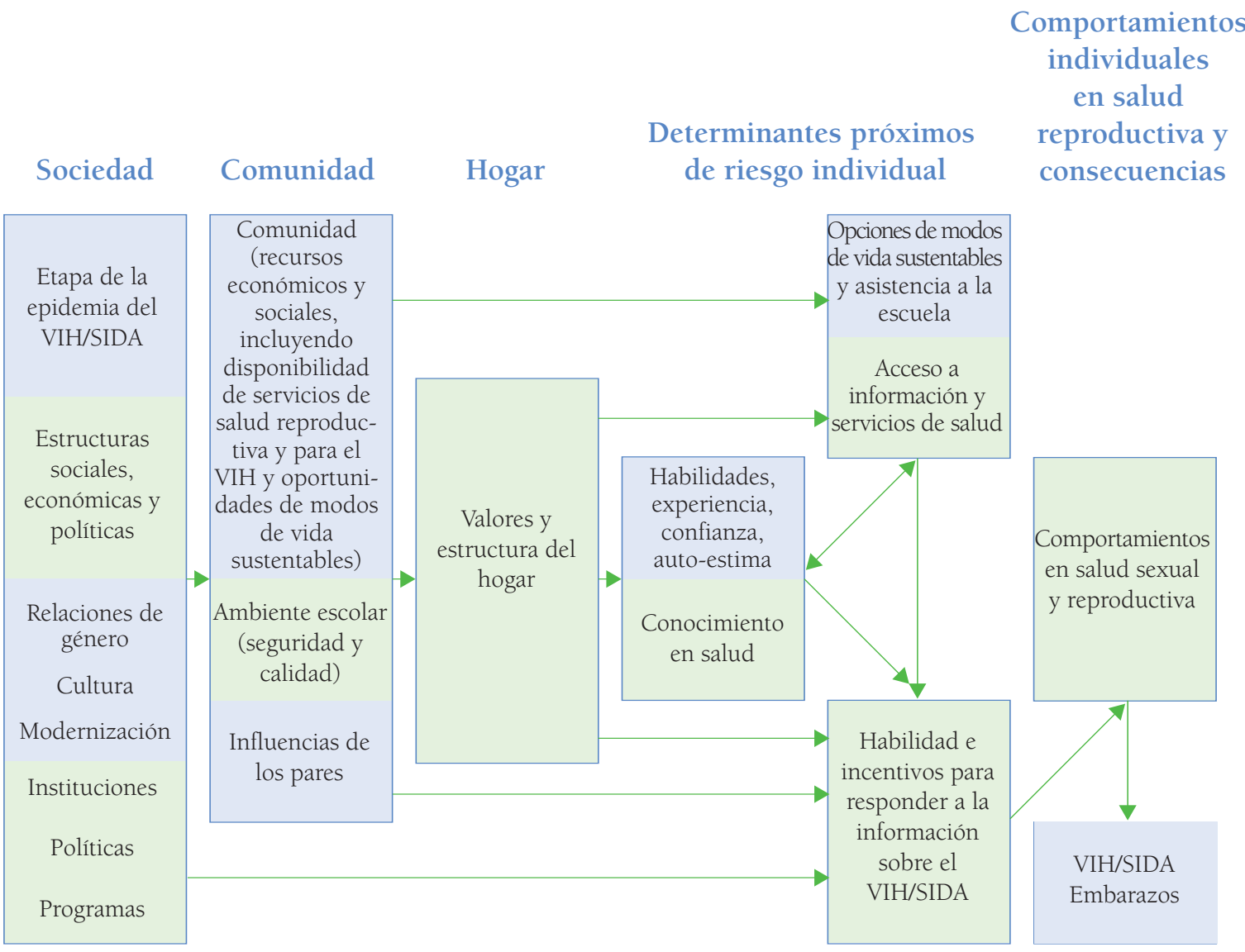

Fuente: Hallman (2005)

transmiten las expectativas sociales sobre normas de género, comportamiento sexual, matrimonio y crianza

Al desarrollar su marco conceptual, Hallman (2005) amplió su ámbito para hacer una revisión de la literatura de diversas disciplinas que examinan el riesgo al VIH de mujeres y hombres jóvenes; incluyó la Sociología, Demografía, Economía, Economía Política, Epidemiología, Psicología y Antropología (ver la figura 3 a continuación). El marco presenta un modelo de las múltiples influencias de la sociedad, la comunidad y el hogar sobre los determinantes próximos de riesgo y los comportamientos de salud sexual y reproductiva y sus consecuencias. Contrario a lo que ocurre con los modelos que consideran el comportamiento sexual como determinado en gran medida por las creencias y conocimientos individuales relativos a la salud, este marco reconoce que el conocimiento interactúa con las habilidades, experiencia, confianza, auto-estima, opciones de modos de vida sustentables y asistencia a la escuela para afectar los comportamientos relativos a la salud sexual y reproductiva. 


\section{Desarrollo del cuestionario}

Si un solo instrumento de una encuesta fuera a capturar todas las relaciones descritas en estos marcos conceptuales, sería prohibitivamente extenso; lo que estos modelos más bien pueden hacer es ayudar a aclarar cuáles son las relaciones más importantes para un estudio y orientar el desarrollo de un cuestionario. Los conceptos principales se pueden operacionalizar en preguntas; algunos ejemplos de temas para preguntas serían:

\section{Comportamiento sexual}

Edad a la primera relación sexual

Uso de condón

Experiencia de sexo forzado/bajo coerción

\section{Conocimiento en salud}

Fuentes de conocimiento

Acceso a los medios masivos de comunicación Personas en las que se confía y con quienes se pueden discutir problemas

Conocimiento de estrategias de prevención del VIH/ITS

Acceso a servicios de salud

Asistencia a la escuela

Situación actual de inscripción

Nivel de educación escolar alcanzado

Adecuación del grado escolar a la edad

Estructura del hogar

Residencia de los padres

Condición de orfandad

Miembros del hogar afectados por el VIH

\section{Aislamiento social}

Proximidad a familiares y amigos

Frecuencia con la que se ve a familiares y amigos Movilidad

Participación en la vida comunitaria y en organizaciones
Vulnerabilidad económica de la familia e individual

Experiencia laboral

Control de ingresos

Ahorros

\section{Recursos para indicadores}

Adamchack, Susan, Katherine Bond, Laurel MacLaren, Robert Magnani, Kristin Nelson, y Judith Seltzer. 2000. A Guide to Monitoring and Evaluating Adolescent Reproductive Health Programs, Tool Series 5 (Una Guía para el Monitoreo y Evaluación de Programas de Salud Reproductiva para Jóvenes. Serie de Herramientas 5). Washington, DC: FOCUS on Young Adults.

AIDSQuest. The HIV/AIDS Survey Library. Se puede acceder en: http://www.popcouncil.org/ horizons/AIDSquest/index.html

UNAIDS. 1999. Sex and Youth: Contextual Factors Affecting Risk for HIV/AIDS (Sexo y Juventud: Factores del Contexto que Afectan el Riesgo del VIH/SIDA). UNAIDS Best Practice Collection. Se puede acceder en: http://www.unaids.org/html/pub/ publications/irc-pub01/jc096-sex_youth_en_pdf.pdf

World Health Organization (WHO), Family Health Internatioinal, MEASURE DHS, UNAIDS, UNESCO, UNFPA, UNICEF, UNAID, y Banco Mundial. 2004. National AIDS Programmes: A Guide to Indicators for Monitoring and Evaluating National HIV/AIDS Prevention Programmes for Young People (Programas Nacionales sobre SIDA: Una Guía de los Indicadores para el Monitoreo y Evaluación de Programas Nacionales de Prevención del VIH/SIDA para Jóvenes). Ginebra: WHO. 


\section{Apéndice G: AEAAC}

Las AEAAC son una metodología cuya aplicación en países en desarrollo aún se está valorando. No existe una "herramienta" disponible fácilmente para su aplicación; sin embargo, incluimos una descripción detallada de su implementación. La siguiente información se extrajo de Mensch y cols. (2003); se refiere a un estudio de AEAAC hecho en Kenya que involucró a jóvenes mujeres y varones de 15 a 21 años.

El cuestionario de Kenya era relativamente corto (65 preguntas en la encuesta de Nyeri y 69 en la de Kisumu); cerca de un tercio de esas preguntas se referían a comportamiento sexual, consumo de alcohol y drogas, uso de anticonceptivos, embarazo y crianza. Mediante audífonos, el informante escuchaba las preguntas y la selección de opciones de respuesta. Los audífonos y un mini-teclado numérico estaban conectados a una computadora laptop que permanecía guardada en su estuche durante la entrevista. El informante podía elegir el idioma de la entrevista: inglés, kiswahili, kikuyu (en Nyeri) o luo (en Kisumu). El sexo de la voz grabada iba acorde con el del informante, de modo que las niñas escuchaban una voz femenina y los niños una masculina. Los informantes ingresaban sus respuestas utilizando el mini-teclado. Para preguntas dicotómicas, el "1" denotaba "sî" y el "2" denotaba "no"; a las preguntas no dicotómicas se les asignaron números que se correspondían con las categorías de respuesta. Los informantes a quienes se les dificultaba recordar las categorías podían volver a escuchar la respuesta tantas veces como fuera necesario. En Nyeri, al ingresar cada contestación, la computadora repetía la respuesta y el informante tenía la oportunidad de modificarla. Inmediatamente después de la AEAAC se realizó una entrevista de salida individual; en ella se indagaba con los informantes sus sentimientos sobre la encuesta y la entrevista. El entrevistador anotaba si alguien más había estado presente durante la AEAAC y si el informante había tenido dificultades para completarla. 